\title{
A User's Guide for CFAST Version 1.6
}

Rebecca W. Portier

Paul A. Reneke

Walter W. Jones

Richard D. Peacock

Building and Fire Research Laboratory

Gaithersburg, Maryland 20899

$\mathrm{OC}$

100

.056

4985

1992

$\square+\infty$

United States Department of Commerce

Technology Administration

National Institute of Standards and Technology 



\section{A User's Guide for CFAST Version $\mathbf{1 . 6}$}

Rebecca W. Portier

Paul A. Reneke

Walter W. Jones

Richard D. Peacock

December 1992

Building and Fire Research Laboratory

National Institute of Standards and Technology

Gaithersburg, MD 20899

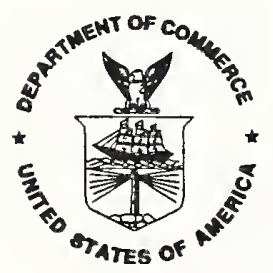

\section{U.S. Department of Commerce}

Barbara Franklin, Secretary

Technology Administration

Robert M. White, Under Secretary for Technology

National Institute of Standards and Technology

John W. Lyons, Director 


\section{$-$}




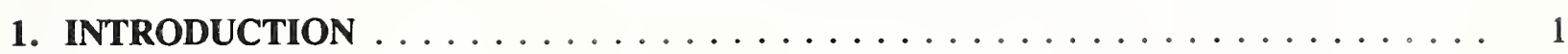

2. DISTRIBUTION AND INSTALLATION $\ldots \ldots \ldots \ldots \ldots \ldots \ldots \ldots$

2.1 New in CFAST $1.6 \quad 3$

2.2 Hardware Requirements 4

2.3 Contents of the Distribution Disks 4

2.4 Installation 6

2.5 Test Cases 8

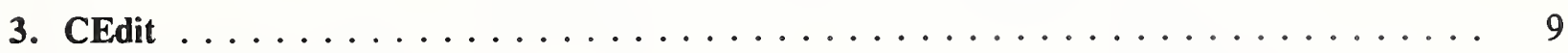

3.1 Using CEdit 9

3.2 Initialization Screen 12

$\begin{array}{ll}3.3 \text { Overview Screen } & 13\end{array}$

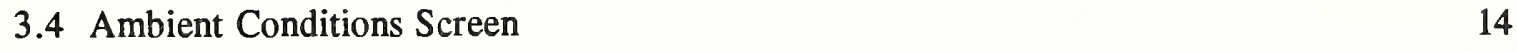

3.5 Geometry Screen 15

$\begin{array}{ll}3.6 \text { Vents(doors,...) Screen } & 16\end{array}$

3.7 Vents(ceiling,...) Screen 18

$\begin{array}{lr}3.8 \text { Fans, Ducts,... Screen } & 19\end{array}$

3.9 Thermal Properties Screen 22

$\begin{array}{ll}3.10 & \text { Fire Specification Screen }\end{array}$

3.11 Objects Screen $\quad 26$

3.12 Files,... Screen 29

3.13 Version and Settings Screen $\quad 30$

3.14 Quitting CEdit 32

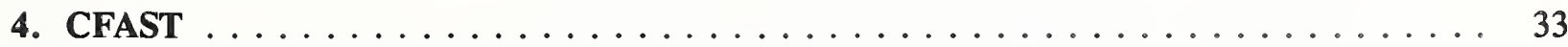

4.1 Using CFAST 33

4.2 Summary of Input Data 34

4.2.1 Overview 34

4.2.2 Geometry 34

4.2.3 Vents (doors, ...) $\quad 34$

4.2.4 Fans, Ducts,...

4.2.5 Thermal Properties $\quad 36$

4.2.6 "Other Objects" 36

4.2.7 Fire Specification $\quad 38$

$\begin{array}{ll}4.2 .8 \text { Initial Conditions } & 39\end{array}$

4.3 Results of Calculations 39

5. CPlot ........................... 41

$\begin{array}{ll}5.1 & \text { Entering Data Into CPlot }\end{array}$

5.2 Generating Tables and Graphs With CPlot 45

$\begin{array}{ll}5.3 \text { Saving Data With CPlot } & 47\end{array}$

5.4 Changing the Default Parameters in CPlot 48

5.5 Getting Online Help in CPlot 49

5.6 Exiting CPlot 49 


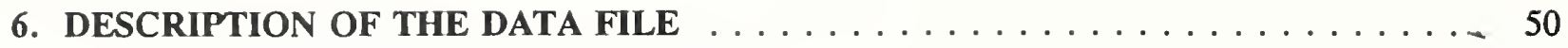

6.1 General Format of an Input File Line $\quad 50$

6.2 Key Words Available in CEdit $\quad 52$

6.2.1 Overview $\quad 52$

6.2.2 Ambient Conditions 53

6.2.3 Geometry $\quad 55$

6.2 .4 Vents(doors,...)

6.2.5 Vents(ceiling,...) $\quad 59$

6.2.6 Fans, Ducts,... $\quad 60$

6.2.7 Thermal Properties 63

6.2.8 Fire Specification 64

$\begin{array}{ll}6.2 .9 \text { Objects } & 70\end{array}$

6.2.10 Files $\quad 72$

6.3 Additional Key Words Unavailable in CEdit 73

$\begin{array}{ll}\text { 6.3.1 Fire Specification } & 73\end{array}$

$\begin{array}{ll}\text { 6.3.2 Graphics Specification } & 74\end{array}$

7. UTILITY PROGRAMS $\ldots \ldots \ldots \ldots \ldots \ldots \ldots \ldots \ldots \ldots \ldots \ldots$

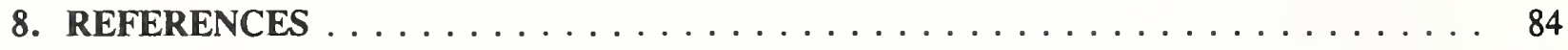

Appendix A: EXAMPLE INPUT FILES $\ldots \ldots \ldots \ldots \ldots \ldots \ldots \ldots \ldots \ldots$

$\begin{array}{ll}\text { A.1 PRM.DAT } & 86\end{array}$

$\begin{array}{ll}\text { A.2 School Building Fire } & 87\end{array}$

A.3 Mechanical Ventilation $\quad 88$

A.4 Hotel Lobby Fire $\quad 89$

$\begin{array}{ll}\text { A.5 Opening and Closing Doors and Windows } & 90\end{array}$

A.6 Interaction of Mechanical Ventilation and $\mathrm{HCl}$ Deposition 91

A.7 Specification of Graphical Output from CFAST 92

Appendix B: COMMAND LINE OPTIONS $\ldots \ldots \ldots \ldots \ldots \ldots \ldots \ldots \ldots \ldots$

Appendix C: THERMAL DATABASE ................... 97

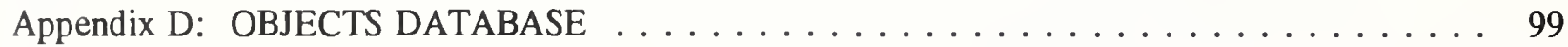

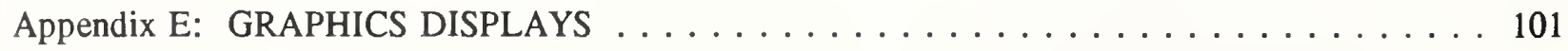




\title{
User's Guide for CFAST Version $\mathbf{1 . 6}$
}

\author{
Rebecca W. Portier \\ Paul A. Reneke \\ Walter W. Jones \\ Richard D. Peacock \\ Building and Fire Research Laboratory \\ National Institute of Standards and Technology
}

\begin{abstract}
CFAST is a zone model capable of predicting the environment in a multi-compartment structure subjected to a fire. This guide provides a detailed description of the pre- and post-processing routines used by the model, the data input requirements, and the output produced by version 1.6 of the model.
\end{abstract}

Key words: compartment fires; room fires; fire growth; mathematical models; numerical models; smoke; toxicity

\section{INTRODUCTION}

Considerable research has been done regarding the spread of fire and smoke from a compartment of fire origin to connected compartments. The work is motivated by a need to understand and predict the environmental conditions which occur as a fire develops and spreads. Much of the attention has focused on the development of numerical models which are able to make a reasonably accurate assessment of the environment resulting from a specified fire.

CFAST [1] ${ }^{1}$ is such a model. This reference guide covers the use of the computer programs which comprise CFAST.

CFAST is a model which is intended to predict fire growth and smoke transport in multicompartment structures. This model is the result of a merger of ideas that came out of the FAST [1,2] and CCFM.VENTS [3] development projects. The implementation consists of a set of programs to describe the structure to be modeled, run the model and produce usable output. This guide provides detailed instructions for operating each of these programs and a description of the data input file requirements. A companion technical reference guide [4] and several additional papers $[5,6,7,8]$ provide details of the physical basis of zone models, the development of the predictive equations, the limitations of the current implementation of the model, and the level of agreement with experimental measurements.

1 Numbers in brackets refer to literature references listed in section 8 at the end of this report. 
Functionality within CFAST is provided by the following programs:

$\begin{array}{ll}\text { CEdit } & \text { interactive input } \\ \text { CFAST } & \text { the model itself } \\ \text { CPlot } & \text { interactive output to display data produced by the model } \\ \text { Report } & \text { produce time history (ASCII) output text } \\ \text { ReportG } & \text { animation of graphics description(s) }\end{array}$

CFAST and most of the associated routines work on a wide variety of hardware, from supercomputers through microcomputers. CEdit is specific to MS DOS ${ }^{2}$ based microcomputers, although it does generate an ASCII data file which can be used with CFAST on other computers. There are also several utility routines discussed later.

The order for the remaining sections of this guide represents a typical progression in using the CFAST model. These sections should be reviewed sequentially by those unfamiliar with CFAST and its associated routines. The presentation for each section assumes the use of MS DOS microcomputers. Alternate command lines are detailed in Appendix B. Section 2 details the contents of the diskettes distributed with CFAST 1.6 and the installation instructions for the software. Section 3 covers the interactive input editor, CEdit, which can be used to specify the physical phenomena and structural geometry of a fire scenario. Section 4 describes the operation of the CFAST model and provides some sample output. Section 5 demonstrates the use of output from the model in generating a variety of graphical presentations within CPlot. Section 7 discusses a variety of utility routines available in CFAST including Report and ReportG.

Throughout the remaining sections of this guide an example data input file, "PRM.DAT", is referenced. Each line of this file details some aspect of the fire scenario by specifying one of a limited number of recognized phrases or key words at the beginning of each line. A complete listing of this file can be found in Appendix A. This example file is not intended to illustrate all available CFAST input key words. Additional examples can be found in the appendix with "PRM.DAT" as well as in the Fire Hazard Assessment Methodology [9]. Additional data files are also supplied with the model as a means of testing the various components. A complete list of key words available in CFAST is provided in Section 6 for those who prefer to edit the input file using an ASCII text editor.

\footnotetext{
2 The use of company names or trade names within this report is made only for the purpose of identifying those computer hardware or software products with which the compatibility of the programs of CFAST has been tested. Such use does not constitute any endorsement of those products by the National Institute of Standards and Technology.
} 


\section{DISTRIBUTION AND INSTALLATION}

\subsection{New in CFAST 1.6}

- New horizontal flow (doors) and vertical flow (ceilings) algorithms

- New conduction and radiation algorithms

- Ceiling jet algorithm

- Multiple fire objects

- Generates better solutions since the pressure equations are more accurately calculated

- CFAST input files allow up to 15 compartments, 18 ducts, and 5 fans

- Press the <f5 > function key within the CFAST model to show the current time and time step. Press escape to stop the model.

- Faster calculations. By way of comparison, the actual clock time required to get to the first second of simulation time and a subsequent simulation time of 1200 seconds with one of our test cases is:

\begin{tabular}{|c|c|c|c|}
\hline $\begin{array}{c}\text { CFAST } \\
\text { Version }\end{array}$ & $\begin{array}{c}\text { After 1 } \\
\text { Second } \\
\text { Simulation }\end{array}$ & $\begin{array}{c}\text { At } 1200 \\
\text { Seconds } \\
\text { Simulation }\end{array}$ & $\begin{array}{c}\text { Elapsed } \\
\text { Time }\end{array}$ \\
\hline 1.4 & $0.4 \mathrm{~s}$ & $127.7 \mathrm{~s}$ & $\approx 127 \mathrm{~s}$ \\
\hline 1.5 & $12.2 \mathrm{~s}$ & $41.6 \mathrm{~s}$ & $\approx 29 \mathrm{~s}$ \\
\hline 1.6 & $1.9 \mathrm{~s}$ & $21.5 \mathrm{~s}$ & $\approx 20 \mathrm{~s}$ \\
\hline
\end{tabular}




\subsection{Hardware Requirements}

- A 386 or higher PC with at least 2.5 megabytes of free extended memory, or a Unix platform. CFAST does not run on 8086 microcomputers.

- A graphics display included on the list of supported displays in Appendix E

NOTE: CFAST on a PC looks first for expanded memory, then XMS memory, then unmapped EMS memory. It utilizes the first type that is available and cannot mix types. Thus, if there is expanded memory available, but not enough, the error message "insufficient memory to load EXP file" is displayed. The intention is to reduce memory requirements in later versions.

\subsection{Contents of the Distribution Disks}

CFAST routines:

\begin{tabular}{|l|l|}
\hline File Name & Function \\
\hline CEdit & $\begin{array}{l}\text { The data editor. Use CEdit when creating or modifying the ASCII input } \\
\text { file. Previous versions of CFAST provided the < f4 > function to run the } \\
\text { model within CEdit. This functionality is no longer supported. }\end{array}$ \\
\hline CFAST & This is the model. \\
\hline CPlot & Produce plots, lists, etc. \\
\hline Report & The report generator (reproduce original listings). \\
\hline ReportG & $\begin{array}{l}\text { A routine to replay the graphics output as though the CFAST model were } \\
\text { being run without actually running the model. Functions like a VCR. }\end{array}$ \\
\hline CF_Set & Modify the configuration file HV1.CF. \\
\hline List_clr & Show the colors that will be used by the main model. \\
\hline List_tpp & List the thermophysical database. \\
\hline List_obj & List the data in the multiple objects database. \\
\hline Obj2df & $\begin{array}{l}\text { Converts OBJECTS.ORG to OBJECTS.DF. Allows the user to edit } \\
\text { OBJECTS.ORG and then generate an OBJECTS.DF file in the proper } \\
\text { format. }\end{array}$ \\
\hline
\end{tabular}


ASCII data files required by CFAST:

\begin{tabular}{|l|l|}
\hline File Name & Function \\
\hline HV1.CF & $\begin{array}{l}\text { User-specific configuration information such as the path to search for data } \\
\text { input files, color settings within CEdit, and the default units. }\end{array}$ \\
\hline CPLOT.CF & Configuration file for CPlot. \\
\hline HLPTXT.CV1 & Required to provide context-sensitive help information within CEdit. \\
\hline THERMAL.DF & $\begin{array}{l}\text { Details the thermophysical properties for several preselected materials. This } \\
\text { database file is discussed in detail in Appendix C for users who need to } \\
\text { modify the current contents. }\end{array}$ \\
\hline OBJECTS.DF & $\begin{array}{l}\text { Contains the burning characteristics and geometric details of a limited } \\
\text { number of common objects such as a table or chair. This database file is } \\
\text { discussed in detail in Appendix D for users who need to modify the current } \\
\text { contents. This file should never be edited by the user. }\end{array}$ \\
\hline OBJECTS.ORG & $\begin{array}{l}\text { Contains the same details as OBJECTS.DF. This file can be modified by } \\
\text { the user. Once modifications are completed, OBJ2DF.EXE can be used to } \\
\text { generate the proper OBJECTS.DF file. See Appendix D for details. }\end{array}$ \\
\hline
\end{tabular}

Data input files to be used in testing for proper installation of the software:

\begin{tabular}{|l|l|}
\hline File Name & Function Tested \\
\hline TEST01.DAT & Initialization \\
\hline TEST02.DAT & Multiple compartments \\
\hline TEST03.DAT & Multiple compartments \\
\hline TEST04.DAT & History File \\
\hline TESTG1.DAT & Basic Graphics \\
\hline TESTG2.DAT & More Basic Graphics \\
\hline TESTG3.DAT & 3D Views \\
\hline TESTOBJ1.DAT & Multiple Fires \\
\hline
\end{tabular}


Building descriptor files required to produce CFAST graphics for the TESTG3.DAT data file:

\begin{tabular}{|l|l|}
\hline File Name & Description \\
\hline TESTG3T.PIC & Cross-sectional view \\
\hline TESTG3B.PIC & Plan view \\
\hline
\end{tabular}

Graphics files required by the kernel. One file for each extension is needed:

\begin{tabular}{|l|l|}
\hline File Name & Function \\
\hline *.DSP & Device dependent graphics instructions. \\
\hline *.FNT & Fonts. \\
\hline DEVFONT.* & Fonts. \\
\hline *.KRN & Graphics kernel. \\
\hline *.LOC & Device locator interface to kernel. \\
\hline
\end{tabular}

\subsection{Installation}

An automatic installation program which prompts you for the necessary information and copies the CFAST files onto your hard disk is included on the distribution disks for CFAST. Since the CFAST programs are provided on the diskettes in compressed form (to save disk space), you must use the automatic installation program to copy CFAST to your hard disk. For those in need of specific custom installations for unique hardware, several utility programs are provided to customize CFAST for your system.

To install CFAST on your PC computer system, place the diskette labeled "CFAST Disk $\# 1 "$ into diskette drive A: and enter the following DOS commands:

A :

INSTALL

Several questions are asked about the computer system and how and where to install the modules. You may answer none, some, or all of the questions as appropriate for your specific needs. Follow the directions on the screen closely and provide answers to questions as desired. Usually, the defaults provided by the installation program are sufficient. On several of the screens, you are asked to fill in information or change the defaults suggested by the installation module if desired. These screens are described in more detail below. 
on thich disk drive do you wish to install CFAST?

\section{Orive A: \\ Drive B: \\ Drive C: \\ Drive D: \\ Drive E:}

CFAST is installed in a single subdirectory on a hard disk. The first two screens prompt for the drive letter of the hard disk (usually $\mathrm{C}$ :), and the name of the target directory. For most installations, the defaults are sufficient provided the drive selected contains at least four megabytes of free space. For custom installations, any drive containing at least four megabytes of free space may be selected. Any valid nonexistent directory may be used for the program directory. Once installed, additional directories can be set up for datafiles, databases and so on.

As the files are copied from the installation diskettes to the hard disk, the installation program shows the progress on the screen. Prompts are displayed at the appropriate times prior to inserting each of the distribution disks.

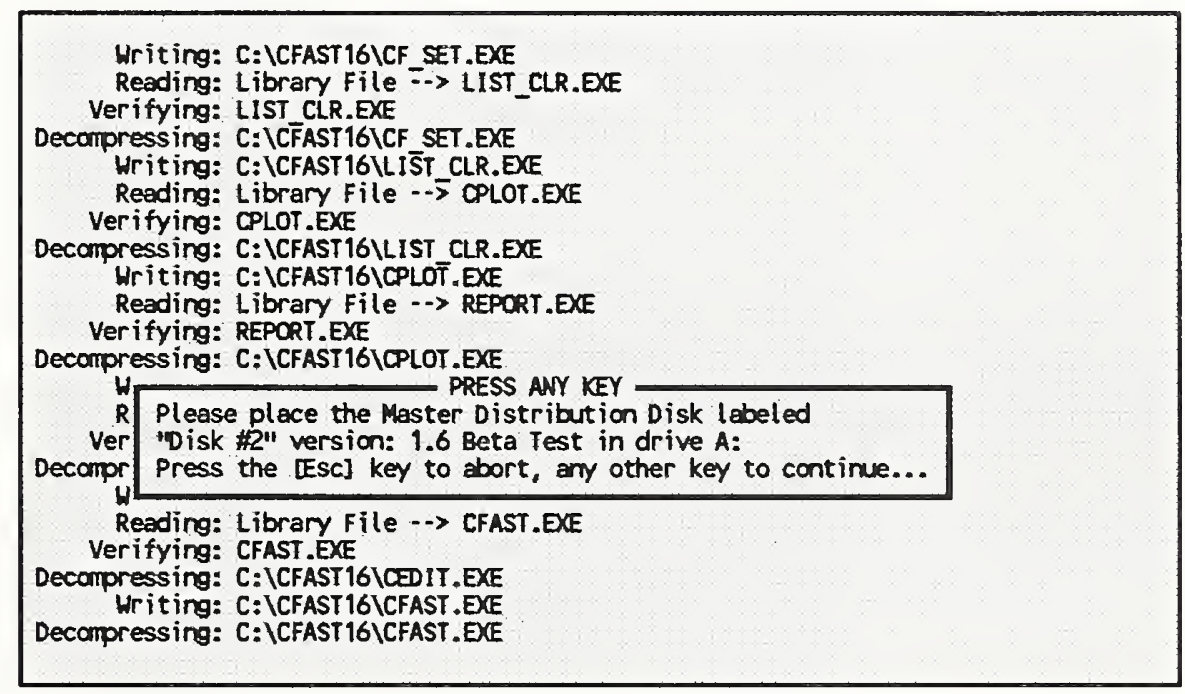

In order to operate correctly, the installation module may need to create or modify the FILES = statement in the DOS startup file CONFIG.SYS. If you wish to modify the file 
yourself, you may skip this step. The FILES = statement must specify a minimum of 20 files for the software to operate correctly.

\subsection{Test Cases}

Eight data input files are provided as test cases. They are intended only to test various capabilities of the computer and ascertain whether the model is working. The following table lists the files along with the purpose of each and sample execution times obtained using a 486 PC.

\begin{tabular}{|l|c|c|c|l|}
\hline File Name & $\begin{array}{c}\text { Simulation } \\
\text { Time }(\mathrm{s})\end{array}$ & $\begin{array}{c}\text { No. } \\
\text { Rooms }\end{array}$ & $\begin{array}{c}\text { Execution time (s) on a } \\
486 / 25(\mathrm{~s})\end{array}$ & Function Tested \\
\hline TEST01.DAT & 10 & 1 & 2 & Initialization \\
\hline TEST02.DAT & 10 & 6 & 54 & Multiple compartments \\
\hline TEST03.DAT & 10 & 6 & 23 & \\
\hline TEST04.DAT & 300 & 6 & 360 & History File \\
\hline TESTG1.DAT & 35 & 1 & 23 & Basic Graphics \\
\hline TESTG2.DAT & 35 & 1 & 15 & More Basic Graphics \\
\hline TESTG3.DAT & 300 & 6 & 294 & 3D Views \\
\hline TESTOBJ1.DAT & 300 & 2 & 17 & Multiple Fires \\
\hline
\end{tabular}

To test the installation and computer performance, run each of the test cases in turn. The command for TEST01.DAT is:

CFAST TEST01.DAT 


\section{CEdit}

CEdit is an interactive, user-friendly program used to generate most data files for input to the CFAST model. As such, it is difficult to describe all the functions of the program in a reference guide. Rather, it is best learned through use. This section will describe the types of information entered on each of the screens of CEdit and relate those to the specific sections of Section 6 which describe the corresponding CFAST input file key words.

\subsection{Using CEdit}

The user interface is organized into a series of screens, each of which addresses a general area of the process of modeling a fire. General and key word help is always available except within the key word help section itself. The top of the screen shows which section is active. These names are shown below and are roughly descriptive of the area which is covered. The bottom of each screen shows which special keys are active, or indicates what action is expected. If data can be entered, then the range and units are shown if appropriate. For example, compartment width is in units of length, whereas a title has no dimensions.

\begin{tabular}{ll|l}
0 & Initialization \\
1 & Overview \\
2 & Ambient Conditions \\
3 & Geometry \\
4 & Vents (doors,...) \\
5 & Vents (ceiling,...) \\
6 & Fans, Ducts,... \\
7 & Thermal Properties \\
8 & Fire Specification \\
9 & Objects \\
10 & Files,... & \\
& & \\
11 & Version and Settings & show the current CFAST version number and \\
& & make permanent changes in the colors and units
\end{tabular}

Note that the Initialization screen (screen 0) and the Version and Settings screen (screen 11) do not correspond to sections of the data file. Rather, they are used to retrieve a CEdit data file and to customize the CEdit display environment, respectively. 


\begin{tabular}{||c|l||}
\hline Overview & $\begin{array}{l}\text { Title from section } 6.2 .1 \\
\text { Time specifications from section } 6.2 .1\end{array}$ \\
\hline Ambient Conditions & Ambient conditions from section 6.2 .2 \\
\hline Geometry & Floor plan data from section 6.2 .3 \\
\hline Vents(doors,...) & Horizontal flow connections from section 6.2 .4 \\
\hline Vents(ceiling,...) & Vertical flow connections from section 6.2 .5 \\
\hline Fans, Ducts,... & Mechanical ventilation from section 6.2 .6 \\
\hline Thermal Properties & $\begin{array}{l}\text { Thermophysical properties of enclosing surfaces from } \\
\text { section } 6.2 .7\end{array}$ \\
\hline Fire Specification & $\begin{array}{l}\text { Description of fire sources from section } 6.2 .8 \\
\text { Species production from section } 6.2 .8\end{array}$ \\
\hline Objects & Object specifications from section 6.2 .9 \\
\hline Files,... & File specifications from section 6.2 .10 \\
\hline
\end{tabular}

In general, CEdit requests either data from the keyboard, or selection information from the function keys (or mouse if present). Any active function keys are shown at the bottom of the screen. If the meaning is not clear, the show keys function key, 99 , will give further explanation. Otherwise, there are directions as to what further actions are possible. Select an entry to be changed by moving the highlight bar using the arrow keys $(\leftarrow \uparrow \downarrow \rightarrow)$. If alphanumeric input (data) is being requested, the entry must always be completed by pressing the Enter key. For function keys, only a single keystroke is required. Some of the function keys are active throughout CEdit; others are specific to certain screens. Those specific to individual screens are described in more detail on the following pages. Those active throughout the program are discussed below.

\begin{tabular}{|l|l|l|}
\hline key & key label & function \\
\hline $\mathrm{f1}$ & help & $\begin{array}{l}\text { You may press the HELP key, f1, at any time to receive context } \\
\text { sensitive help describing the current screen or current quantity } \\
\text { being entered. Pressing f1 a second time brings up a list of key } \\
\text { words for which more detailed help is available. }\end{array}$ \\
\hline $\mathrm{f} 2$ & go to screen & $\begin{array}{l}\text { Allows you to move directly from one screen to another within } \\
\text { CEdit. From any screen, pressing f2 brings up a menu listing } \\
\text { all the screens in CEdit. Using the mouse or the arrow keys, } \\
\text { select the screen of interest and press enter or the left mouse } \\
\text { button. }\end{array}$ \\
\hline
\end{tabular}




\begin{tabular}{|l|l|l|}
\hline f8 & change units & $\begin{array}{l}\text { You may temporarily change the working engineering units } \\
\text { displayed by CEdit and used for data entry at any time by } \\
\text { pressing f8 and selecting the quantity to be changed with the up } \\
\text { and down arrow keys. Pressing the right or left arrow keys } \\
\text { changes the working units of the currently selected quantity. To } \\
\text { change the units permanently, you must modify the installation } \\
\text { parameters. }\end{array}$ \\
\hline f9 & show keys & $\begin{array}{l}\text { Provides a brief description of the function keys currently active } \\
\text { and can be used to provide a quick reference of the current } \\
\text { function of each of the keys. }\end{array}$ \\
\hline f10 & quit & Used to end CEdit. \\
\hline
\end{tabular}

Four additional keys have special meaning in CEdit when pressed on any of the main screens (screens 1-11 above).

\begin{tabular}{|l|l|l|}
\hline key & key label & function \\
\hline Home & first screen & $\begin{array}{l}\text { Move immediately to the Overview screen from any CEdit main } \\
\text { screen. }\end{array}$ \\
\hline End & last screen & $\begin{array}{l}\text { Move directly to the Files screen from any CEdit main screen } \\
\text { and save the current changes. }\end{array}$ \\
\hline PgDn & Page Down & $\begin{array}{l}\text { Move one screen forward. Forward direction is determined by } \\
\text { the order of the screens on the go to screen (f2) menu. }\end{array}$ \\
\hline PgUp & Page Up & $\begin{array}{l}\text { Move one screen backward. Backward direction is determined } \\
\text { by the order of the screen on the go to screen (f2) menu. }\end{array}$ \\
\hline
\end{tabular}

Again, these special keys must be used from one of the main screens to retain their functionality. Alternate meanings exist within many of the subpages or windows displayed by each screen. When an alternate meaning does apply, this is indicated in the sections below.

There are several ways to start CEdit. The simplest is to enter the command: cedit

Refer to Appendix B for alternative CEdit command lines. 


\subsection{Initialization Screen}

On the Initialization screen, the CFAST input file to be edited with CEdit is selected in one of three ways.

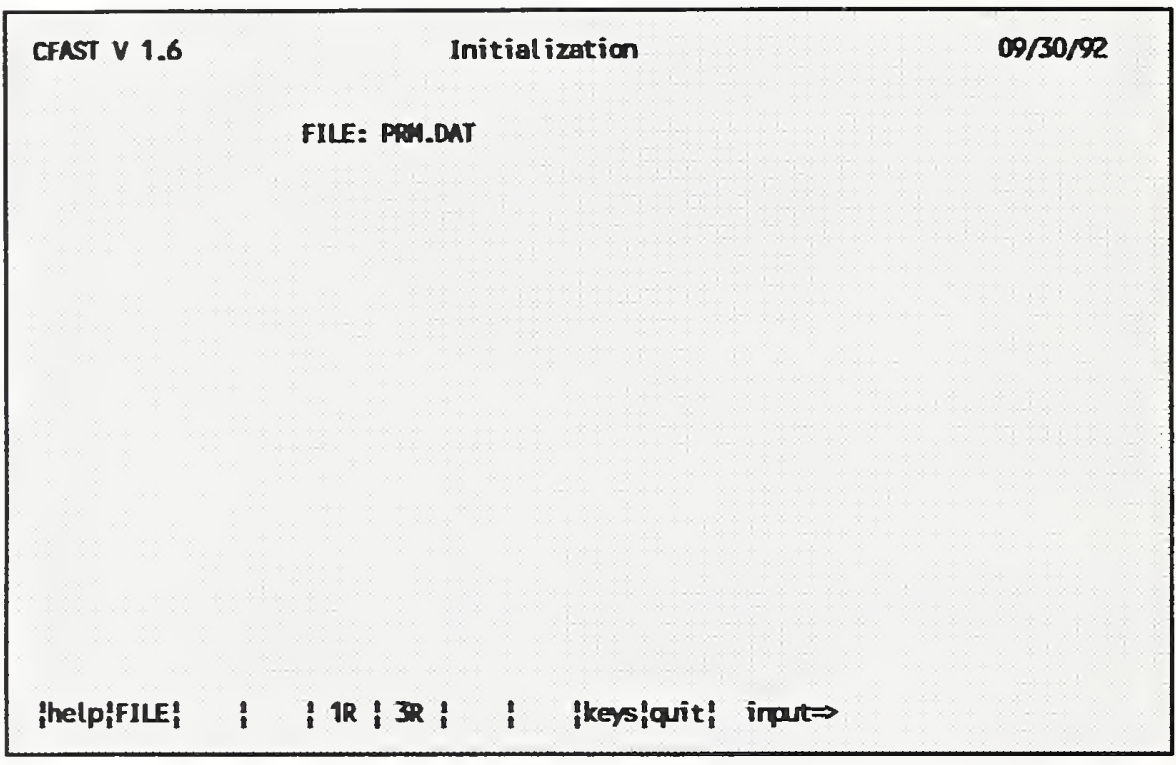

If the file desired was the last file used by CEdit or the file name was entered on the command line, press Enter to select that file automatically. Alternatively, the name of any existing DOS file may be selected directly by typing in the name of the file. To use the existing example file, type PRM.DAT, and press Enter.

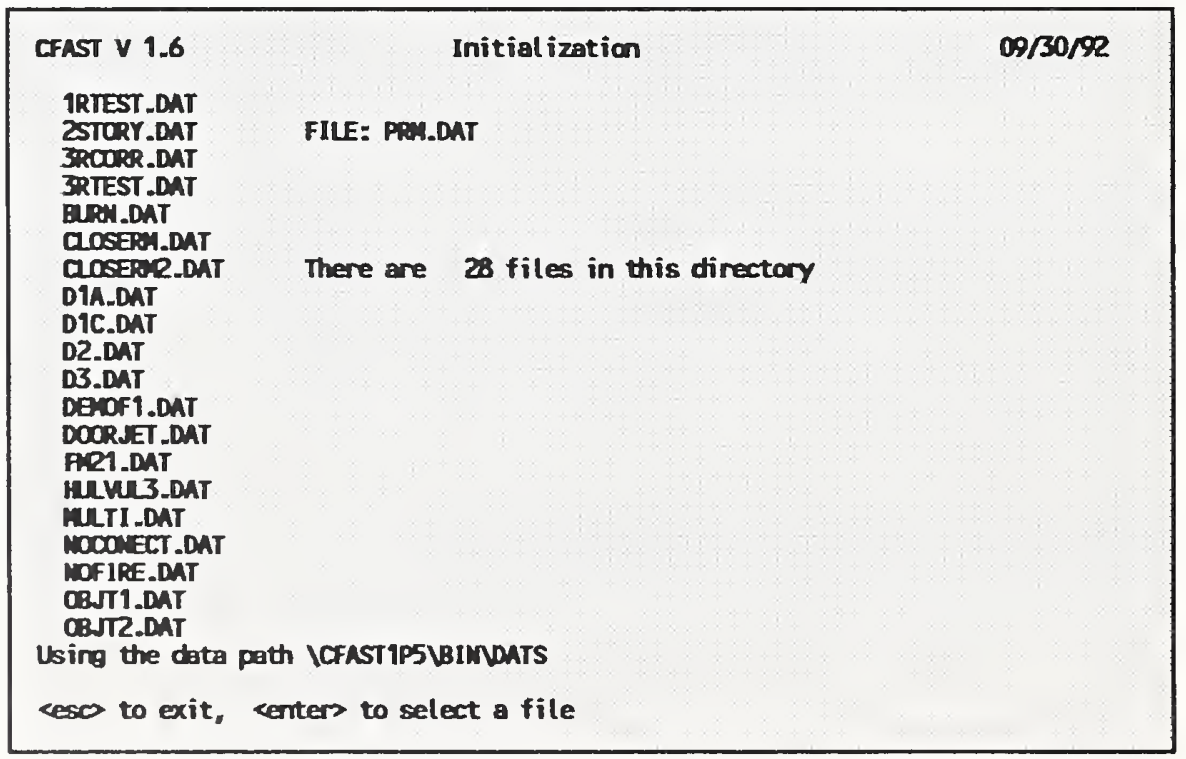


An alternative to entering the file name is to press the select file key, f2, to see a list of files in the current working directory. By default, all files with an extension of .DAT are included in the list. If desired, one may type a file matching pattern (such as ** to see all files in the subdirectory) before pressing $\mathrm{f} 2$. The same rules for wildcards apply here as they do to all DOS file commands.

In addition to showing the name of the current screen, "Initialization" in this case, the name of the module, the version number and the current date are shown. The latter two can change, as CEdit is enhanced, and when run on dates different than shown in the figure.

If a completely new data file is to be created, one of two generic data sets built into CEdit may be selected. Key f5 may be pressed to use a single compartment case and key f6 may be pressed to use a three compartment case.

\subsection{Overview Screen}

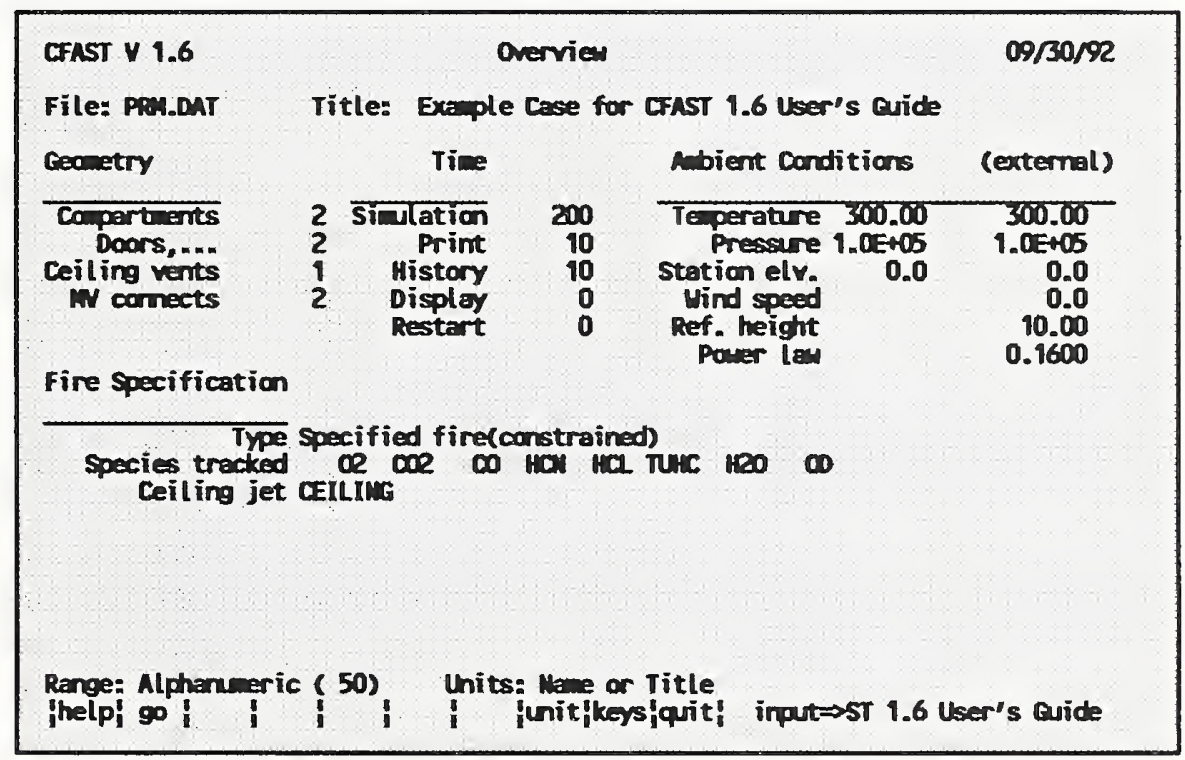

The Overview screen presents a summary of the CFAST data file. The title, simulation time, print interval, history interval, display interval, and restart time may be changed on the screen. All other information displayed is changed on other screens in CEdit and is included here (in the "protected text" color) to provide a summary of the data set. Key words in the data file effected by these changes include VERSN, TIMES, and RESTR. 


\subsection{Ambient Conditions Screen}

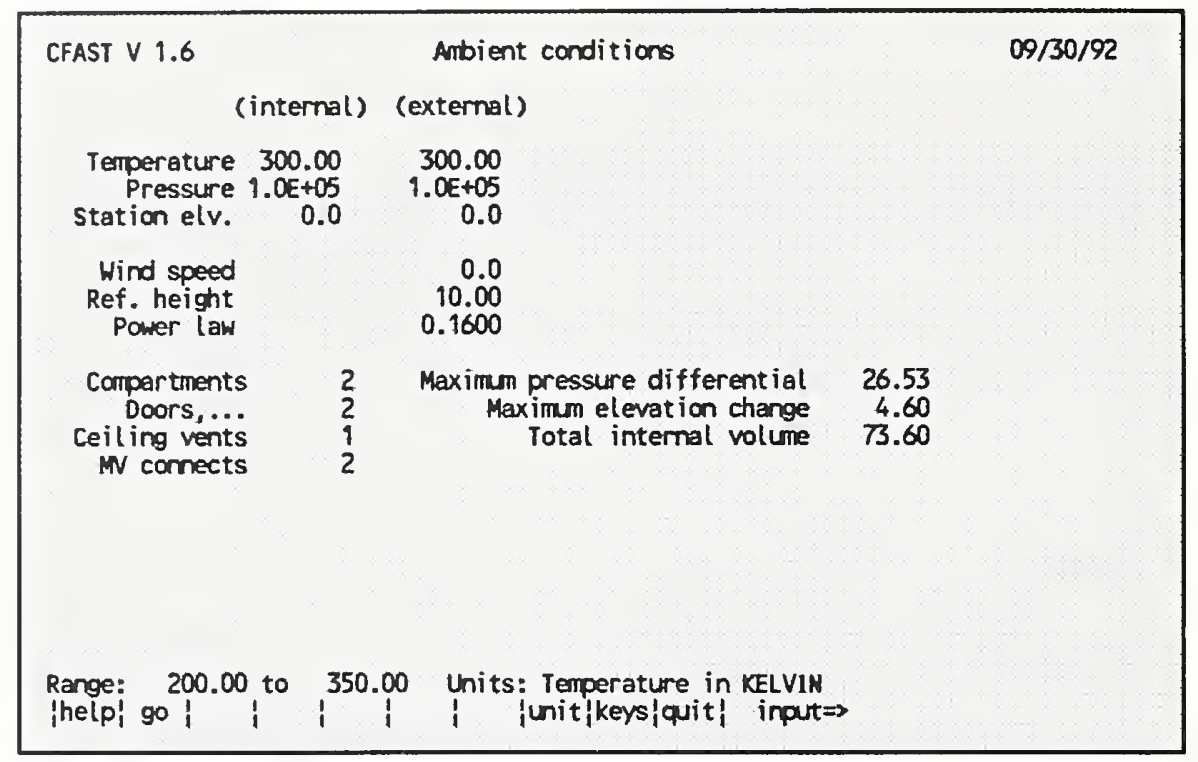

On the Ambient Conditions screen, the internal and external ambient temperature, pressure, and station elevation along with information on external wind may be changed. The wind speed, scale height, and power law are used to calculate the wind coefficient for each vent connected to the outside. The wind velocity is specified at some reference height. The power law then provides a lapse rate for the wind speed. An assumption is that the wind speed is zero at the surface. The formula used to calculate the wind speed at the height of any vent is (wind speed) $\cdot((\text { vent height }) /(\text { scale height }))^{\text {(power law) }}$. The wind is applied to each external opening as a change in pressure outside of the vent. It is further modified by the wind coefficient used for the openings. The vent connections, entered on the two vent screens, are summarized here along with the geometry of the structure and the mechanical ventilation connections. This summary information together with additional information concerning pressure, elevation and volume is displayed as an aid to data entry. Changes on this screen effect the TAMB, EAMB, and WIND key words when the data file is saved. 


\subsection{Geometry Screen}

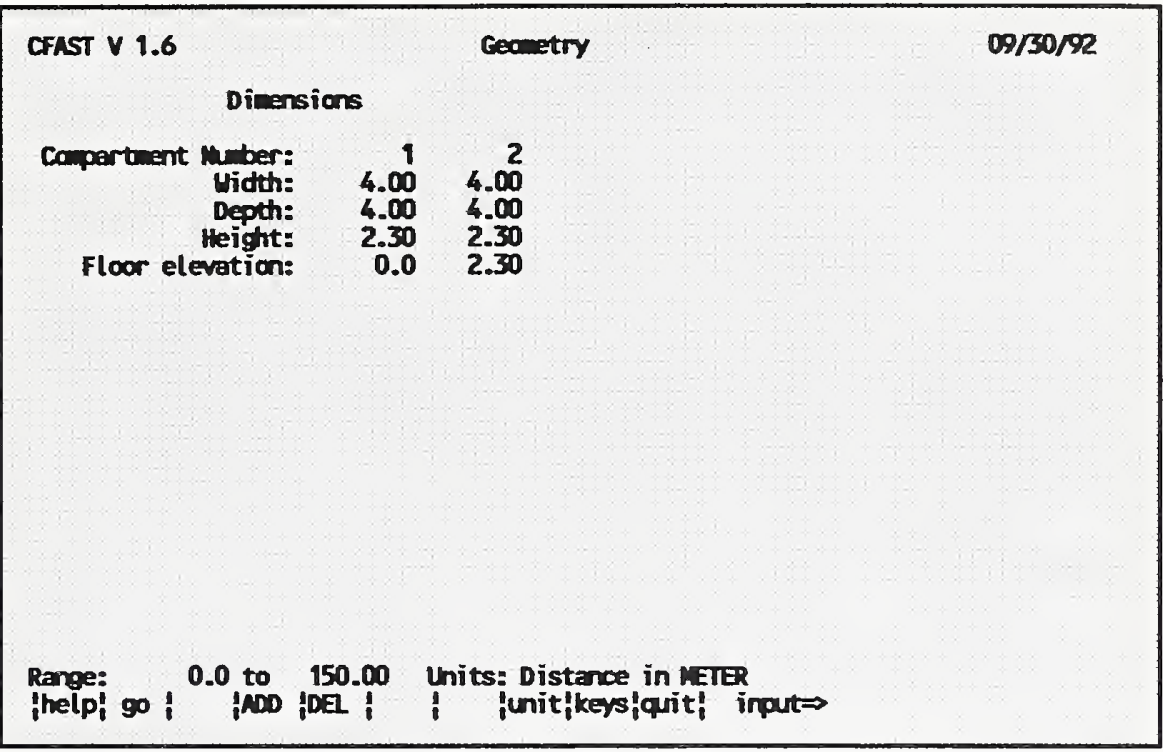

On the Geometry screen, information on the sizes of all of the compartments is entered. The key words associated with this screen are WIDTH, DEPTH, HEIGH, and HI/F. The DELETE key (f5) may be used to delete a compartment.

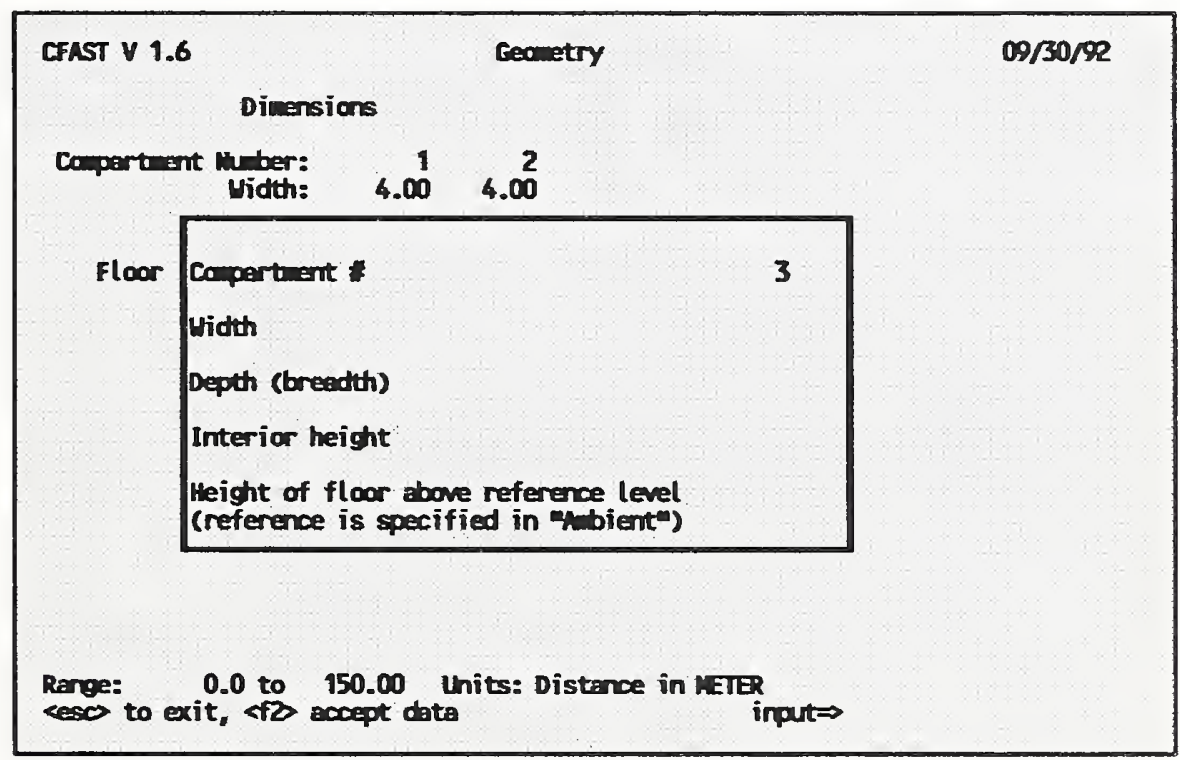

Compartments may be added to the simulation with the ADD key (f4) on the Geometry screen. Dimensions of the compartment, along with the height of the compartment floor above the reference height (specified on the Ambient Screen) are entered in the overlaid window. 


\subsection{Vents(doors,...) Screen}

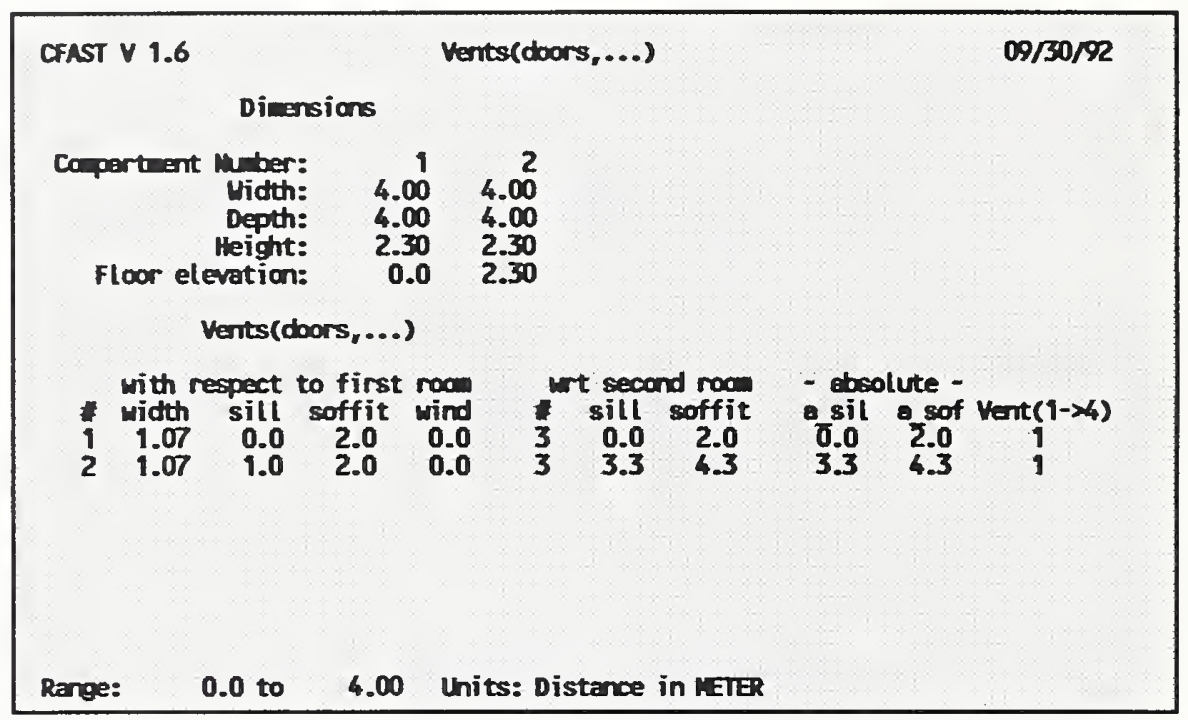

On the Vents(doors,...) screen, all horizontal flow connections between compartments and openings to the outside are specified. A vent may be added using the ADD key (f4) or deleted using the DELETE key (f5). The OPEN/CLOSE key (f6) allows specification of the vent position over the course of the fire for the currently selected vent.

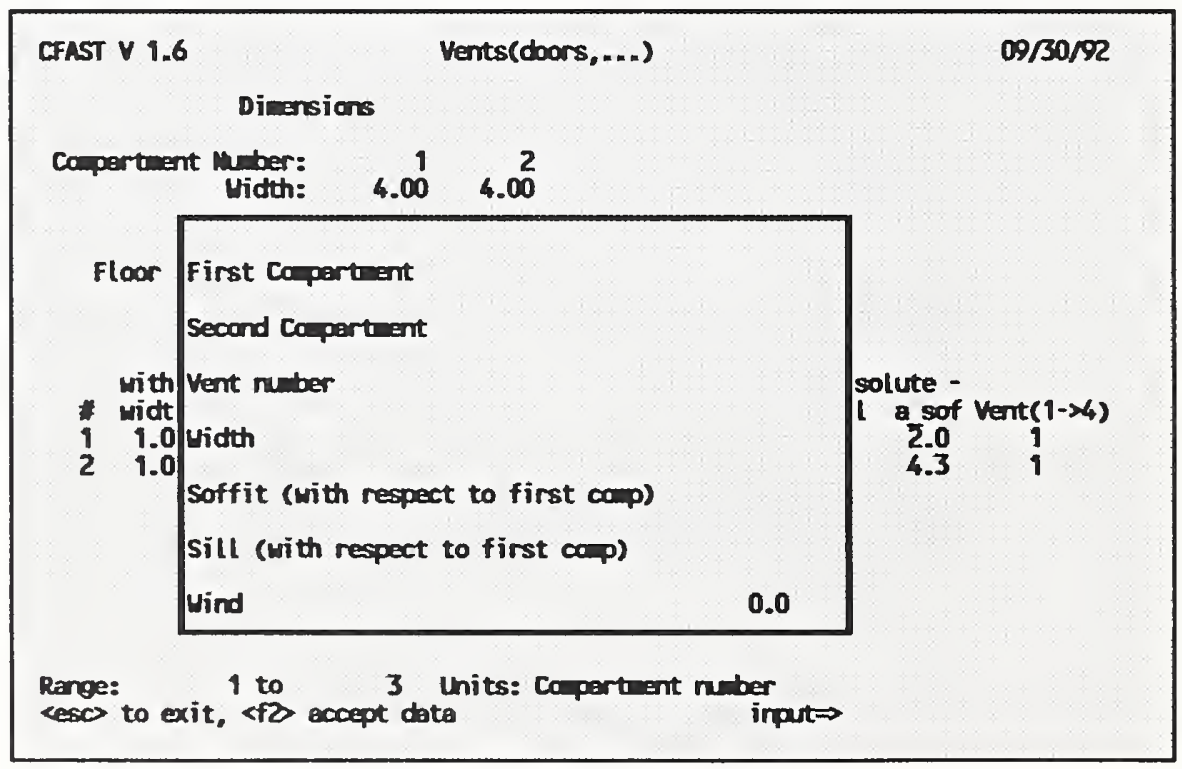

Like adding a compartment on the geometry screen, the ADD key (f4) may be used on the Vents(doors,...) screen. A vent is specified by the two connecting compartments, the vent number, and the size and location of the vent. A connection to the outside is defined by using a 
compartment number for the "Second Compartment" one greater than the total number of compartments entered on the Geometry screen. Each entry on this screen creates the appropriate HVENT key word in the data file.

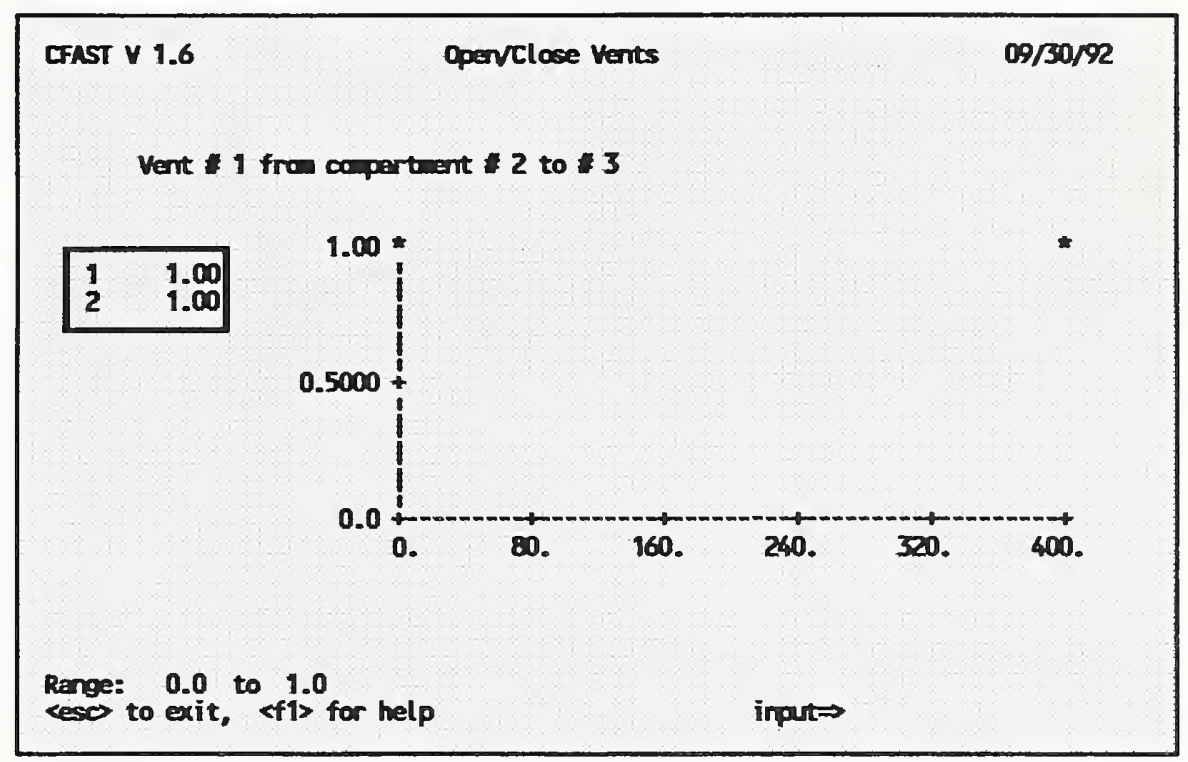

The OPEN/CLOSE positions for any vent can be specified by moving the highlight bar to that vent on the main vents screen and pressing the f6 key. The current timeline values (horizontal axis on the graph above) for the selected vent are displayed. Move the highlight bar to the entry to be changed and enter a value from 0 (closed) to 1 (completely open). The default value is 1 . This entry is applied in CFAST by multiplying the width of the vent by this value. The number of possible entries on this screen is determined by the number of specified points on the timeline which is specified the Fire Specification screen. For a more complete explanation of the timeline, please read the section in Fire Specification about modification of the duration of the fire. These OPEN/CLOSE events are always related to the course of the fire. One CVENT key word is created in the data file for each complete entry. 
3.7 Vents(ceiling,...) Screen

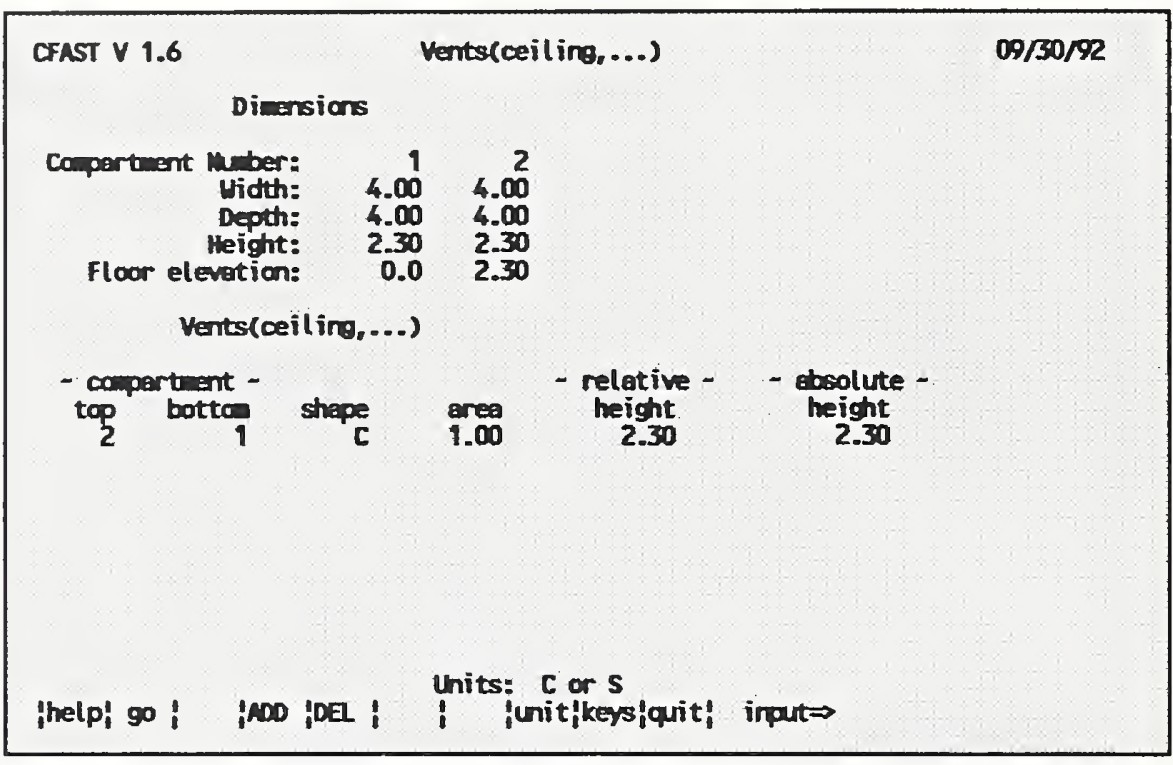

On the Vents(ceiling,...) screen, all vertical flow connections between compartments and openings to the outside are specified. A vent may be added using the ADD key (f4) or deleted using the DELETE key (f5). Vertical flow entry does not provide an equivalent to CVENT to allow specification of the vent position over the course of the fire.

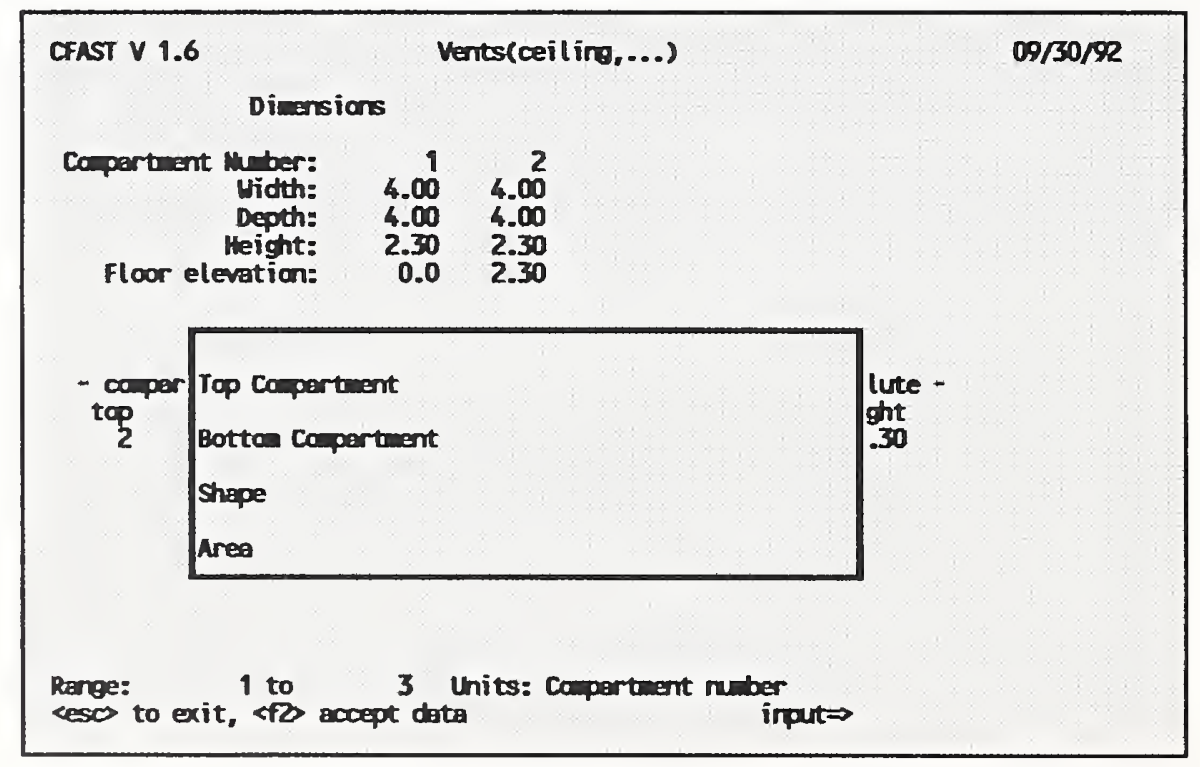

Vertical flow vents may be added by using the ADD key (f4) on the Vents(ceiling,...) screen to create VVENT key words in the data file. The vent is specified by the upper and lower connecting compartments, the shape of the vent (Circle or Square), and the area of the vent. A 
connection to the outside is permitted for either the "Top Compartment" or the "Bottom Compartment". Such a connection is defined by entering a compartment number one greater than the total number of compartments on the Geometry screen. The upper compartment can not have a floor height lower than the ceiling of the lower compartment and must be within 0.1 meters of the ceiling height for the lower compartment.

\subsection{Fans, Ducts,... Screen}

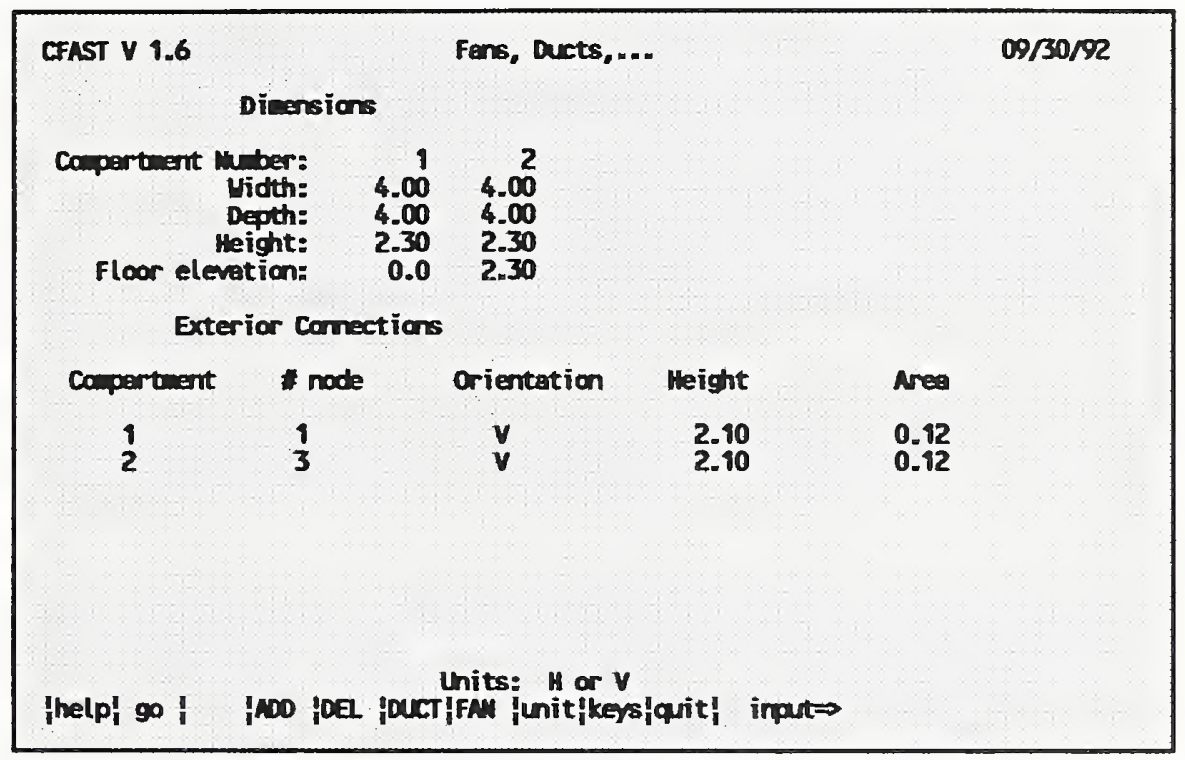

Mechanical ventilation systems are entered using this screen. This includes details of the connections from compartments to the ventilation system, and of the ductwork and fans within the system. These are specified on the three separate pages of the Fans, Ducts screen. On this first page, the connections between compartments and the ventilation system are detailed. These correspond to the MVOPN key word in the CFAST data file. Like the Geometry and Vents screens, these connections may be added with the ADD key (f4) or deleted with the DELETE key (f5). The DUCT key (f6) allows specification of the ductwork on the Duct page. The FANS key (f7) allows specification of the operating characteristics of the fans in the system. 


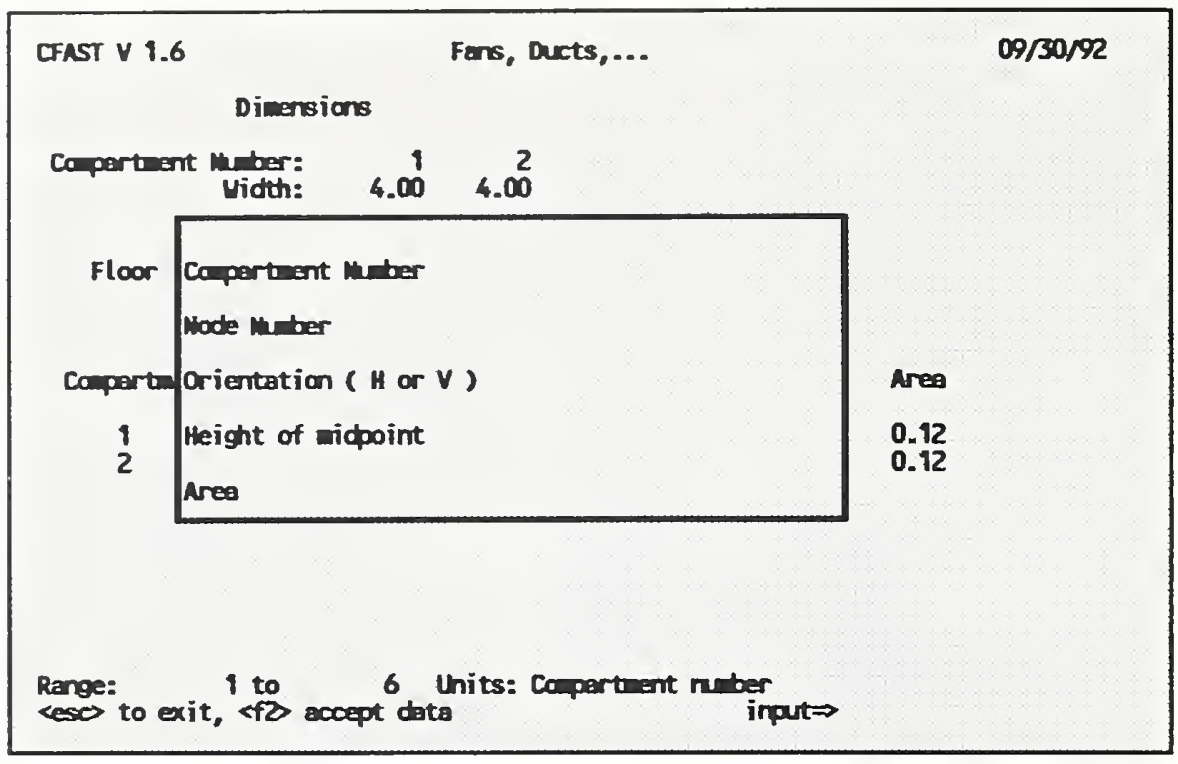

Connections from compartments to the ventilation system are added using the ADD key (f4) from the main mechanical ventilation screen. A connection is fully specified by the compartment number, mechanical ventilation node number, orientation (Horizontal or Vertical), height, and area.

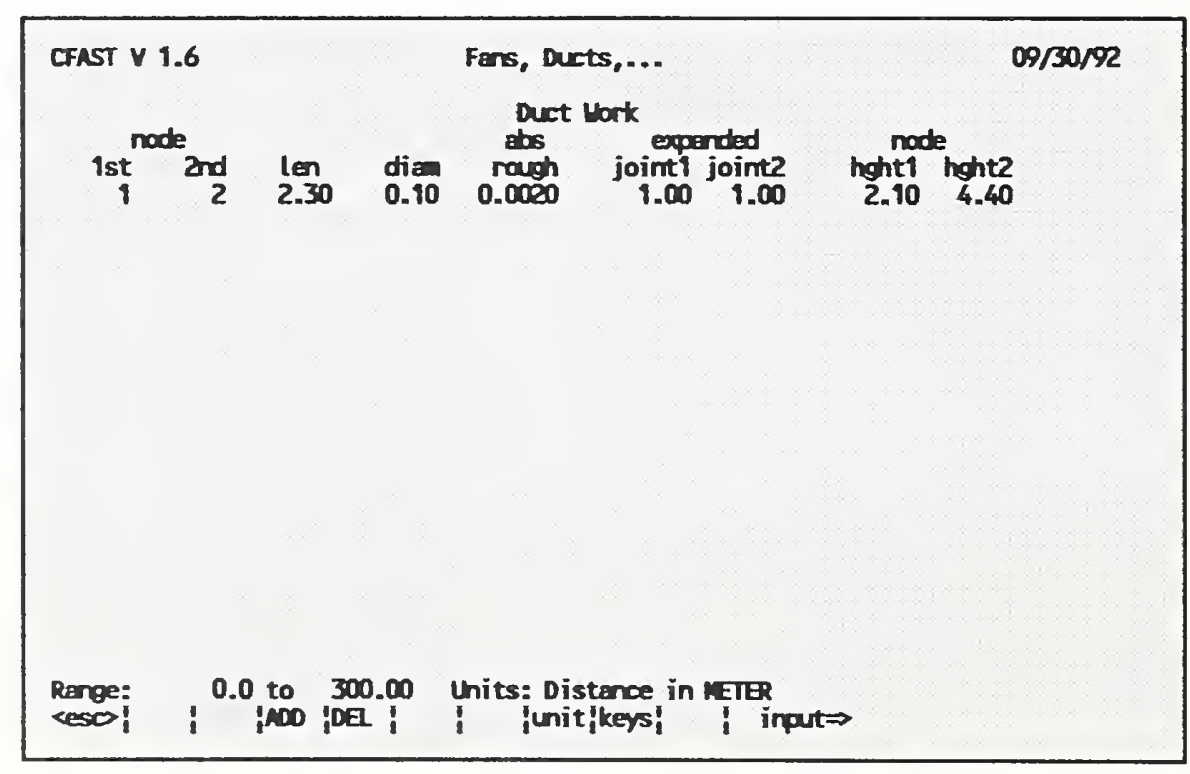

The ductwork in the ventilation system is specified on the Duct page by pressing f6 from the main screen. Internal connections may be added with the ADD key (f4) or deleted with the DELETE key (f5). Pressing Page Up will return to the main screen. 


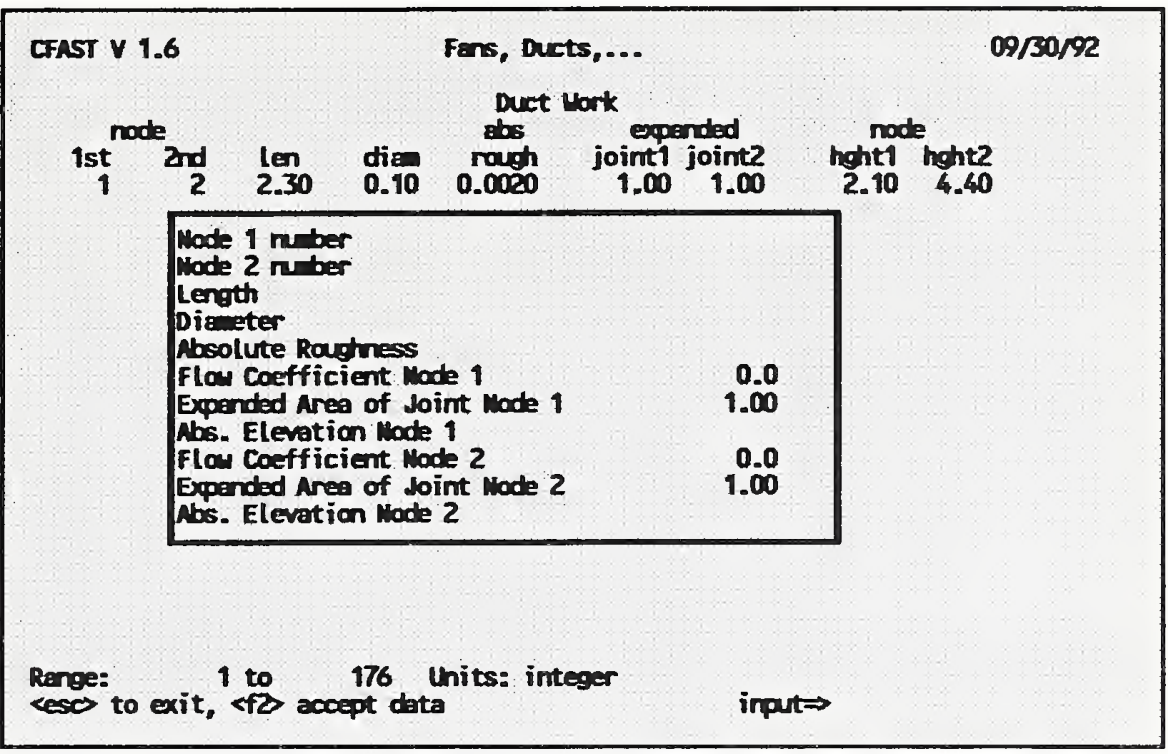

The ADD key on the Duct page creates a window to specify a connection between internal nodes of the mechanical ventilation system. All of the information for the MVDCT and INELV key words in the CFAST data file are entered for a single connection.

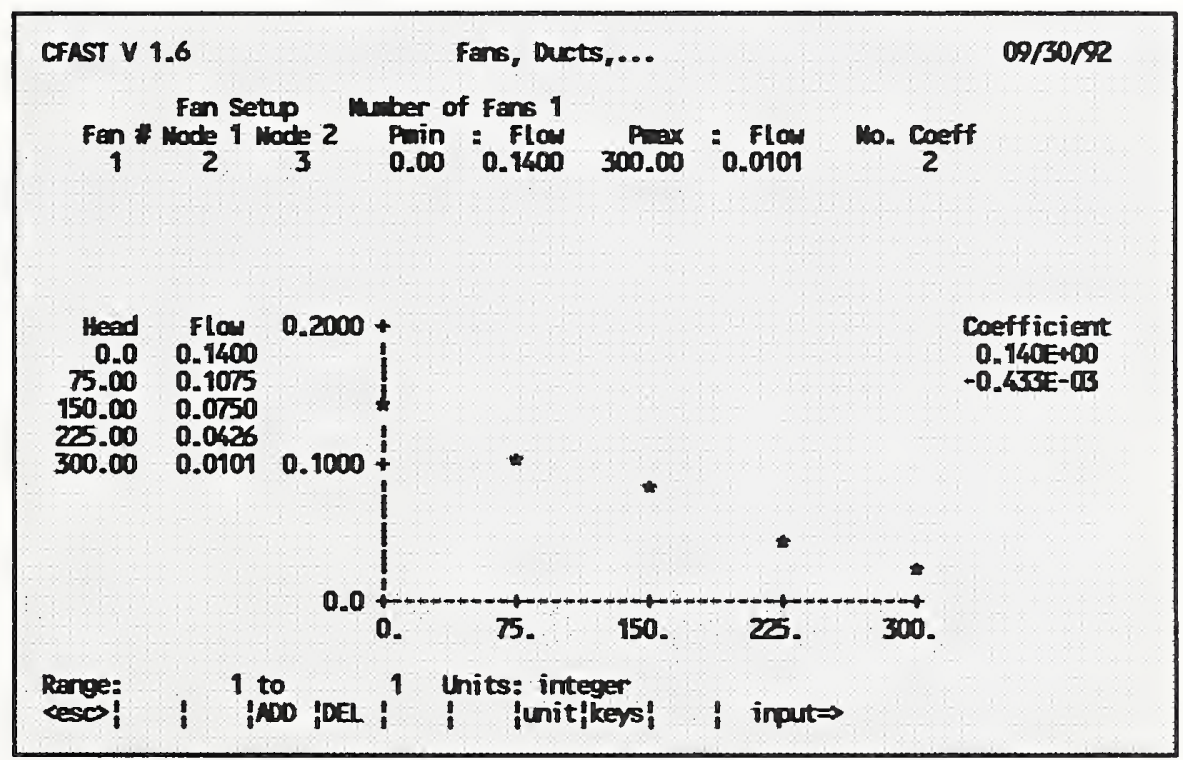

Operating characteristics of the fans in the ventilation system are specified on the Fan setup page. Fans may be added with the ADD key (f4) or deleted with the DELETE key (f5). Once a fan has been added to the system, the fan curve may be modified by either entering a set of pressure and flow data or a set of coefficients for the fan curve. In either case, CEdit will calculate the other quantity before leaving the Fan setup page. Pressing Page Up will return to the main screen. 


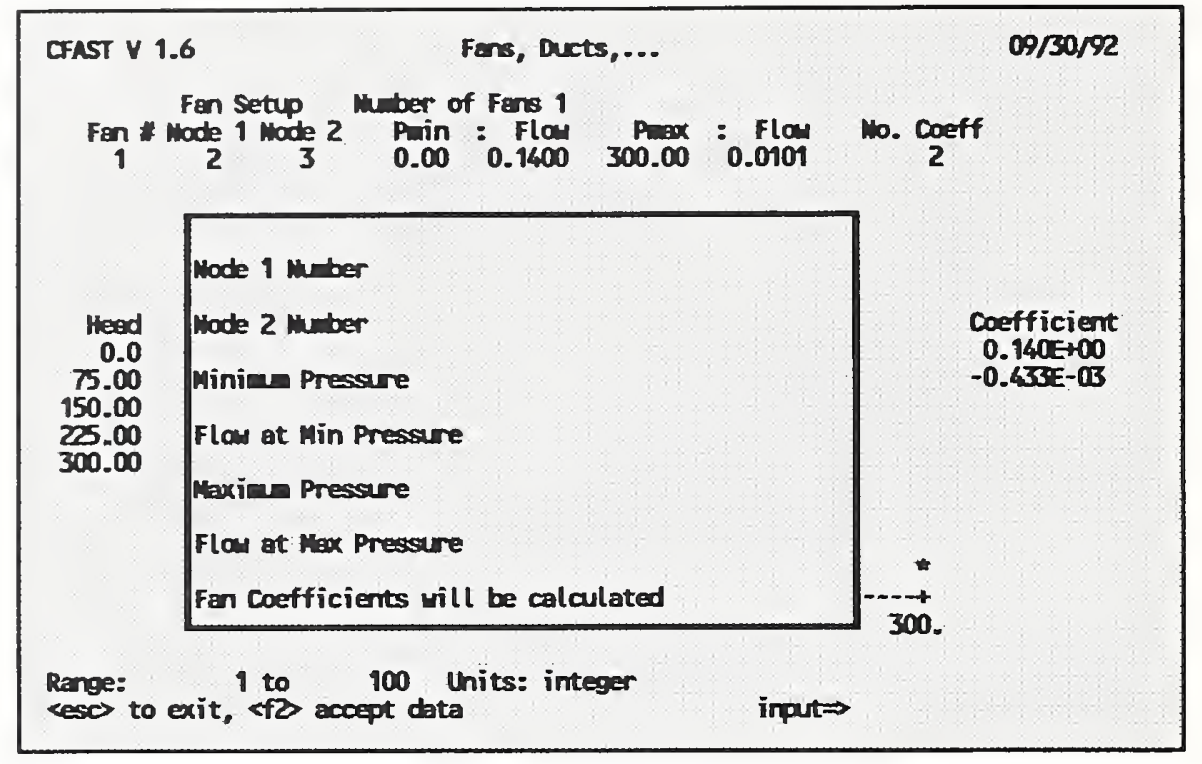

New fans are added to the system using the ADD key (f4) from the Fans page. A fan is specified by entering internal node numbers, minimum and maximum pressures, and flow at each pressure. A MVFAN key word is created for each entry on this page when the data file is saved.

\subsection{Thermal Properties Screen}

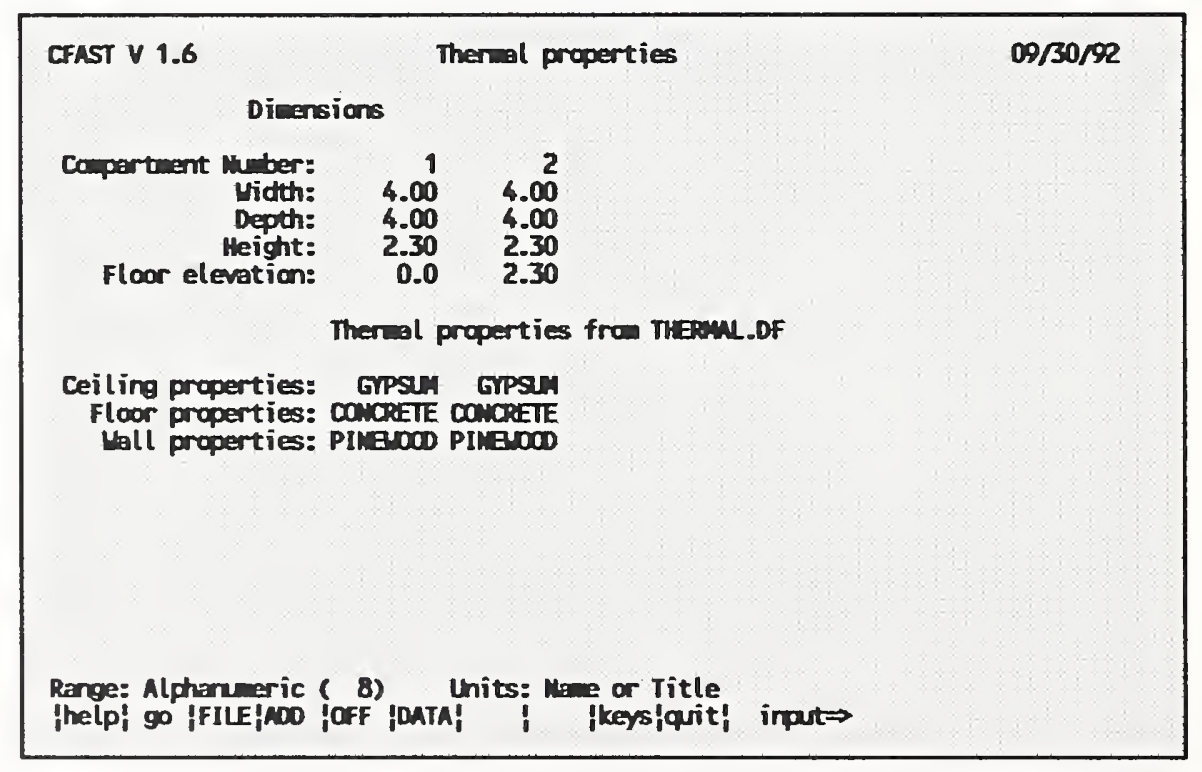

The Thermal Properties screen details the materials used for the ceiling, walls, and floor of each compartment. The name of a material contained in the CFAST Thermal Database may be entered by first positioning the highlighted selection bar over the entry of interest and typing the material name exactly as it exists in the database. To make the process easier, a material name 
may be selected on the Thermal Database page below for the currently highlighted surface. Once a material has been selected on the Database page, it can be designated for additional surfaces by selecting the desired surface and pressing the ADD PICKED key (f4). To specify an adiabatic surface, press the OFF key (f5) to turn OFF the heat transfer calculation for that surface. If the word NONE is displayed for a material, it means that the name entered does not appear in the Thermal Database. Key words associated with this screen include CEILI, WALLS, and FLOOR.

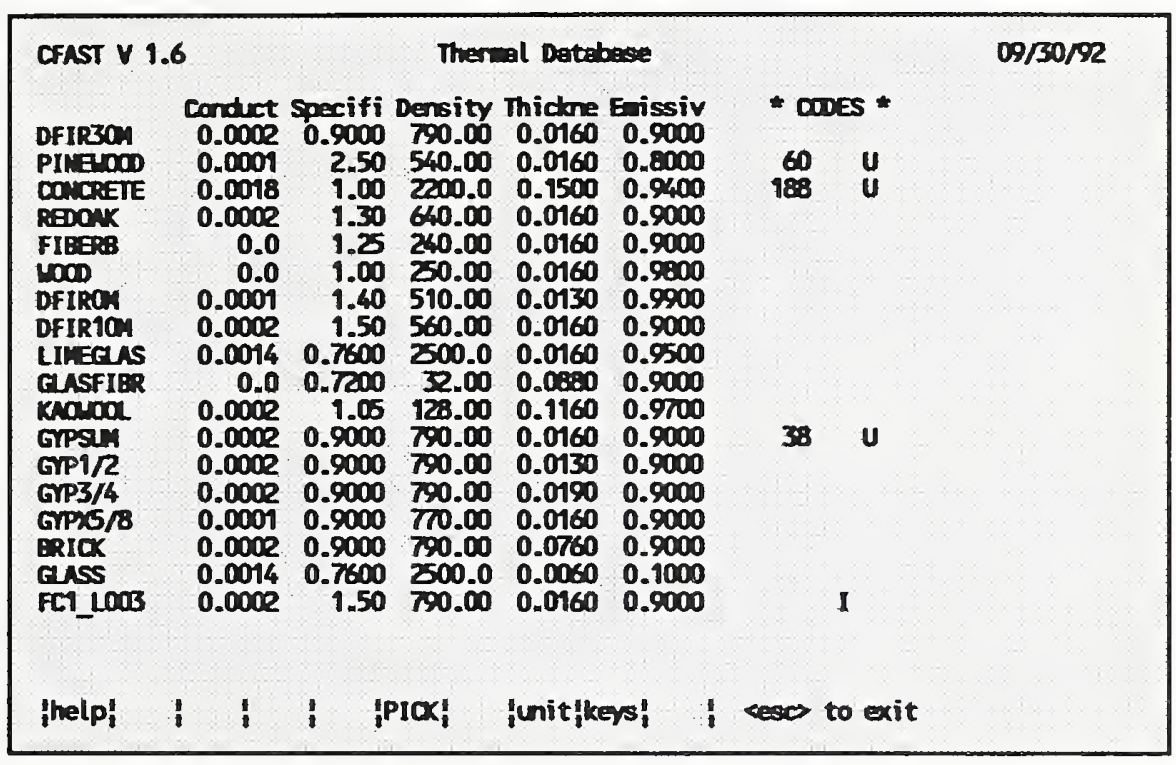

The DATA key (f6) displays the CFAST Thermal Database from the Thermal Properties screen. The contents of the database may be examined, and a material can be chosen (and later added in the Thermal Properties screen) by positioning the highlighted selection bar over the material and pressing the PICK MATERIAL key (f6). Press the Page Up and Page Down keys to quickly browse through the database. Move to the first database entry by pressing the Home key or the last entry by pressing the End key. The thermophysical database can not be changed by CEdit. 


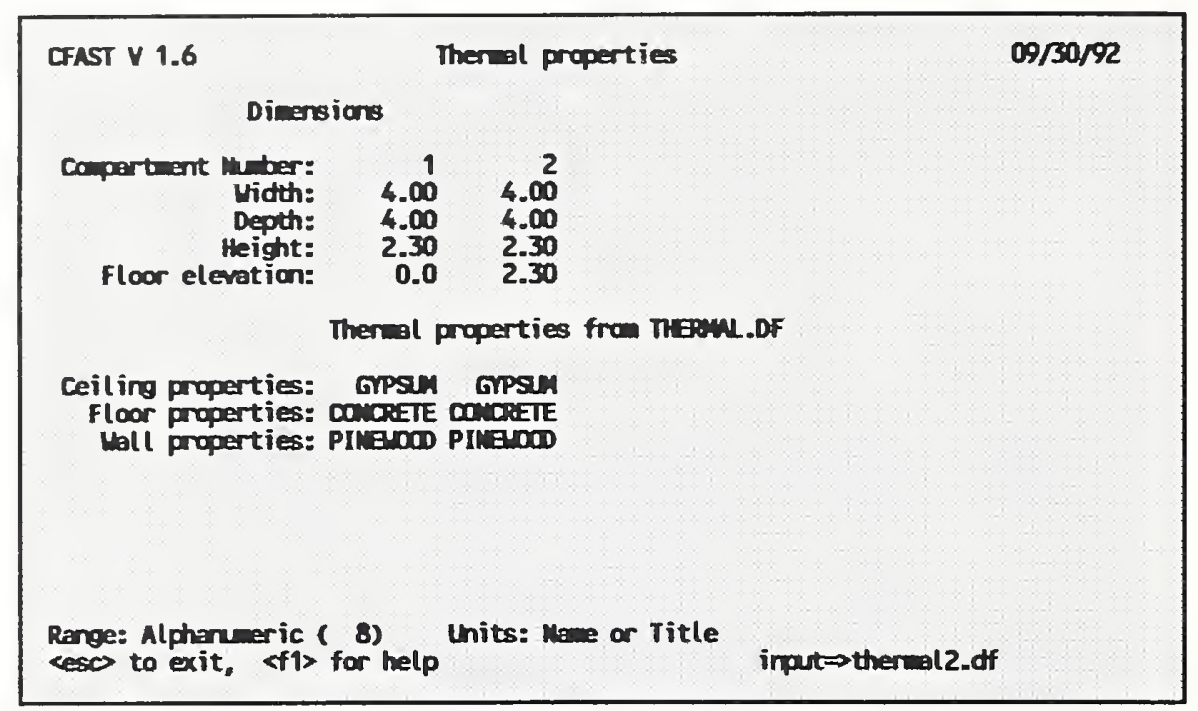

An alternate CFAST Thermal Database can be specified by pressing the FILE key (f3) from the Thermal Properties screen. Enter the alternate database file name and press Enter, or press Esc to leave the name unchanged. Materials selected previously which are not found in the new database are set to NONE and redisplayed. The new database file name becomes the Thermal Database for this input file only. If this file name differs from the database specified in the configuration file (see CF_Set), the THRMF key word is added to the input file when it is saved. It is important to note that once an alternate database has been specified, this database must be available when the model is run with this data input file.

\subsection{Fire Specification Screen}

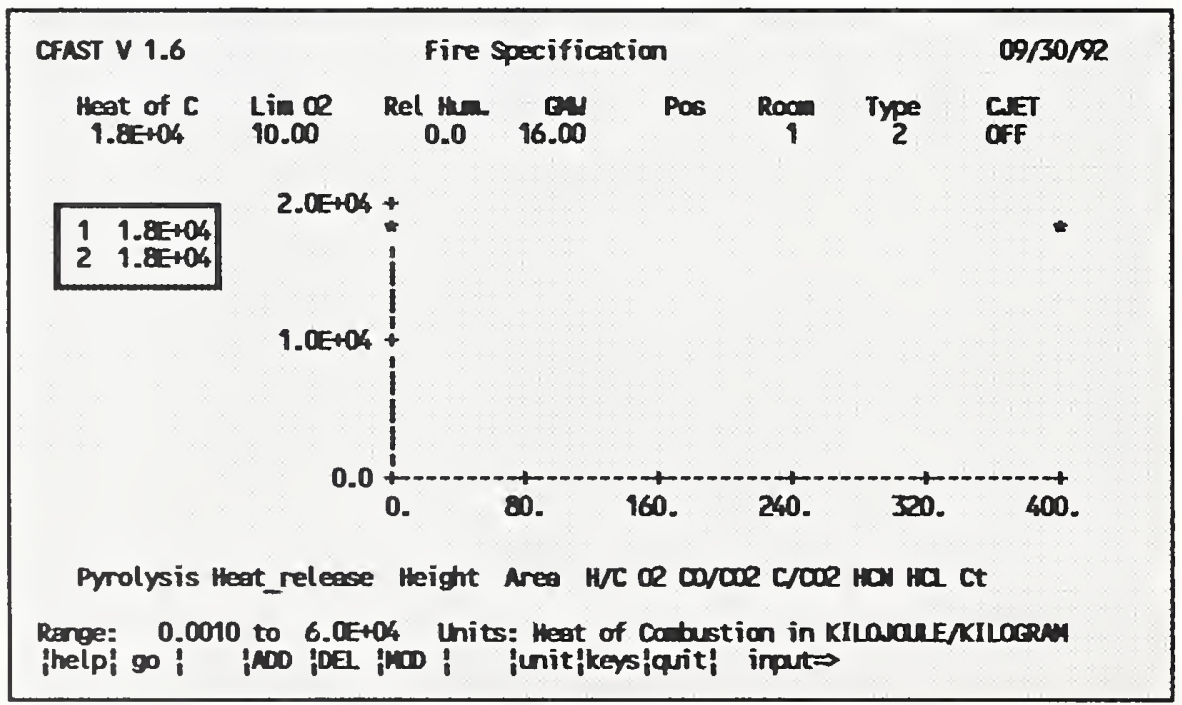


All data pertaining to the combustion properties of the main fire are entered on this screen. The heat of combustion, mass loss rate, and species yields are entered, along with selection of the fire compartment and fire type as described in the data file format section. The number of possible entries for each time dependent variable is determined by the number of specified points on the fire timeline below. Note that fire chemistry is only allowed for constrained (type 2) fires. The ceiling jet option can be set by moving to the ceiling jet entry and using the arrow keys to highlight the desired option. The default value for ceiling jet is OFF. Data file key words for this screen include LFBO, LFBT, CHEMI, FPOS, FMASS, FHIGH, FAREA, FQDOT, and CJET. Individual objects may be entered on the Objects screen below.

Note that a time history for the heat of combustion is only available if a time history has been entered for both the mass loss rate and the rate of heat release. Any value entered directly for the heat of combustion is a constant value throughout the simulation. If you have time dependent values available for the mass loss rate and rate of heat release, enter these values and CEdit will calculate the corresponding time history for the heat of combustion.

If the fire compartment for an existing data file is changed, the fire position is recalculated so that the relative position in the original compartment is maintained in the new compartment. If the fire compartment was not set previously, the fire is positioned in the center of the specified compartment. See Section 6.2.8 for an explanation of the coordinate system used in specifying the position of the fire. A zero (0) entry for the compartment indicates no main fire leaving only object fires specified on the Objects screen below.

A species may be added to the calculation using the ADD key (f4) or deleted from the calculation using the DELETE key (f5) after moving the highlight bar to the desired species. Each species added to the calculation is represented in the data file by a unique key word.

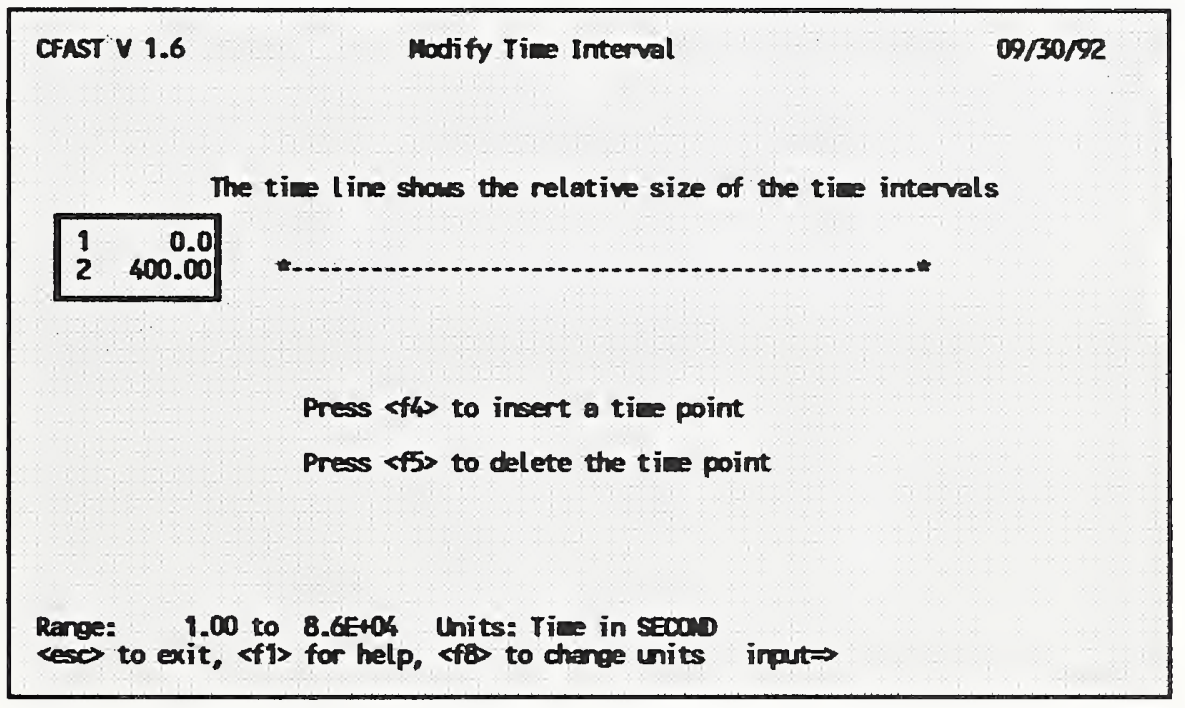

The FTIME time points in the data file may be modified by pressing the MODIFY TIME key (f6) from the Fire Specification screen. The timeline is modified by adding new points with 
the ADD (f4) key, deleting existing points using the DELETE (f5) key, or pointing to an entry and entering a new value. 'When the ADD key is pressed, a new point is created with a value that splits the time interval between the currently highlighted point and the previous one into two equal intervals, i.e., the midpoint of the interval.

\subsection{Objects Screen}

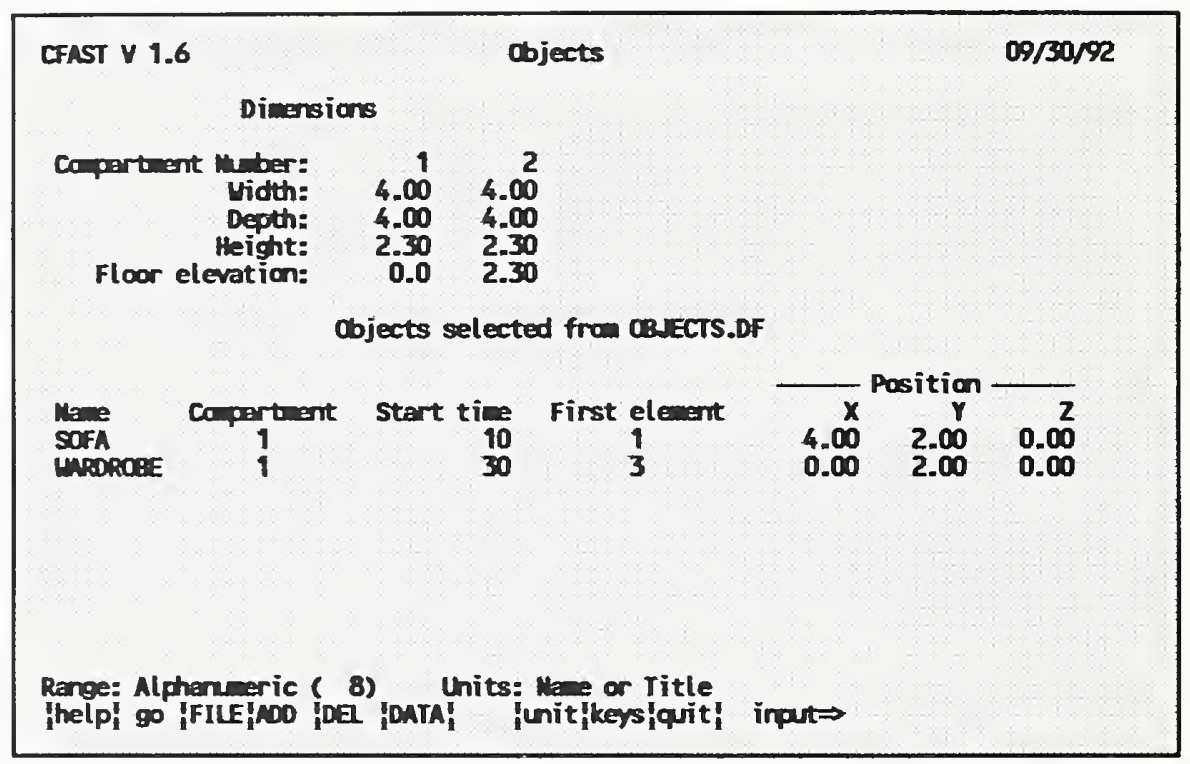

Objects to be burned in the fire scenario can be specified on the Objects screen. Any object name found in the CFAST Objects Database may be entered. Objects may be added with the ADD key (f4) or deleted with the DELETE key (f5). The DATA key (f6) displays the current objects database and provides an easy method for object selection. An alternate database can be specified by pressing the FILE key ( $\mathrm{f}$ ). 


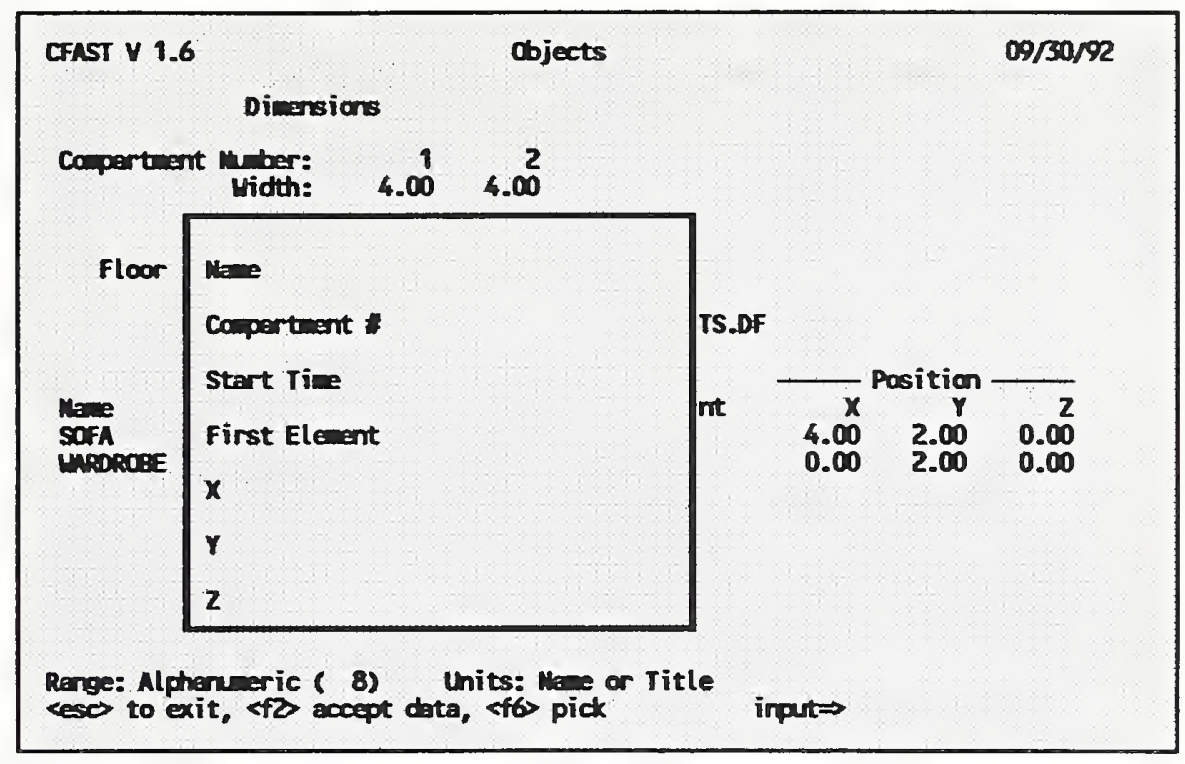

The ADD key (f4) on the Objects screen uses an overlaid window to specify a new object. Entry includes the object name, compartment, and the object position. The object position uses a similar $\mathrm{x}, \mathrm{y}, \mathrm{z}$ coordinate system to the fire position on the Fire Specification screen. The first element entry indicates where on the object ignition begins, however, it is not used by the model at this time. Entry is required for future compatibility with the CFAST model. $A$ value of 1 should be entered unless a different value is known. In addition, a time should be entered indicating the earliest time during the simulation that the CFAST model should check the fire scenario to determine if conditions have been met for the object to begin burning. If the flux to the object and the surface temperature are high enough beyond this time in the simulation, the object starts to burn. Each complete entry on this screen creates an OBJECT entry in the data file.

\begin{tabular}{|c|c|c|c|c|c|c|}
\hline \multicolumn{2}{|l|}{ CFAST V 1.6} & \multicolumn{3}{|c|}{ Cbjects Database } & \multirow[b]{2}{*}{$\begin{array}{l}\text { PANE } \\
\text { Thidoness } \\
0.20 \\
0.20 \\
0.20 \\
0.20\end{array}$} & \multirow{2}{*}{$\begin{array}{c}09 / 30 / 98 \\
\text { Eleants } \\
9 \\
9 \\
9 \\
9\end{array}$} \\
\hline $\begin{array}{l}\text { TNBAE } \\
\text { DESK } \\
\text { SOFA } \\
\text { UMDDROE }\end{array}$ & $\begin{array}{r}\text { Type } \\
2 \\
2 \\
2 \\
2\end{array}$ & $\begin{array}{c}\text { Ignition Teap } \\
273.00 \\
273.00 \\
300.00 \\
300.00\end{array}$ & $\begin{array}{l}\text { Length } \\
1.00 \\
1.00 \\
1.00 \\
1.00\end{array}$ & $\begin{array}{l}\text { Width } \\
1.00 \\
1.00 \\
1.00 \\
1.00\end{array}$ & & \\
\hline 'thelp! & : & :PIC: & funit'keys? & 1 & $\operatorname{ces} 0$ to exit & \\
\hline
\end{tabular}


The contents of the CFAST Objects Database may be examined, and an object can be selected by positioning the highlighted selection bar over the object and pressing the PICK OBJECT key (f6). This is available in both the Add Objects window and the main Objects screen. Press the Page Up and Page Down keys to quickly browse through the database. Move to the first database entry by pressing the Home key or the last entry by pressing the End key. The objects database can not be changed by CEdit.

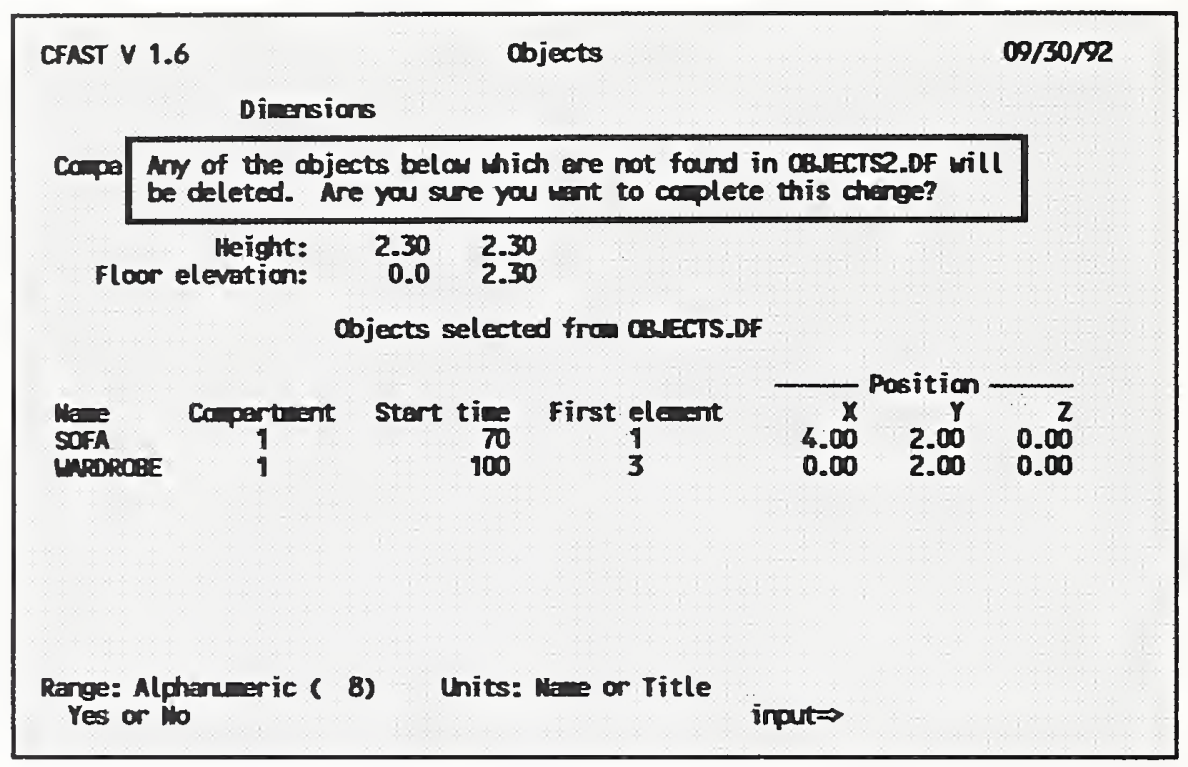

An alternate CFAST Objects Database can be specified in a manner similar to the Thermal Properties Database by pressing the FILE key (f3) from the Objects screen. Enter the new database file name and press Enter, or press Esc to leave the name unchanged. If any of the objects specified previously are not found in the new database, a warning message is displayed. Respond " $\mathrm{Y}$ " to the warning message only if it is acceptable to have undefined objects deleted. If the new database file name is accepted, it becomes the Objects Database for this input file only. The OBJFL key word is added to the data file when it is saved if this file name differs from the one specified in the configuration file (see CF_Set). It is important to note that once an alternate database has been specified, this database must be available when the model is run with this data input file. 


\subsection{Files,... Screen}

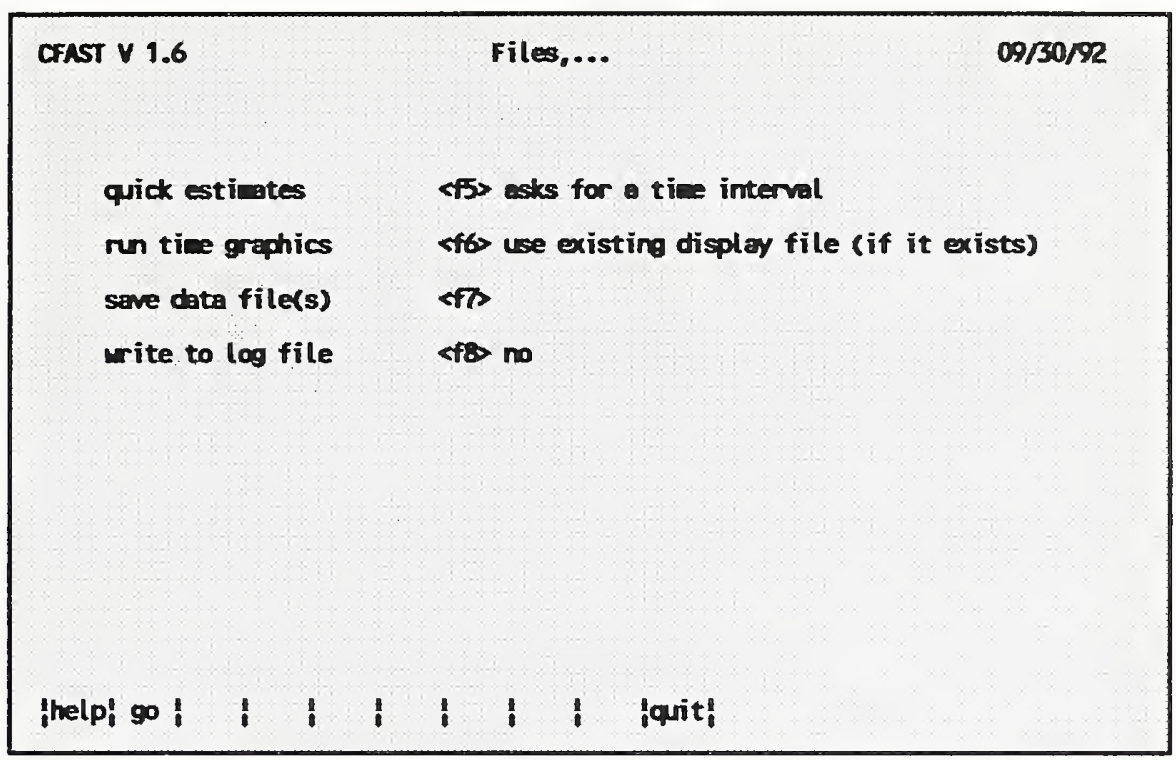

The Files screen is used to specify the file name for the input file and to access some additional options. If problems are encountered within CEdit, you can document the problem by generating a $\log$ file with the $f 8$ function key and repeating the sequence of commands which generated the problem. Append a simple graphics descriptor to the CFAST data file by pressing f6 on the Files screen. The resulting display will show selected variables in a simple X-Y plot on the screen as the CFAST model calculates the results. Pressing f6 again indicates that any graphics descriptors currently in the data file are to be rewritten to the data file when it is saved. The graphics descriptors in the current data file can not be modified using CEdit but must be modified using an ASCII text editor. 


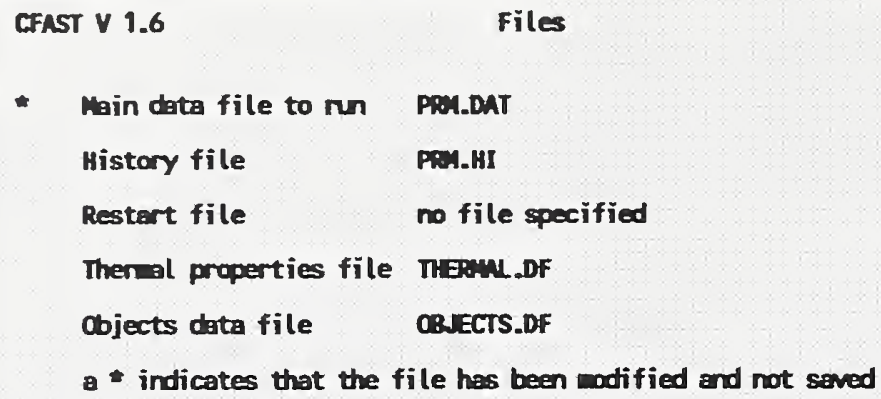

Once data for a test case has been entered or modified using CEdit, you should save the data to disk to run with the CFAST model. To save the data to a disk file, press $\mathrm{f} 7$. Type the file name and press Enter. The output from the CFAST model may be written to a disk file for further processing by programs such as CPlot or to restart CFAST. The DUMPR and RESTR data file key words are created for the corresponding entries on this screen. File names for the Thermal and Objects Databases are displayed as summary items and can not be changed on this screen. To change these database file names, you must use the FILE option on the appropriate Thermal Properties or Objects screen.

\subsection{Version and Settings Screen}

CFAST Y 1.6

Version and Settings

$09 / 30 / 92$

The current version of CFAST is 1.6

The adules wich reflect this are

CFAST, CEdit, CF_Set, Repart, Reparto, CPlot, and survival.

Permanent changes can be ade for the colors and units hich are used by these prograus. These changes are then saved in the configuration file and will be used the next time one of the

above prograns is used. The path for data files, and the nane of the thermophysical and other data files can not be changed here, but only by reruming the installation progra.

To chenge colors

To change units

$\langle f \&>$

Reset colors/unite
$<5>$

(f6) 
The display colors and units within CEdit can be altered using the version and settings screen. Unlike the $\mathbf{8} \mathbf{8}$ key on the individual screens, the unit selection here makes the changes permanent, as would be accomplished with the CF_Set utility.

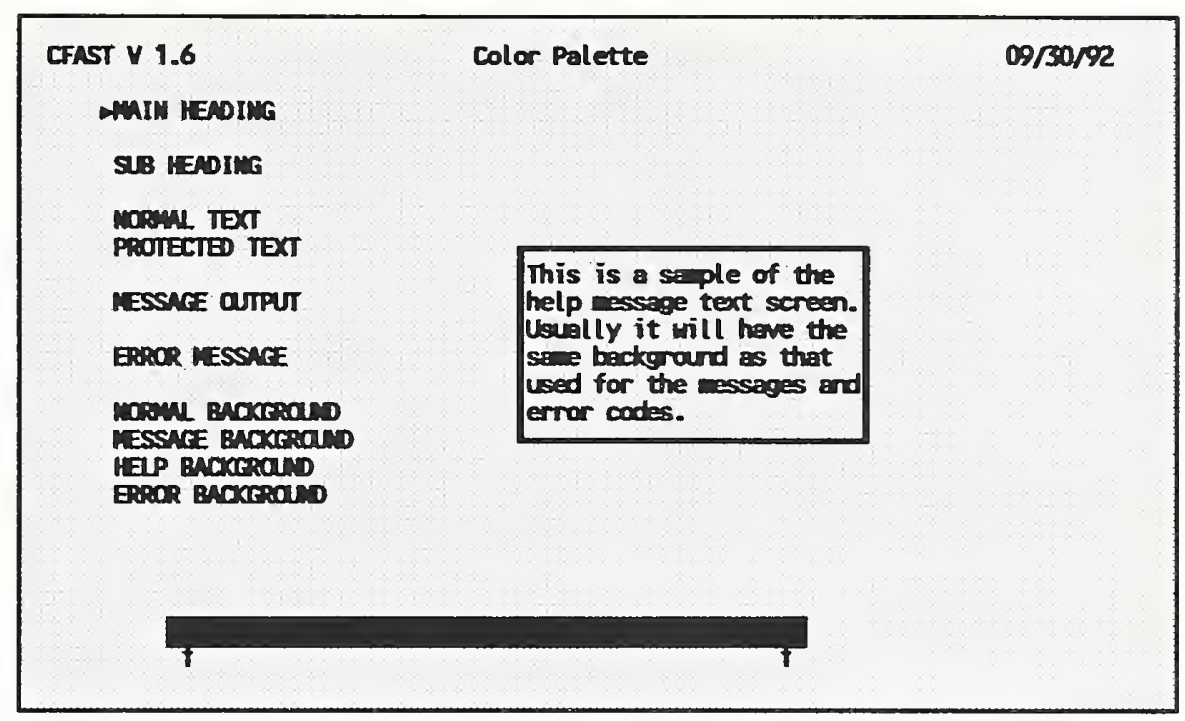

Any or all of the colors used by CEdit for screen displays may be changed. Use the arrow keys up and down to select the type of display text to be changed and the right and left arrow keys to select the color for the foreground or background. The defaults have been selected to produce acceptable displays on both monochrome and color displays.

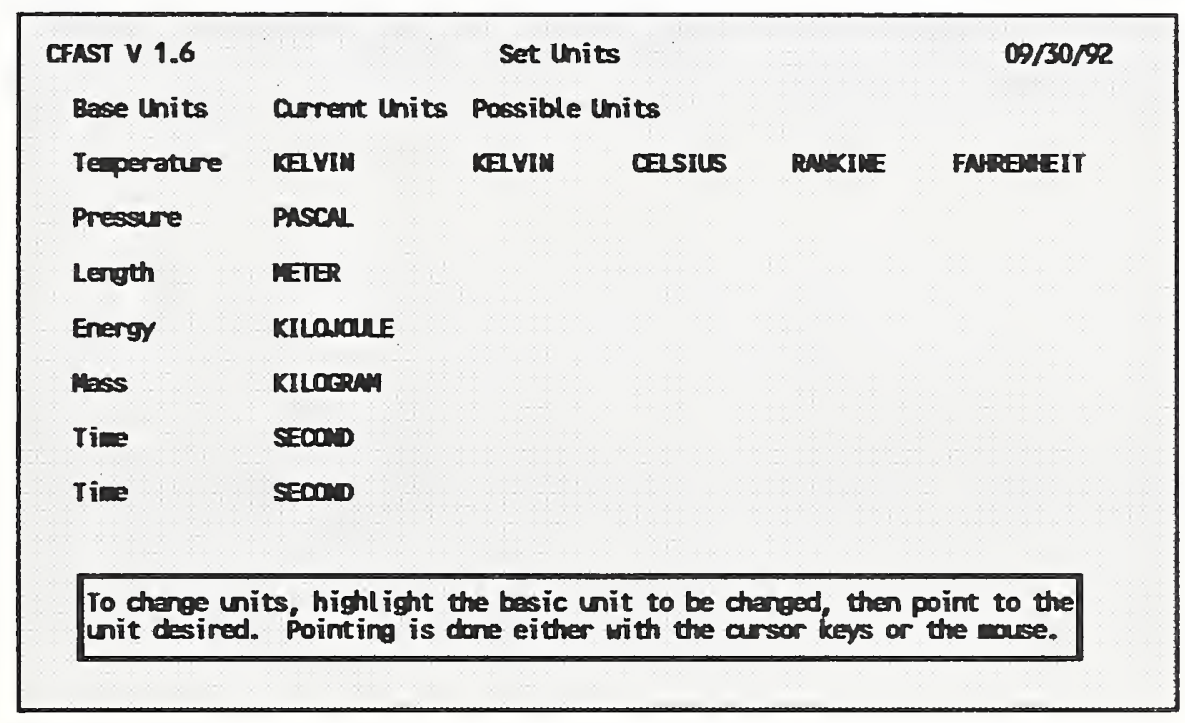

As supplied, most of the engineering units used for interactive input and display by CEdit are standard SI units. Energy defaults to $\mathrm{kJ}$ since rates of energy release are typically specified in $\mathrm{kJ} / \mathrm{s}$ (kiloWatts). Use the up and down arrow keys to select the unit to change and the left and 
right arrow keys to change the units. This screen is also available from each of the main screens in CEdit by pressing the UNIT key (f8).

\subsection{Quitting CEdit}

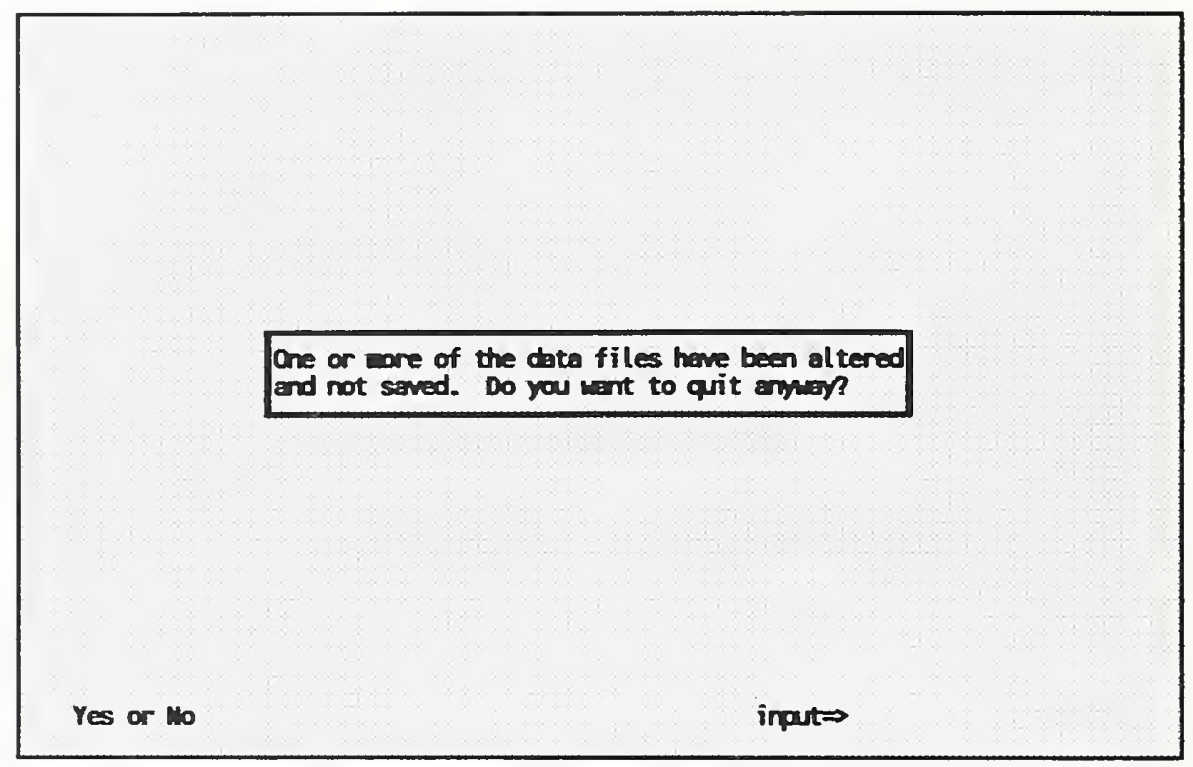

When data entry for the input file is finished, press the QUIT (f10) key from any main screen. If changes have been made without saving, a warning window is displayed. Enter $Y$ and press Enter to quit without saving current changes. Respond $\mathrm{N}$ to return to CEdit, then press the END key to access the Files screen. 


\section{CFAST}

The output of the CFAST program consists of two major parts. The first is a summary of the input data and the initial conditions. The second consists of the calculated results at the end of each print interval. The particular example comes from PRM.DAT explained in the chapters on CEdit. Due to the effect of the computer's internal precision on the solution of the equations, it is possible that the results from other computers will differ slightly from those found below. The output is labeled and most of it is self explanatory. There are, however, several abbreviations used which are explained in the following sections along with a general description of the output. The output pertaining to each of the compartments is listed across the page beginning with compartment one in the left most column and proceeding to the right to the highest number compartment.

\subsection{Using CFAST}

There are several ways to run CFAST. If CEdit has already been used to set up a file, all that is needed is to enter the command:

cfast

In this case, the last file used in CEdit is used as the datafile. In the case of PRM.DAT, this would not be desirable. PRM.DAT has both a graphics display as well as a request to print out the ASCII text history. Both of these default to the screen so that the text and graphics overwrite each other leading to a very messy and confusing output. To get around this problem, the command line should be:

cfast prm.dat prm.out

This allows the graphics display to be drawn to the screen and the ASCII text to be written to the output file PRM.OUT.

As was stated in Section 2.1, pressing the $\langle\mathrm{f} 5\rangle$ function key will show the current time and time step. Pressing escape will terminate the run. For example, if $\langle\mathrm{f} 5\rangle$ is pressed during the run, the following might display:

$$
\text { Time }=9.58550207410571 \quad \text { DT }=0.353489940990121
$$




\subsection{Summary of Input Data}

The summary of the input data is divided into seven sections. These are geometrical data, connections between compartments, mechanical ventilation, thermophysical properties, objects, the fire specification, and the initial conditions. An overview section precedes these sections and lists the version number and any title which was in the data file. To make changes to the input file, see the section on CEdit.

\subsubsection{Overview}

CFAST version 1.6.0 - created May 15, 1992 Example Case for CFAST 1.6 User's Guide

\subsubsection{Geometry}

This section lists the total number of compartments along with the width, depth, height, area, and volume for each compartment. It also gives the ceiling and floor height with respect to the reference datum.

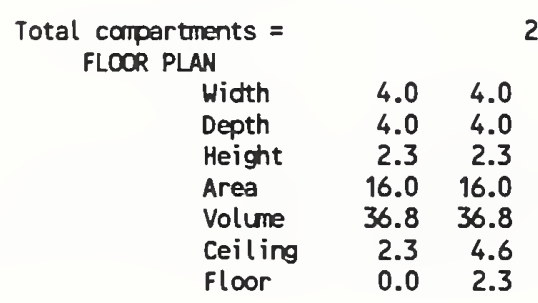

\subsubsection{Vents(doors,...)}

The next section is connections between the compartments. Each compartment is listed vertically down the page and horizontally across the page. The connections between compartments are given at the intersection of the vertical and horizontal lists. The final compartment in the horizontal list is the exterior space. The numbers in parentheses in the vertical compartment list are the number of openings for each compartment. For example, if the number of openings between any two compartments is three, there would be three parts for each compartment in the vertical list. Each part consists of the following:

1) opening width (m)

2) height of top of opening above floor $(m)$

3 ) height of bottom of opening above floor (m)

4) height of top of opening above reference datum (m)

5 ) height of bottom of opening above reference datum (m) 
NORMAL CONNECTIONS

$\begin{array}{lllll}1 \text { ( 1) Width } & 0.00 & 0.00 & 1.07 \\ & \text { Soffit } & 0.00 & 0.00 & 2.00 \\ & \text { Sill } & 0.00 & 0.00 & 0.00 \\ & \text { a.Soffit } & 0.00 & 0.00 & 2.00 \\ & \text { a.Sill } & 0.00 & 0.00 & 0.00 \\ 2(1) \text { Width } & 0.00 & 0.00 & 1.07 \\ & \text { Soffit } & 0.00 & 0.00 & 2.00 \\ & \text { Sill } & 0.00 & 0.00 & 1.00 \\ & \text { a.Soffit } & 0.00 & 0.00 & 4.30 \\ & \text { a.Sill } & 0.00 & 0.00 & 3.30\end{array}$

\subsubsection{Fans, Ducts,...}

The mechanical ventilation summary follows the data on connections. The mechanical ventilation page is broken up into three parts. The first part lists the nodes and their ducts. Like the connections, mechanical ventilation is printed out as a matrix. Down the side and along the top are the nodes that make up the system. At the intersection of two nodes, if the space is nonblank, the nodes are connected. If the values are all zero, the nodes are connected by a fan. The description of the duct connecting two nodes is the following information:

1) the length of the duct $(\mathrm{m})$

2) the area of the duct (m)

3) the absolute roughness of the duct walls $(\mathrm{mm})$

MECHANICAL VENTILATION (RESISTIVE) CONNECTIONS

\begin{tabular}{|c|c|c|c|c|c|}
\hline NOOE & & 1 & 2 & & ARTMENT \\
\hline 1 & $\begin{array}{l}\text { Length } \\
\text { Area } \\
\text { ARgh(nim) }\end{array}$ & & $\begin{array}{r}2.30 \\
0.01 \\
20.00\end{array}$ & & 1 \\
\hline 2 & $\begin{array}{l}\text { Length } \\
\text { Area } \\
\text { ARgh(nm) }\end{array}$ & $\begin{array}{r}2.30 \\
0.01 \\
20.00\end{array}$ & & $\begin{array}{l}0.00 \\
0.00 \\
0.00\end{array}$ & \\
\hline 3 & $\begin{array}{l}\text { Length } \\
\text { Area }\end{array}$ & & $\begin{array}{l}0.00 \\
0.00\end{array}$ & & 2 \\
\hline & ARgh (mm) & & 0.00 & & \\
\hline
\end{tabular}

The second part is the interior elevation of the nodes. This is the absolute elevation of the nodes above the reference height. The nodes are given in numeric order.

Interior Elevation $\quad 2.10 \quad 4.40 \quad 4.40$

The final part of the mechanical ventilation summary is the fan connections. First there is a declaration of how many fans are in the system, and then a line of numbers describing each fan. The first number is the fan number followed by the head node, the end node, the number of coefficients in the fan curve, the minimum head pressure, the maximum head pressure, and finally the fan curve coefficients.

THERE IS ONE FAN CONNECTION

$\begin{array}{llllllll}1 & 2 & 3 & 2 & 0.0 & 300.0 & 0.140 & -4.330 E-04\end{array}$




\subsubsection{Thermal Properties}

This section lists the thermophysical properties of the ceiling, floor, and wall, respectively, for each compartment. The initial information specifies the names as given in the data file along with the name of the current thermal properties database. Following this is a listing of the conductivity, specific heat, density, thickness and emissivity obtained for each of the thermophysical items. Additionally, the $\mathrm{HCl}$ constants used to calculate the $\mathrm{HCl}$ deposition for a surface are displayed. The final column indicates any applicable codes. See Appendix $C$ for a detailed explanation of these codes. If CFAST is unable to find a specified name, it will stop at this point.

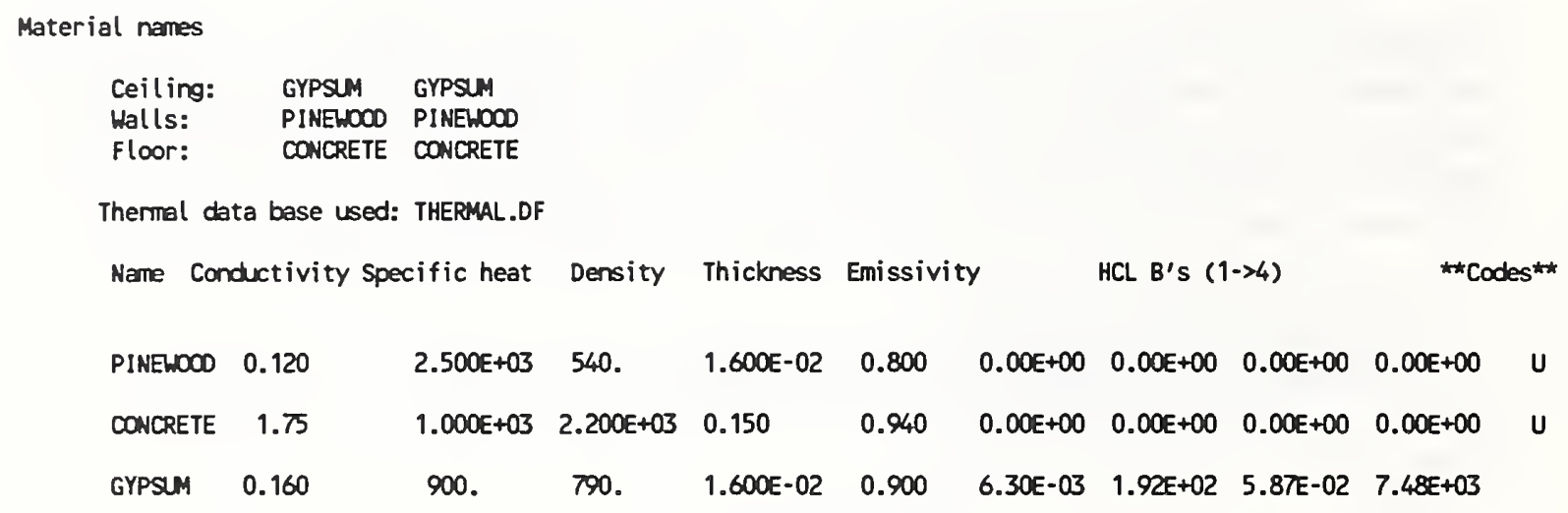

\subsection{6 "Other Objects"}

The "other objects" section summarizes information about the objects being burned in the simulation. The first line tells which data file is being used by CFAST to get the information for the objects. Then information about each object is listed. The listing of each object is in two parts. The first part lists general information about the object. This information is labelled and is as follows:

1) object name

2) reference number

3) the fire type

1 is a free burn

2 is a constrained fire

4) the number of intervals in the object specification

5) the time that the object should start burning (sec)

6) the minimum flux to the surface needed to start the object burning (w/m $\mathrm{m}^{2}$ )

7) the minimum surface temperature to start the object burning (k)

8) the total mass of the object $(\mathrm{kg})$

9) the gram molecular weight of the object

10) the volatilization temperature $(\mathrm{k})$ 
The second part of the object summary is a print out of the time dependent variables. The line labeled time val lists the time points for which the values of the time dependent variables are exactly defined. The time dependent variables are:
1) pyrolysis rate $(\mathrm{kg} / \mathrm{sec})$
2) heat release rate (w)
3) heat of combustion
4) area of the fire $\left(\mathrm{m}^{2}\right)$
5) height of the flame $(\mathrm{m})$
6) ratio of $\mathrm{CO}$ to $\mathrm{CO}_{2}$
7) ratio of soot to $\mathrm{CO}_{2}$
8) ratio of hydrogen to carbon
9) $\mathrm{HCl}$ production
10) HCN production
11) CT values

"Other abjects" datafile: OBJECTS.DF

Name: SOFA Referenced as object \# 1

Type: 2 No. Intervals: 8

Time: 10. Flux 0.0 surface ignition temp: 0.

Total Mass: 100000. GM: 16. Volatile temp: 300.

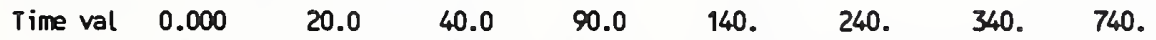

Pyrol 5.500E-03 5.500E-03 5.500E-03 5.500E-03 5.500E-03 5.500E-03 5.500E-03 5.500E-03

odot 1.000E+05 1.000E+05 1.000E+05 1.000E+05 1.000E+05 1.000E+05 1.000E+05 1.000E+05

Hcamb 1.818E+07 1.818E+07 1.818E+07 1.818E+07 1.818E+07 1.818E+07 1.818E+07 1.818E+07

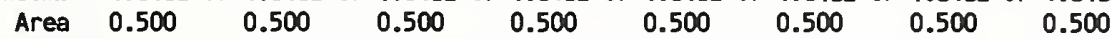

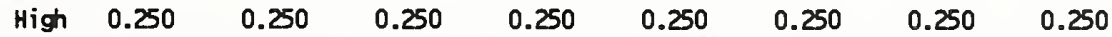

CO/CO2 2.000E-02 2.000E-02 2.000E-02 2.000E-02 2.000E-02 2.000E-02 2.000E-02 2.000E-02

$\begin{array}{rllllllll}\text { Soot/co2 } & 0.000 & 0.000 & 0.000 & 0.000 & 0.000 & 0.000 & 0.000 & 0.000 \\ \mathrm{~h} / \mathrm{c} & 0.333 & 0.333 & 0.333 & 0.333 & 0.333 & 0.333 & 0.333 & 0.333 \\ \mathrm{HCl} & 0.000 & 0.000 & 0.000 & 0.000 & 0.000 & 0.000 & 0.000 & 0.000 \\ \mathrm{HCN} & 0.000 & 0.000 & 0.000 & 0.000 & 0.000 & 0.000 & 0.000 & 0.000 \\ \mathrm{c} \star \mathrm{t} & 0.000 & 0.000 & 0.000 & 0.000 & 0.000 & 0.000 & 0.000 & 0.000\end{array}$

Name: WARDROBE Referenced as abject \# 2

Type: 2 No. Intervals: 8

Time: 30 . Flux 0.0 surface ignition terlp: 0.

Total Mass: 37. GM: 162. Volatile temp: 300.

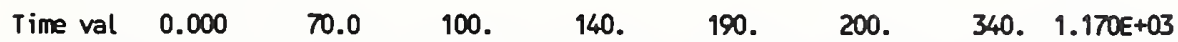
Pyrol $0.000 \quad 3.140 E-02$ 8.170E-02 0.333 1.570E-02 3.7TOE-02 1.570E-02 3.100E-03

Qdot $0.000 \quad 5.000 E+04 \quad 1.300 E+05 \quad 5.300 E+05 \quad 2.500 E+04 \quad 6.000 E+042.500 E+04 \quad 5.000 E+03$

Hcanb $1.590 E+061.592 E+061.591 E+061.592 E+061.5922+061.592 E+061.592 E+061.613 E+06$

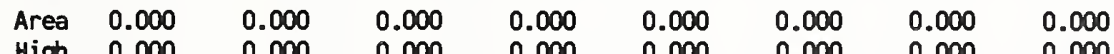

$\begin{array}{lllllllll}\mathrm{CO} / \mathrm{CO} 2 & 0.000 & 0.234 & 0.134 & 9.000 E-03 & 1.600 E-02 & 3.100 E-02 & 6.300 E-02 & 0.000\end{array}$

Soot/cO2 $\quad 0.000$

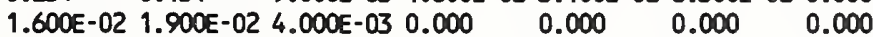

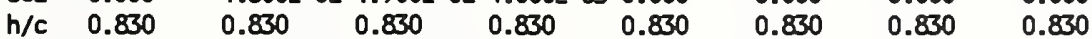

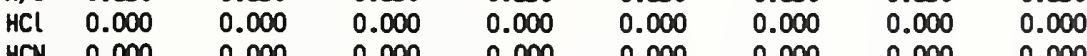

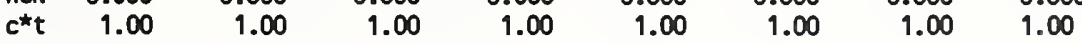




\subsubsection{Fire Specification}

This section consists of three parts. The first part lists the compartment number of the compartment of fire origin, how often output is to be printed, the number of time points for which the mass loss rate is specified, the total time over which the results are printed, the fire location within the compartment of origin, the lower oxygen limit, the initial relative humidity, the fire type, and the surfaces for which the ceiling jet algorithm is turned on.

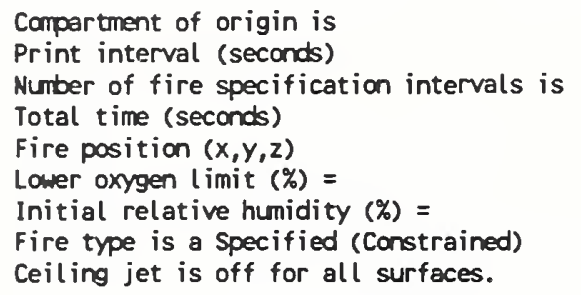

The second part lists the initial fuel temperature, the ambient air temperature, and the ambient sea level reference pressure for the interior and exterior.

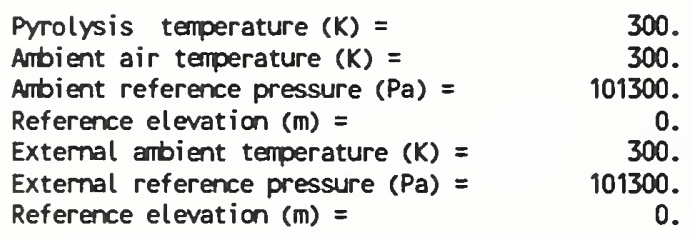

The third part lists for each specified point of the fire the mass loss rate of the burning fuel, the heat of combustion, the rate of heat release, the height of the base of the fire with respect to the floor, and the fractional production rates of the species. Also listed is the corresponding time points.

$\begin{array}{lll}\text { Fmass }= & 1.40 E-03 & 1.40 E-03 \\ \text { Hcomb }= & 1.81 E+07 & 1.81 E+07 \\ \text { Fqdot }= & 2.53 E+04 & 2.53 E+04 \\ \text { Fhigh }= & 0.00 & 1.00 E-02 \\ \mathrm{C} / \mathrm{COZ}= & 0.00 & 0.00 \\ \mathrm{CO} / \mathrm{CO}= & 1.00 \mathrm{E}-02 & 1.00 \mathrm{E}-02 \\ \mathrm{H} / \mathrm{C}= & 0.33 & 0.33 \\ \mathrm{OZ}= & 0.00 & 0.00 \\ \mathrm{HCN}= & 0.00 & 0.00 \\ \mathrm{HCL}= & 0.00 & 0.00 \\ \text { Ftime }= & 0.00 & 4.00 E+02\end{array}$




\subsubsection{Initial Conditions}

This section shows the conditions in the structure at the beginning. If this is a restart, then the conditions are those at the time step used for the restart.

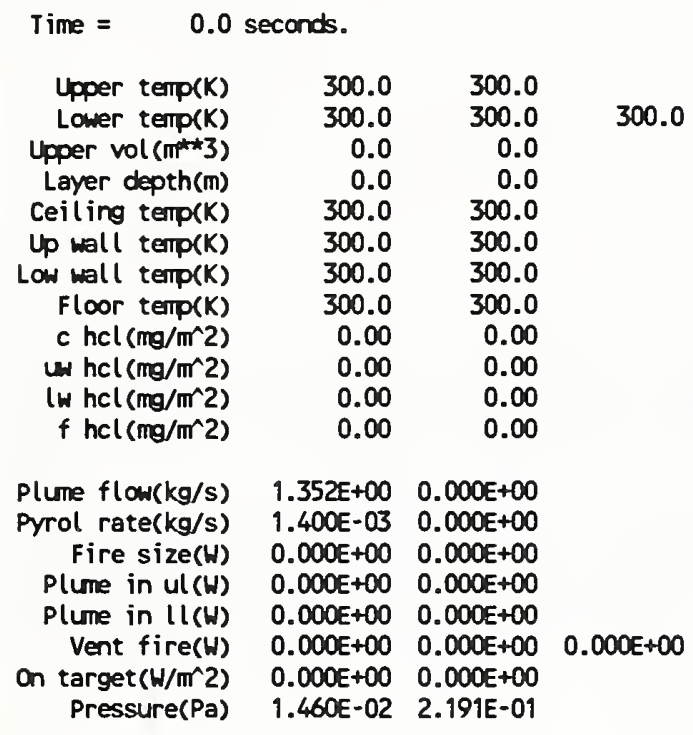

\subsection{Results of Calculations}

The final part of the output consists of the calculated results at the end of each print interval. The first line of the output is the simulation time. In this example, the results have only been listed for $200 \mathrm{~s}$ (see the data file above). Following the time are the temperatures of the upper and lower layers, the upper layer volume and thickness, and the temperatures of the ceiling, upper (UW.TEMP) (K) and lower walls, and the floor. The last four entries are the $\mathrm{HCl}$ deposition to the four surfaces: ceiling, upper wall, lower wall, and floor.

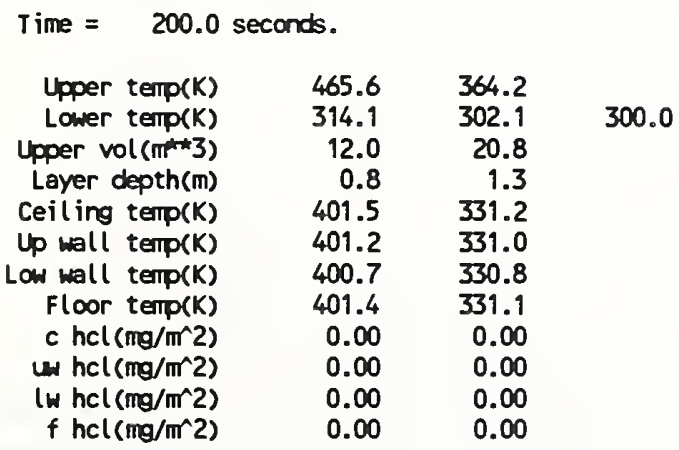


Next is the flow of combustion products and entrained air into the upper layer from the plume, the pyrolysis rate of the fuel, the enthalpy release rate of the fire, the total convective heat transfer from the surfaces surrounding the layers to the upper and lower layers respectively, the total heat release rate from all vent fires in the compartment, the radiant heat transfer per unit area from the upper layer to an object on the floor, and the difference between the current pressure and the initial pressure at the floor.

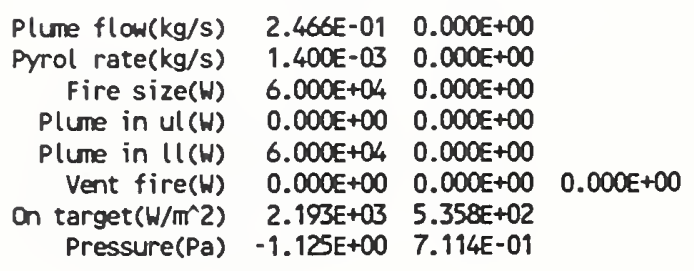

When PRM.DAT is run, the default graphics are displayed to the screen. The default graphics consist of four graphs. The upper left hand graph displays the upper layer temperature for each compartment. The upper right graph shows the $\%_{2}$ in the upper layer. The lower left hand graph gives the height above the floor of the interface between the upper and lower layer. The last graph in the lower right is of the heat release rate of the fire. The graph is updated according to the display interval in the input file, in this case every 5 seconds. When the CFAST run is over, the graph clears from the screen and returns to text mode. An example of the final display for PRM.DAT is:
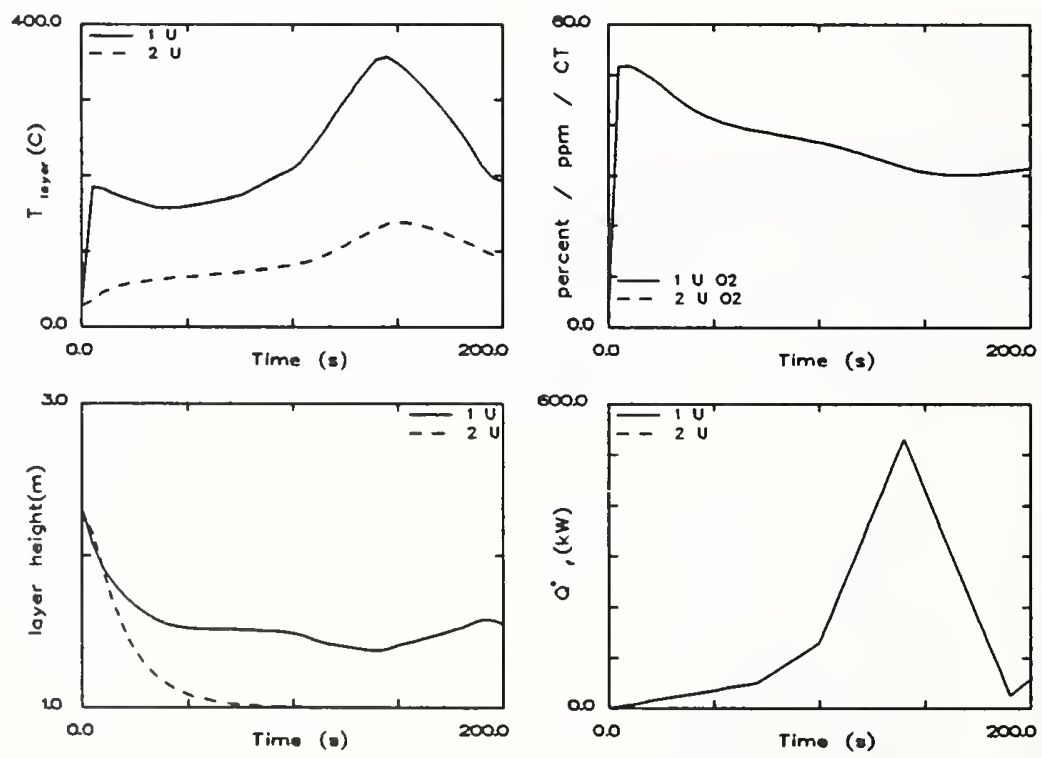


\title{
5. CPlot
}

The CFAST model provides 3-D pictorial results and graphs while the model is executing. The model predicts the environment produced by a fire in one of several compartments, and follows smoke and toxic gases from one compartment to another, separately predicting values for each of the variables in both the upper and lower layers. The results of these calculations are written to a special data file (the "history" file) at designated time steps. CPlot is intended to provide a visual interface to generate graphs and tables from the time histories saved by the model. CPlot has the capability to form a list of variables, read in their values at each time interval, list the values in tabular form, plot the values, and save the variables in a formatted file for use with other software. In addition, it has the capability to read history files created by other programs to plot along with CFAST data. It can read these files for several runs of each program and combine them into one or more plots and lists. To start CPlot enter the command:

eplot

See Appendix B for alternative CPlot command lines.

Once the CPlot command line has been entered, identifying information and a "command prompt" are displayed. Commands to direct the generation of the tables and graphs may now be entered. Commands available at the "command prompt" are:

\author{
ADD, DELETE \\ AGAIN \\ CLEAR \\ DEFAULT \\ DIRECTORY \\ END \\ HELP \\ FILE, ASCII, RAPID, TENAB \\ LIST \\ PLOT, REPLOT \\ READ \\ REVIEW \\ SAVE \\ SHIFT \\ VARIABLE
}

These commands can be broken into five major groups that describe the process used to generate tabular or graphical output with CPlot. Each command has a sub-menu from which specific choices are made or actions taken. The following is a description of each of the commands. At least three characters must be used to identify a command. 


\subsection{Entering Data Into CPlot}

The general procedure for using CPlot is to select the data from one or more files, then plot or print the data. The first step involves selecting the file. CPlot can currently read four types of data files:

- data created by the CFAST model (CFAST history files),

- data created by the TENAB model (TENAB history files)[10],

- data created in specially formatted ASCII text files from other programs including RAPID, a program developed by the Building and Fire Research Laboratory for analysis of large-scale fire tests[11], and

- ASCII text files, with data which is blank delimited.

The command for reading each of these file types is FILE, TENAB, RAPID, or ASCII, respectively. Variables for the TENAB, RAPID, and ASCII file types are specified at the same time as the command. For the CFAST history file, variables are selected with the ADD command. In addition to the file type and variable selection commands, several utility commands are available to provide support for data entry.

FILE Allows the user to specify the CFAST history file name. To select particular variables from a selected history file, use the ADD command.

TENAB

Reads a file in the TENAB format. The TENAB program produces estimates for a number of tenability criteria for persons exposed to a fire environment predicted by the CFAST model. The user must enter the "person number" and the desired criteria to be read from the file. The possibilities are:

Tenab Variable List

1. Fractional Effective Dose Due to Gases - Bukowski

2. Fractional Effective Dose Due to Gases - Purser

3. Fractional Effective Dose Due to $\mathrm{CO} 2$ - Purser

4. Temperature - Deg C

5. Fractional Effective Dose Due to Convective Heat

6. CT (G-MIN/M3)

7. Flux (KW-MIN/M2)

8. Derksen Curve 
Reads a file in the RAPID format after querying for the channels to read. In order for this to work, there must be a channel which corresponds to the default channel as selected by the DEFAULT command. Normally this is the time channel, but it can be any other desired channel.

ASCII

Reads a file in columnar ASCII format after querying for the columns to read. In order for this to work, there must be a column which corresponds to the default column as selected by the DEFAULT command. Normally this is the time, but it can be any other desired column.

If a CFAST history file has been specified using the FILE command, variables must then be selected with the ADD command. The variables currently available are:

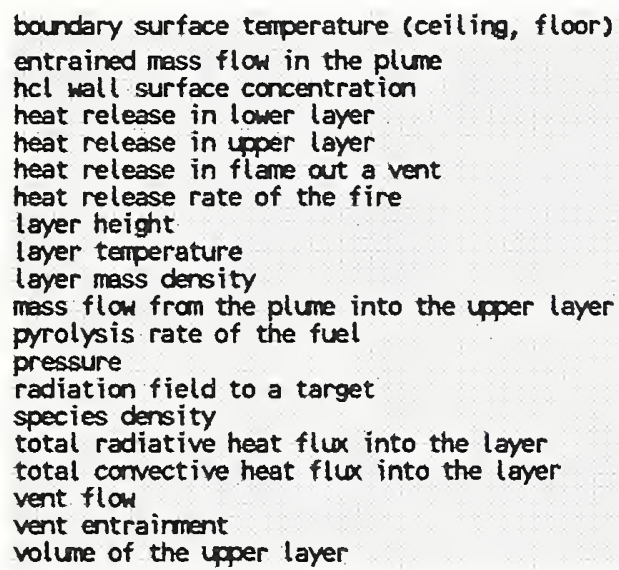

$\begin{array}{ll}\text { UALL } & \mathrm{C} \\ \text { ENTRAIN } & \mathrm{kg} / \mathrm{s} \\ \text { HCL } & \mathrm{kg} / \mathrm{m}^{2} \\ \text { LPLUNE } & \mathrm{kH} \\ \text { UPLUNE } & \mathrm{kH} \\ \text { VFIRE } & \mathrm{kH} \\ \text { HEAT } & \mathrm{kH} \\ \text { INTE } & \mathrm{m} \\ \text { TEMP } & \mathrm{C} \\ \text { HASS } & \mathrm{kg} / \mathrm{m}^{3} \\ \text { PLUNE } & \mathrm{kg} / \mathrm{s} \\ \text { PYROL } & \mathrm{kg} / \mathrm{s} \\ \text { PRES } & \mathrm{Pa} \\ \text { TARGET } & \mathrm{H} / \mathrm{m}^{2} \\ \text { SPECIES } & \\ \text { RAD } & \mathrm{H} \\ \text { CONVEC } & \mathrm{H} \\ \text { VENT } & \mathrm{kg} / \mathrm{s} \\ \text { JET } & \mathrm{kg} / \mathrm{s} \\ \text { VOLUNE } & \mathrm{m}\end{array}$

This command is used to build a list of CFAST variables to be read into the active list. This command applies only to files selected with the FILE command. ADD may be entered by itself or together with a list of variables that are to be added. If it is entered alone, the variables that are to be added to the list are requested. For example:

ADD

- INPUT VARIABLES TO BE ADDED > TEMP,PRES

or

$>$ ADD TEMP,PRES 
For each variable selected, a series of questions are displayed in order to identify exactly the type of variable desired. One question displayed for all variables is:

\section{WHICH COMPARTMENT? ->}

For layer dependent variables, the user is requested to input the layer (U for upper or $\mathrm{L}$ for lower):

\section{WHICH LAYER? ->}

The current default value is assumed for each question when the Enter key is pressed without providing a response to the prompt. See the DEFAULT command to change these default values.

If the VENTFLOW variable is chosen, the compartments of origin and destination are requested along with the vent number. If the SPECIES variable is selected, the species name $\left(\mathrm{O}_{2}, \mathrm{CO}_{2}, \ldots\right)$ is requested.

The maximum number of variables allowed in the active list at any one time is 40. If the list is full or the variable is currently in the active list, the addition is disallowed, and control returns to the CPlot command prompt.

The AGAIN, CLEAR, DELETE, READ, and REVIEW commands allow the user to view and manipulate the list of variables read with the data entry commands.

Repeats the input of a list of variables for a new CFAST history file. CPlot maintains a list of the most recently acquired CFAST variables. As an example, select a file with the FILE command, and select a set of variables. Now use the FILE command again to select a new file. Enter the AGAIN command to select the original list of variables for this new file. This function simplifies direct comparisons between runs of CFAST. It works only with files selected with the FILE command. 
When this command is entered, the current list of CFAST variables is displayed on the screen. The user is asked to select the variables to delete by entering the associated number from the list. The variables must be entered on a single line separated by commas or blanks. If the variable number entered does not correspond to one currently on the list, it is ignored. After the deletions have been completed, a new list is displayed. If the list is currently empty, an appropriate error message is displayed. One caution concerning order. The variables are deleted by the associated number in the list, not by rank ordering within the group. This is important in conjunction with use of the AGAIN command.

READ

Used to force a read of the data files. This is most useful for script files which can be processed automatically to display data. It is equivalent to pressing an enter at the "read prompt" in the interactive mode.

REVIEW

At times, the user may wish to view the current list before entering a command. This may be done with the REVIEW command. It prints out the current list along with the compartment number, species, and layer specified for each of the variables.

\subsection{Generating Tables and Graphs With CPlot}

Once the data has been selected and read, CPlot can plot or print the data values. The commands LIST and PLOT allow the user to generate a table of values or a graph for selected variables. The SHIFT command allows the user to shift the abscissa (horizontal) or ordinate (vertical) axis of a variable.

LIST

Lists the values of any of the variables in the current list to the screen. The variables desired and the time range for the list are requested. Once the list is displayed on the screen, it can be printed with the PRINT SCREEN key.

After entering the PLOT command, the current list of variables is displayed. To group variables together for a single graph use parentheses. Separate variables within the parentheses by commas or blank spaces. Variables to be plotted together on a single graph must be of the same type. As an example:

Select 1->4 graphs by graping variables

with parentheses foll laved by a return $>\left(\begin{array}{llll}1 & 2 & 3 & 4\end{array}\right)$

will plot 1 graph with 4 variables to the screen, 
while:

Select 1->4 graphs by graping variables

with parentheses followed by a return $>1,2,3,4$

or

Select 1->4 graphs by graping variables

with parentheses followed by a return $>1234$

plots 4 graphs of 1 variable each to the screen.

Normally, CPlot will scale the axes automatically. However, if the automatic formatting option has been turned off using the DEFAULT command, the user is given the opportunity to change the range of the $\mathrm{X}$ and $\mathrm{Y}$ axes along with the graph legends before the graph is drawn. The maximum and minimum values for the $\mathrm{X}$ and $\mathrm{Y}$ axes are displayed followed by a request for any changes. Press enter if no change is desired. The next axis change request is displayed:

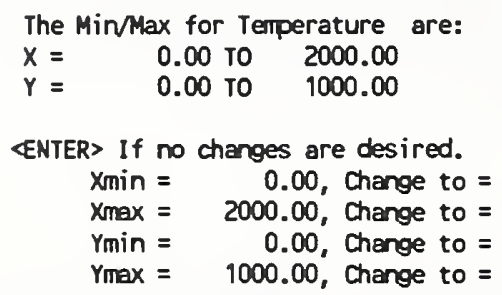

Similar prompts are made for the legends for each graph. The user is allowed to change the text for each curve label and the position. If no changes are desired, the Enter key may be pressed to accept the suggested values for the legend text and position:

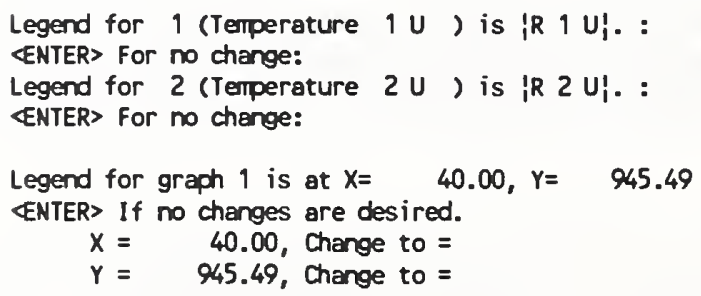

When all changes have been made, the selected graphs are plotted. 
Used to adjust the variable axes. For example, it may be used when plotting variables from different files to normalize the data to a common ignition time or initial temperature. The required input is a selection of the axis to shift, the amount of shift, and a list of channels. Please note that shifting the time axis for a single variable will shift the time axis for all variables associated with that particular file. Such an effect occurs because only one vector of values is kept to represent the timeline for each file.

\subsection{Saving Data With CPlot}

The SAVE command allows the user to create an ASCII text file in one of two formats. These files may be used for future CPlot runs or for exporting CFAST or TENAB data to other programs.

Saves the values for the variables in the current list into a file. The format used depends on the option chosen by the DEFAULT command. Columnar data can be used for spreadsheet and charting programs. Row data is used to make the data compatible with the data processing program (RAPID) designed for the reduction of experimental data in the Building and Fire Research Laboratory.

The user is prompted for the file name. A verification is made to determine if the file currently exists. If the file does exist, the user is asked if the new data should write over the old file. If the response is NO, no data is stored in the file. If the response is YES or the file does not already exist, the file is created, and the data stored.

Columnar data files are straightforward with each variable listed. The time channel is the first column.

For files in the row format, each variable in the list is saved with the following line at the beginning of each block of data:

$16,16, \mathrm{~A} 6, *-\ldots-\mathrm{COMMENT}$

The first I6 represents the number of data points for that variable, the next I6 specifies the number given to that variable on the list, and the A6 is the actual variable name. Everything after the "*" is a comment block and contains information relevant to that particular variable, such as species number, compartment number, layer, etc. The actual numerical data is written using the format $7 \mathrm{E} 11.5$. 


\subsection{Changing the Default Parameters in CPlot}

The DEFAULT command allows the user to change a number of default parameters within CPlot. These defaults include the format of the graphical output along with values assumed by CPlot when the user presses the Enter key without specifying input.

Enables the user to set default parameters for the following:

Default compartment specifies the compartment number to be used whenever the user presses an Enter in response to a question requesting a compartment number. Ventflow destination specifies the compartment number for the "to compartment" for vent flows. Default species and default layer specify the species and layer, respectively, to be used whenever the user presses an Enter in response to a request for a species or a layer. Character set is a number from 1 to 25 which specifies a different typeface to be used. Only character sets $4,7,24$, and 25 are supplied with CFAST. Graphics device specifies where the graphic output is placed. Allowable outputs are type 1 or SCREEN for output to the screen, and type 6 or HPGL for output to a file formatted for Hewlett-Packard format devices. Automatic plot formatting allows the user to customize the format of the graphical output. A response of Yes instructs CPlot to format the axes and legends automatically. A response of No allows the user to select the axis limits and legend text manually for each plot. Channel for abscissa specifies the channel number to be used for the horizontal axis for data read from RAPID format data files with the RAPID command. Factor for abscissa specifies the data column number to be used for the horizontal axis for data read in ASCII format. Type of save file specifies the format of the file written by the SAVE command. Finally, Draw curves in color $(\mathbf{Y} / \mathbf{N})$ and Draw curves with dashed lines $(\mathbf{Y} / \mathbf{N})$, allow the user to customize the lines to be drawn for each variable in a plot.

The defaults are saved in a permanent file on the disk so the next execution of CPlot will use the defaults most recently selected. 


\subsection{Getting Online Help in CPlot}

The HELP and VARIABLE commands provide some simple online help when using CPlot.

HELP

This command may be entered any time the user is prompted for an option. The purpose is to list to the screen the available commands with a brief explanation of each. After listing the commands, another option is requested.

VARIABLE Shows the list of variables which are available for the files selected with the FILE command (CFAST history files). This list is identical to the one shown in the introduction to this CPlot section.

DIRECTORY Shows a list of files in the current (or remote if set) directory. Functions in a manner similar to the "dir" ("Is" in Unix) command. Wildcards are used in the usual fashion.

\subsection{Exiting CPlot}

The END command terminates the execution of CPlot. If desired, any data which has been read into CPlot should be saved prior to entering this command. Any data not saved is lost upon exiting CPlot and must be re-entered if it is to be used again. 


\section{DESCRIPTION OF THE DATA FILE}

The CFAST model requires a description of the problem to be solved. This section provides a description for the input data used by the model. In general, the order of the data is not important. The one exception to this is the first line which specifies the version number and gives the data file a title.

Most entries in the input data file can be generated using CEdit. CEdit provides online help information in addition to context-sensitive error checking. For example, CEdit will not allow the user to select a fire compartment outside the range of compartments specified on the Geometry screen. Because of these features, CEdit is the preferred method for creating and editing most CFAST input files. However, some input file key words are not supported by CEdit. For these special cases, editing of the ASCII input file using any ASCII text editor is necessary. The following sections detail the available input file key words and group them by their availability within CEdit. Subsection titles for the CEdit key words correspond to the subsection titles in the CEdit chapter of this reference. This has been done as an aid to understanding the organization of the input file.

The number of lines in a given data set will vary depending, for example, on the number of openings or the number of species tracked. A number of parameters such as heat transfer and flow coefficients have been set within CFAST as constants. Please refer to the section on source terms in the technical reference [4] to ascertain the values for these parameters.

\subsection{General Format of an Input File Line}

Each line of the data file begins with a key word which identifies the type of data on the line. The key words currently available are:

CEILI

CHEMI

CJET

$\mathrm{CO}$

CT

CVENT

DEPTH

DUMPR

EAMB

FAREA

FHIGH

FLOOR

FMASS

FPOS

FQDOT specify name of ceiling descriptor(s)

miscellaneous parameters for kinetics

ceiling jet

$\mathrm{CO} / \mathrm{CO}_{2}$ mass ratio

fraction of fuel which is toxic

opening/closing parameter

depth of compartments

specify a file name for saving time histories

external ambient

area of the base of the fire

height of the base of the fire

specify the name of floor property descriptor(s)

pyrolysis rate

exact position of the fire using $x, y, z$ coordinates

heat release rate
(Ifmax) (lfmax)

(Ifmax) 
FTIME

HCL

$\mathrm{HCN}$

HCR

HEIGH

$\mathrm{HI} / \mathrm{F}$

HVENT

INELV

LFBO

LFBT

LFMAX

LFPOS

MVDCT

MVFAN

MVOPN

OBJECT

OBJFL

OD

$\mathrm{O} 2$

RESTR

TAMB

THRMF

TIMES

VERSN

VVENT

WALLS

WIDTH

WIND points of time on the fire timeline (DETERMINED BY MAXIMUM LINE SIZE) $\mathrm{hcl} / \mathrm{pyrolysis}$ mass ratio

hen/pyrolysis mass ratio

hydrogen/carbon mass ratio of the fuel

interior height of a compartment

absolute height of the floor of a compartment

specify vent which connect compartments horizontally

specify interior node elevations (for ventilation ducts)

compartment of fire origin

type of fire

NO LONGER SUPPORTED IN THE DATA FILE

position of the fire in the compartment

describe a piece of (circular) duct work

give the pressure - flow relationship for a fan

Specify an opening between a compartment and ventilation system

(Ifmax)

(Ifmax)

(lfmax)

( $2 \mathrm{x} \#$ of interior nodes)

additional objects to be burned

alternative object database file

$\mathrm{C} / \mathrm{CO}_{2}$ mass ratio

(Ifmax)

(lfmax)

specify a restart file

(fixed format 2)

The number in parenthesis is the maximum number of entries for that line. " $\mathrm{N}$ " represents the number of compartments being modeled. The outside (ambient) is designated by one more than the number of compartments, $\mathrm{N}+1$. Thus, a three compartment model would refer to the outside as compartment four. An entry for LFMAX is no longer supported directly. The value for LFMAX is determined by the number of entries on the FTIME line.

Each line of input consists of a label followed by one or more alphanumeric parameters associated with that input label. The label must always begin in the first space of the line and be in capital letters. Following the label, the values may start in any column, and all values must be separated by either a comma or a space. Values may contain decimal points if needed or desired. They are not required. Units are standard SI units. Most parameters have default values which can be utilized by omitting the appropriate line. These are indicated in the discussion. The maximum line length is 128 characters, so all data for each key word must fit in this number of characters. 


\subsection{Key Words Available in CEdit}

\subsubsection{Overview}

The first line in the file must be the version identification. It is a required input. The VERSN line is the line that CFAST keys on to determine whether it has a correct data file. The format is fixed, that is the data must appear in the columns specified in the text. A TIMES line is also required in order to specify the length of time over which the simulation takes place. The RESTR line is an optional line used to restart the model at a specified simulation time within an existing history file.

\section{Example:}

$\begin{array}{lllcccc}\text { VERSN } & 1 & \text { Example } & \text { Case for } & \text { CFAST } & 1.6 & \text { User's Guide } \\ \text { TIMES } & 200 & 10 & 10 & 0 & 0 & \end{array}$

Key word: RESTR

Input: $\quad$ Restart File (See Section 6.2.10), Restart Time

Restart Time

(s)

A time step is given after the name of the file and specifies at what time the restart should occur.

\section{Key word: VERSN \\ Inputs: Version Number, Title}

\begin{tabular}{|c|l|}
\hline Version Number & $\begin{array}{l}\text { The version number parameter specifies the version of CFAST for } \\
\text { which the input data file was prepared. Normally, this would be } 1 . \\
\text { It must be in columns 8-9. }\end{array}$ \\
\hline Title & $\begin{array}{l}\text { The title is optional and may consist of letters, numbers, and/or } \\
\text { symbols that start in column } 11 \text { and may be up to } 50 \text { characters. It } \\
\text { permits the user to uniquely label each run. }\end{array}$ \\
\hline
\end{tabular}




\begin{tabular}{|c|l|}
\hline $\begin{array}{c}\text { Key word: } \\
\text { Inputs: }\end{array}$ & Simes \\
\hline $\begin{array}{c}\text { Simulation Time } \\
\text { (s) }\end{array}$ & $\begin{array}{l}\text { Simulation time is the length of time over which the simulation } \\
\text { takes place. The maximum value for this input is } 86400 \mathrm{~s} \text { (1 day). } \\
\text { The simulation time parameter is required. }\end{array}$ \\
\hline $\begin{array}{c}\text { Print Interval } \\
\text { (s) }\end{array}$ & $\begin{array}{l}\text { The print interval is the time interval between each printing of the } \\
\text { output values. If omitted or less than or equal to zero, no printing } \\
\text { of the output values will occur. }\end{array}$ \\
\hline History Interval & $\begin{array}{l}\text { The history interval is the time interval between each writing of the } \\
\text { output to the history file. The history file stores all of the output } \\
\text { of the model at the specified interval in a format which can be } \\
\text { efficiently retrieved for use by other programs. Section 6.2.10 } \\
\text { provides details of the history file. A zero must be used if no } \\
\text { history file is to be used. }\end{array}$ \\
\hline Display Interval & $\begin{array}{l}\text { The display interval is the time interval between each graphical } \\
\text { display of the output as specified in the graphics specification, } \\
\text { section 6.3.2. If omitted, no graphical display will occur. There } \\
\text { is a maximum of 200 intervals allowed. If the choice for this } \\
\text { parameter would yield more than 200 writes, the graphs are } \\
\text { truncated to the first 200 points. }\end{array}$ \\
\hline Copy Count & $\begin{array}{l}\text { Copy count is the number of copies of each graphical display to be } \\
\text { made on the selected hard copy device as specified in the graphics } \\
\text { specification, section 6.3.2. If omitted, a value of zero (no copies) } \\
\text { is assumed. }\end{array}$ \\
\hline
\end{tabular}

\subsubsection{Ambient Conditions}

The ambient conditions section of the input data allows the user to specify the temperature, pressure, and station elevation of the ambient atmosphere, as well as the absolute wind pressure to which the structure is subjected. There is an ambient for the interior and for the exterior of the structure. The key word for the interior of the structure is TAMB and for the exterior of the structure is EAMB. The form is the same for both. The key word for the wind information is WIND. The wind modification is applied only to the vents which lead to the exterior. Pressure interior to a structure is calculated simply as a lapse rate based on the NOAA tables [12]. For the exterior, the nominal pressure is modified by:

$$
\delta(p)=C_{w} \rho V^{2} \quad \text { where } \quad V=V_{w}\left(\frac{H_{i}}{H_{w}}\right)^{p_{w}}
$$


This modification is applied to the vents which lead to the exterior ambient. The pressure change calculated above is modified by the wind coefficient for each vent. This coefficient, which can vary from -1.0 to +1.0 , nominally from -0.8 to +0.8 , determines whether the vent is facing away from or into the wind. The pressure change is multiplied by the vent wind coefficient and added to the external ambient for each vent which is connected to the outside.

The choice for the station elevation, temperature and pressure must be consistent. Outside of that limitation, the choice is arbitrary. It is often convenient to choose the base of a structure to be at zero height and then reference the height of the structure with respect to that height. The temperature and pressure must then be measured at that position. Another possible choice would be the pressure and temperature at sea level, with the structure elevations then given with respect to mean sea level. This is also acceptable, but somewhat more tedious in specifying the construction of a structure. Either of these choices works though because consistent data for temperature and pressure are available from the Weather Service for either case.

If the EAMB or TAMB line is not included in the input file, the default values specified below are used. The WIND line is optional.

\section{Example:}

$\begin{array}{llll}\text { TAMB } & 300 . & 101300 . & 0 . \\ \text { EAMB } & 300 . & 101300 . & 0 .\end{array}$

$$
\begin{array}{ll}
\begin{array}{l}
\text { Key words: } \\
\text { Inputs: }
\end{array} & \begin{array}{l}
\text { EAMB and TAMB } \\
\text { Ambient Temperature, Ambient Pressure, Station Elevation } \\
\text { (External and Internal, respectively) }
\end{array} \\
\hline
\end{array}
$$

\begin{tabular}{|c|l|}
\hline $\begin{array}{c}\text { Ambient } \\
\text { Temperature } \\
(\mathrm{K})\end{array}$ & $\begin{array}{l}\text { Ambient temperature is the temperature of the ambient atmosphere. } \\
\text { Default is } 300 .\end{array}$ \\
\hline $\begin{array}{c}\text { Ambient } \\
\text { Pressure } \\
(\mathrm{Pa})\end{array}$ & $\begin{array}{l}\text { The ambient pressure is the pressure of the ambient atmosphere. } \\
\text { Default is } 101300 .\end{array}$ \\
\hline $\begin{array}{c}\text { Station } \\
\text { Elevation } \\
(\mathrm{m})\end{array}$ & $\begin{array}{l}\text { The station elevation is the elevation of the point at which the } \\
\text { ambient pressure and temperature (see above) are measured. The } \\
\text { reference point for the elevation, pressure and temperature must be } \\
\text { consistent. This is the reference datum for calculating the density } \\
\text { of the atmosphere as well as the temperature and pressure inside } \\
\text { and outside of the structure as a function of height. Default is } 0 .\end{array}$ \\
\hline
\end{tabular}




\begin{tabular}{|c|l|}
\hline $\begin{array}{c}\text { Key word: } \\
\text { Inputs: }\end{array} \quad \begin{array}{l}\text { WIND } \\
\text { Wind Speed, Reference Height, Lapse Rate Coefficient }\end{array}$ \\
\hline $\begin{array}{c}\text { Wind Speed } \\
(\mathrm{m} / \mathrm{s})\end{array}$ & Wind speed at the reference elevation. The default is 0. \\
\hline $\begin{array}{c}\text { Reference } \\
\text { Height } \\
(\mathrm{m})\end{array}$ & $\begin{array}{l}\text { Height at which the reference wind speed is measured. The default } \\
\text { is } 10 \mathrm{~m} .\end{array}$ \\
\hline $\begin{array}{c}\text { Lapse Rate } \\
\text { Coefficient }\end{array}$ & $\begin{array}{l}\text { The power law used to calculate the wind speed as a function of } \\
\text { height. The default is } 0.16 .\end{array}$ \\
\hline
\end{tabular}

\subsubsection{Geometry}

This section allows the user to portray the geometry of the structure being modeled. The size and location of every compartment in the structure MUST be described. The maximum number of compartments is 15 compartments (plus the outdoors). The structure of the data is such that the compartments are described as entities, and then connected in appropriate ways. It is thus possible to have a set of compartments which can be configured in a variety of ways. In order to specify the geometry of a structure, it is necessary to give the physical characteristics. Thus the lines labelled HI/F, WIDTH, DEPTH and HEIGH are all required. Each of these lines requires " $\mathrm{N}$ " data entries, that is one for each compartment.

Example:

$\begin{array}{lll}\text { WIDTH } & 4.00 & 4.00 \\ \text { DEPTH } & 4.00 & 4.00 \\ \text { HEIGH } & 2.30 & 2.30 \\ \text { HI/F } & 0.00 & 2.30\end{array}$

Key word: WIDTH

Input: Compartment Width

Compartment Width

(m)
Compartment width specifies the width of the compartment. The number of values on the line must equal the number of compartments in the simulation. 


\section{Key word: DEPTH \\ Input: $\quad$ Compartment Depth}

Compartment Depth

(m)
Compartment depth specifies the depth of the compartment. The number of values on the line must equal the number of compartments in the simulation.

\section{Key word: HEIGH \\ Input: Compartment Height}

Compartment Height

(m)
Compartment Height specifies the height of the compartment. The number of values on the line must equal the number of compartments in the simulation.

\section{Key word: $\quad \mathrm{HI} / \mathrm{F}$ \\ Input: Floor Height}

Floor Height

(m)
The floor height is the height of the floor of each compartment with respect to station elevation specified by the TAMB parameter. The reference point must be the same for all elevations in the input data. The number of values on the line must equal the number of compartments in the simulation. 


\subsubsection{Vents(doors,...)}

The Vents(doors,...) section of the input data file is required to specify horizontal flow connections between compartments in the structure. These may include doors between compartments or windows in the compartments (between compartments or to the outdoors). These specifications do not correspond to physically connecting the walls between specified compartments. Lack of an opening prevents flow. Openings to the outside are included as openings to a compartment with a number one greater than the number of compartments described in the Geometry section. The key word is HVENT. If the HVENT line is entered, the first six entries on the line are required. There is an optional seventh parameter to specify a wind coefficient. The soffit and sill specifications are with respect to the first compartment specified and is not symmetric. Reversing the order of the compartment designations does make a difference.

Horizontal flow vents may be opened or closed during the fire with the use of the CVENT key word. The initial format of CVENT is similar to HVENT specifying the connecting compartments and vent number. Each CVENT line in the input file details the open/close time dependent characteristics for one horizontal flow vent by specifying a fractional value for each LFMAX time entry. The default is 1.0 which is a fully open vent. A value of 0.5 would specify a vent which was halfway open.

\section{Example:}

$\begin{array}{llllllll}\text { HVENT } & 1 & 3 & 1 & 1.07 & 2.00 & 0.00 & 0.00 \\ \text { HVENT } & 2 & 3 & 1 & 1.07 & 2.00 & 1.00 & 0.00 \\ \text { CVENT } & 1 & 3 & 1 & 1.00 & 1.00 & & \\ \text { CVENT } & 2 & 3 & 1 & 1.00 & 1.00 & & \end{array}$

\begin{tabular}{|c|l|}
\hline $\begin{array}{c}\text { Key word: } \\
\text { Inputs: }\end{array} \quad \begin{array}{l}\text { CVENT } \\
\text { First Compartment, Second Compartment, Vent Number, Width }\end{array}$ \\
\hline First Compartment & The first compartment. \\
\hline Second Compartment & $\begin{array}{l}\text { The second compartment is the compartment number to which the } \\
\text { first compartment is connected. }\end{array}$ \\
\hline Vent Number & $\begin{array}{l}\text { This number specifies which vent is being described. It can range } \\
\text { from one to four. }\end{array}$ \\
\hline Width & $\begin{array}{l}\text { Fraction that the vent is open. This applies to the width only. The } \\
\text { sill and soffit are not changed. The number of values on the line } \\
\text { must equal the number of points on the fire timeline. }\end{array}$ \\
\hline
\end{tabular}




\begin{tabular}{|c|c|}
\hline $\begin{array}{l}\text { HVENT } \\
\text { First Com } \\
\text { Wind }\end{array}$ & tment, Second Compartment, Vent Number, Width, Soffit, Sill, \\
\hline First Compartment & The first compartment is simply the first connection. \\
\hline Second Compartment & $\begin{array}{l}\text { The second compartment is the compartment number to which the } \\
\text { first compartment is connected. } \\
\text { The order has one significance. The height of the sill and soffit } \\
\text { are with respect to the first compartment specified. }\end{array}$ \\
\hline Vent Number & $\begin{array}{l}\text { There can be as many as four vents between any two } \\
\text { compartments. This number specifies which vent is being } \\
\text { described. It can range from one to four. }\end{array}$ \\
\hline $\begin{array}{l}\text { Width } \\
(\mathrm{m})\end{array}$ & The width of the opening. \\
\hline $\begin{array}{c}\text { Soffit } \\
\text { (m) }\end{array}$ & $\begin{array}{l}\text { Position of the top of the opening above the floor of the } \\
\text { compartment number specified as the first compartment. }\end{array}$ \\
\hline $\begin{array}{l}\text { Sill } \\
(\mathrm{m})\end{array}$ & $\begin{array}{l}\text { Sill height is the height of the bottom of the opening above the } \\
\text { floor of the compartment number specified as the first } \\
\text { compartment. }\end{array}$ \\
\hline Wind & $\begin{array}{l}\text { The wind coefficient is the cosine of the angle between the wind } \\
\text { vector and the vent opening. This applies only to vents which } \\
\text { connect to the outside ambient (specified with EAMB). The range } \\
\text { of values is }-1.0 \text { to }+1.0 \text {. If omitted, the value defaults to zero. }\end{array}$ \\
\hline
\end{tabular}




\subsubsection{Vents(ceiling,...)}

The Vents(ceiling,...) section of the input data file describes any vertical flow openings, such as scuddles, between compartments in the structure (or between a compartment and the outdoors). Openings to the outside are included as openings to a compartment with a number one greater than the number of compartments described in the Geometry section. Each VVENT line in the input file describes one vertical vent. There are four parameters, the connected compartments, the shape of the opening, and the effective area of the vent. At the present time, there is not an equivalent CVENT mechanism for opening or closing the vertical vents.

\section{Example:}

VVENT $\quad 2 \quad 1 \quad 1.00 \quad 1$

\begin{tabular}{|c|l|}
\hline $\begin{array}{c}\text { Key word: } \\
\text { Inputs: }\end{array} \quad \begin{array}{l}\text { VVENT } \\
\text { First Compartment, Second Compartment, Area, Shape }\end{array}$ \\
\hline First Compartment & The first compartment is simply the first connection. \\
\hline Second Compartment & $\begin{array}{l}\text { The second compartment is the compartment number to which the } \\
\text { first compartment is connected. }\end{array}$ \\
\hline $\begin{array}{c}\text { Area } \\
\left(\mathrm{m}^{2}\right)\end{array}$ & $\begin{array}{l}\text { This is the effective area of the opening. For a hole, it would be } \\
\text { the actual opening. For a diffuser, the effective area is somewhat } \\
\text { less than the geometrical size of the opening. }\end{array}$ \\
\hline Shape & 1 for circle or 2 for square. \\
\hline
\end{tabular}




\subsubsection{Fans, Ducts,...}

These key words are used to describe a mechanical ventilation system. The MVOPN line is used to connect a compartment to a node in the mechanical ventilation system. The elevation for each of these exterior nodes is specified as a relative height to the compartment floor on the MVOPN line. The MVDCT key word is used to specify a piece of the mechanical ventilation duct work. CAUTION: Nodes specified by each MVDCT entry must connect with other nodes, fans, or compartments. Do not specify ducts which are isolated from the rest of the system. Specify interior elevations of the mechanical ventilation nodes using the INELV line. All node elevations can be specified, but elevations for the exterior nodes, that is those connected to a compartment, are ignored. These heights are determined by entries on the MVOPN line. The heights for interior nodes are absolute heights above the reference datum specified by TAMB. The heights are specified in pairs with the node number followed by the height.

A fan is defined using the MVFAN line to indicate node numbers and to specify the fan curve with power law coefficients. There must be at least one and a maximum of five coefficients specified for each MVFAN entry. The fan coefficients are simply the coefficients of an interpolating polynomial for the flow speed as a function of the pressure across the fan housing. In this example, the coefficients:

$$
\begin{array}{lll}
B(1)=0.140 E+00 & b(1) \\
B(2)=-0.433 E-03 & b(2) \times p
\end{array}
$$

were calculated from entries made in CEdit:

PRESSURE FLOW

$\begin{array}{lrl}\text { Minimum } & 0.00 & 0.1400 \\ \text { Maximum } & 300.00 & 0.0101\end{array}$

\begin{tabular}{|c|c|c|c|c|c|c|c|c|}
\hline MVOPN & 1 & $1 \mathrm{~V}$ & 2.10 & $0.1-1-1$ & & & & \\
\hline MVOPN & 2 & v & 2.10 & 0.1 & & & & \\
\hline MVDCT & 1 & 2 & 2.30 & 0.10 & .00200 & 0.001 .0000 & 0.00 & 1.0000 \\
\hline MVFAN & 2 & 3 & 0.00 & 300.00 & 0.140 & $+00-0.433 E-03$ & & \\
\hline INELV & 1 & 2.10 & 2 & 4.40 & 3 & 40 & & \\
\hline
\end{tabular}

Example: 


\begin{tabular}{|c|l|}
\hline $\begin{array}{l}\text { Key word: } \\
\text { Inputs: }\end{array} \quad \begin{array}{l}\text { INELV } \\
\text { Node Number, Height }\end{array}$ \\
\hline Node Number & Number of an interior node. \\
\hline $\begin{array}{c}\text { Height } \\
(\mathrm{m})\end{array}$ & $\begin{array}{l}\text { Height of the node with respect to the height of the reference } \\
\text { datum, specified by TAMB or EAMB. }\end{array}$ \\
\hline
\end{tabular}

\section{Key word: MVDCT \\ Inputs: $\quad$ First Node Number, Second Node Number, Length, Diameter, Absolute Roughness, First Flow Coefficient, First Area, Second Flow Coefficient, Second Area}

\begin{tabular}{|c|l|}
\hline $\begin{array}{c}\text { First Node } \\
\text { Number }\end{array}$ & $\begin{array}{l}\text { First node number. This is a node in the mechanical ventilation } \\
\text { scheme, not a compartment number (see MVOPN). }\end{array}$ \\
\hline $\begin{array}{c}\text { Second Node } \\
\text { Number }\end{array}$ & Second node number. \\
\hline $\begin{array}{c}\text { Length } \\
(\mathrm{m})\end{array}$ & Length of the duct. \\
\hline $\begin{array}{c}\text { Diameter } \\
(\mathrm{m})\end{array}$ & $\begin{array}{l}\text { All duct work is assumed to be circular. Other shapes must be } \\
\text { approximated by changing the flow coefficient. This is done } \\
\text { implicitly by network models of mechanical ventilation and forced } \\
\text { flow, but must be done explicitly here. }\end{array}$ \\
\hline $\begin{array}{c}\text { Absolute } \\
\text { Roughness } \\
(\mathrm{m})\end{array}$ & Roughness of the duct. \\
\hline $\begin{array}{c}\text { First Flow } \\
\text { Coefficient }\end{array}$ & $\begin{array}{l}\text { Flow coefficient to allow for an expansion or contraction at the end } \\
\text { of the duct which is connected to node number one. To use a } \\
\text { straight through connection (no expansion or contraction) set to } \\
\text { zero. }\end{array}$ \\
\hline $\begin{array}{c}\text { First Area } \\
\left(\mathrm{m}^{2}\right)\end{array}$ & Area of the expanded joint. \\
\hline $\begin{array}{c}\text { Second Flow } \\
\text { Coefficient }\end{array}$ & Coefficient for second node. \\
\hline $\begin{array}{c}\text { Second Area } \\
\left(\mathrm{m}^{2}\right)\end{array}$ & Area at the second node. \\
\hline
\end{tabular}




\begin{tabular}{|c|l|}
\hline $\begin{array}{c}\text { Key word: } \\
\text { Inputs: }\end{array} \quad \begin{array}{l}\text { MVFAN } \\
\text { First Node, }\end{array}$ & Second Node, Minimum Pressure, Maximum Pressure, Coefficients \\
\hline First Node & $\begin{array}{l}\text { First node in the mechanical ventilation system to which the fan is } \\
\text { connected. }\end{array}$ \\
\hline Second Node & Second node to which the fan is connected. \\
\hline $\begin{array}{c}\text { Minimum } \\
\text { Pressure } \\
(\mathrm{Pa})\end{array}$ & $\begin{array}{l}\text { Lowest pressure of the fan curve. Below this value, the flow is } \\
\text { assumed to be constant. }\end{array}$ \\
\hline $\begin{array}{c}\text { Maximum } \\
\text { Pressure } \\
(\mathrm{Pa})\end{array}$ & $\begin{array}{l}\text { Highest pressure at which the fan will operate. Above this point, } \\
\text { the flow is assumed to stop. }\end{array}$ \\
\hline \begin{tabular}{c} 
Coefficients \\
\hline
\end{tabular} & $\begin{array}{l}\text { At least one, and a maximum of five coefficients, to specify the } \\
\text { flow as a function of pressure. }\end{array}$ \\
\hline
\end{tabular}

\section{Key word: MVOPN}

Inputs: $\quad$ Compartment Number, Duct Work Node Number, Orientation, Height, Area

\begin{tabular}{|c|l|}
\hline $\begin{array}{c}\text { Compartment } \\
\text { Number }\end{array}$ & Specify the compartment number. \\
\hline $\begin{array}{c}\text { Duct Work } \\
\text { Node Number }\end{array}$ & $\begin{array}{l}\text { Corresponding node in the mechanical ventilation system to which } \\
\text { the compartment is to be connected. }\end{array}$ \\
\hline Orientation & V for vertical or H for horizontal. \\
\hline $\begin{array}{c}\text { Height } \\
(\mathrm{m})\end{array}$ & Height of the duct opening above the floor of the compartment. \\
\hline $\begin{array}{c}\text { Area } \\
\left(\mathrm{m}^{2}\right)\end{array}$ & Area of the opening into the compartment. \\
\hline
\end{tabular}




\subsubsection{Thermal Properties}

The thermophysical properties of the enclosing surfaces are described by specifying the thermal conductivity, specific heat, emissivity, density, and thickness of the enclosing surfaces for each compartment. Currently, thermal properties for materials are read from a thermal database file unique to CFAST. The data in the file simply gives a name (such as CONCRETE) which is a pointer to the properties in the thermal database. The thermophysical properties are specified at one condition of temperature, humidity, etc. There can be as many as three layers per boundary, but they are specified in the thermal database itself.

If the thermophysical properties of the enclosing surfaces are not included, CFAST will treat them as adiabatic (no heat transfer). If a name is used which is not in the database, CEdit will turn off the conduction calculation, and CFAST will stop with an appropriate error message.

Since most of the heat conduction is through the ceiling, and since the conduction calculation takes a significant fraction of the computation time, it is recommended that initial calculations be made using the ceiling only. Adding the walls generally has a small effect on the results, and the floor contribution is usually negligible. Clearly, there are cases where the above generalization does not hold, but it may prove to be a useful screening technique.

The default name for the thermal properties database is THERMAL.TPF. Another name can be used by selecting it during installation, or by using the key word THRMF in the CFAST data file.

Example:

$\begin{array}{lll}\text { CEILI GYPSUM } & \text { GYPSUM } \\ \text { WALLS PINEWOOD } & \text { PINEWOOD } \\ \text { FLOOR CONCRETE } & \text { CONCRETE }\end{array}$

\begin{tabular}{|l|l|}
\hline $\begin{array}{l}\text { Key word: } \\
\text { Inputs: }\end{array} \quad \begin{array}{l}\text { CEILI } \\
\text { Ceiling Materials }\end{array}$ \\
\hline \begin{tabular}{c|l} 
Ceiling \\
Materials
\end{tabular} & $\begin{array}{l}\text { The label CEILI indicates that the names of thermophysical } \\
\text { properties on this line describe the ceiling material. If this } \\
\text { parameter is present, there must be an entry for each compartment. }\end{array}$ \\
\hline
\end{tabular}

\begin{tabular}{|l|l|}
\hline $\begin{array}{l}\text { Key word: } \\
\text { Inputs: }\end{array} \quad \begin{array}{l}\text { WALLS } \\
\text { Wall Materials }\end{array}$ \\
\hline \begin{tabular}{c|l} 
Wall \\
Materials
\end{tabular} & $\begin{array}{l}\text { The label WALLS indicates that the names of thermophysical } \\
\text { properties on this line describe the wall material. If this parameter } \\
\text { is present, there must be an entry for each compartment. }\end{array}$ \\
\hline
\end{tabular}




\begin{tabular}{|c|l|}
\hline $\begin{array}{l}\text { Key word: } \\
\text { Inputs: }\end{array} \quad \begin{array}{l}\text { FLOOR } \\
\text { Floor Materials }\end{array}$ \\
\hline $\begin{array}{c}\text { Floor } \\
\text { Materials }\end{array}$ & $\begin{array}{l}\text { The label FLOOR indicates that the names of thermophysical } \\
\text { properties on this line describe the floor material. If this parameter } \\
\text { is present, there must be an entry for each compartment. }\end{array}$ \\
\hline
\end{tabular}

\section{Key word: THRMF \\ Input: Thermal Database}

Thermal Database

The name specifies a file (up to 12 characters) from which the program reads thermophysical data. If this parameter is not specified, then either the default (THERMAL.DAT) is used, or the name is read from the configuration file.

\subsubsection{Fire Specification}

The fire specifications allow the user to describe the fire source in the simulation. The location and position of the fire are specified using the LFBO and FPOS lines. Chemical properties of the fuel are specified with the CHEMI key word along with miscellaneous parameters. Turn the ceiling jet calculations on by using the CJET key word. By default, the ceiling jet is not included in a CFAST simulation.

By default, the fire is placed in the center of the compartment on the floor. To place the fire in a different location, the FPOS key word may be included in the input file. If values for any of the three variables are invalid (i.e., less than zero or greater than the compartment dimension in the appropriate direction), the location for that direction defaults to the center of the appropriate direction.

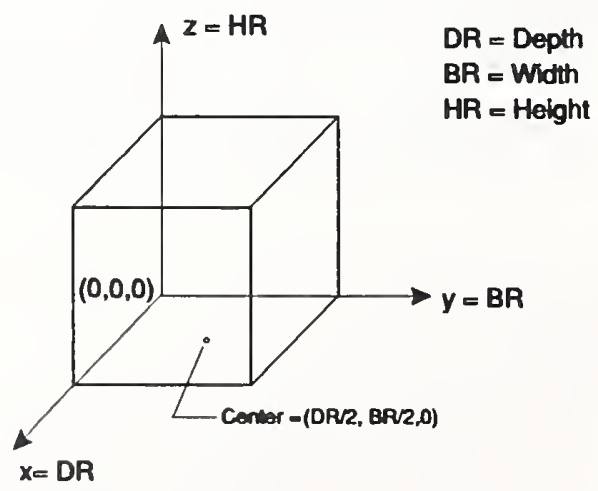


CFAST no longer supports use of the LFMAX key word in the data file. LFMAX is now determined by the number of entries on the FTIME line used to specify points of the fire timeline. The time dependent variables of the fire are described with a series of mass loss rate, rate of heat release, fuel height, and fuel area inputs. All of these specifications are optional. If entered, a total of LFMAX +1 values must be included for each time dependent input line. The defaults shown for each key word reflect the values for methane.

With the three parameters, the heat of combustion (HOC) from CHEMI, FMASS and FQDOT, the pyrolysis and heat release rate are over specified. The model uses the last two of the three to obtain the third parameter. That is, if the three were specified in the order HOC, FMASS and FQDOT, then FQDOT would be divided by FMASS to obtain the HOC for each time interval. If the order were FMASS, FQDOT and HOC, then the pyrolysis rate would be determined by dividing the heat release rate by the heat of combustion. If only two of the three are given, then those two will determine the third, and finally, if none or only one of the parameters is present, the defaults shown are used.

Species production rates are specified in a manner similar to the fire, entering the rates as a series of points with respect to time. The species which are followed by CFAST are:

$\begin{array}{ll}- & \text { Carbon Dioxide } \\ - & \text { Carbon Monoxide } \\ \text { - } & \text { Concentration-Time Product } \\ \text { - } & \text { Hydrogen Cyanide } \\ \text { - } & \text { Hydrogen Chloride } \\ -\quad \text { Nitrogen } \\ \text { - } & \text { Oxygen } \\ \text { - } & \text { Toot (Smoke Density) } \\ \text { - } & \text { Water }\end{array}$

The program performs a linear interpolation between the time points to determine the time of interest.

For a type one $(\mathrm{LFBT}=1)$ fire, only the concentration-time product of pyrolysate $(\mathrm{CT})$ can be specified. No other species are followed. For a type two (LFBT=2) fire, nitrogen (N2), oxygen (O2), carbon dioxide (CO2), carbon monoxide (CO), hydrogen cyanide (HCN), hydrogen chloride $(\mathrm{HCL})$, soot $(\mathrm{OD})$, unburned fuel and water $(\mathrm{H} 2 \mathrm{O})$ are followed. For a type two fire, $\mathrm{HCN}, \mathrm{HCL}, \mathrm{CT}, \mathrm{O} 2, \mathrm{OD}, \mathrm{CO}$ and the hydrogen to carbon ratio (HCR) can be specified. In all cases, the unit of the production rates is $\mathrm{kg} / \mathrm{kg}$. However, the meaning of the production rates is different for the several types of species. See the discussion for each species key word below for the meaning of the corresponding production rate. 
Example:

$\begin{array}{lllllll}\text { CHEMI } & 16 . & 0 . & 10.0 & 18100000 & 300.400 . & 0 . \\ \text { LFBO } & 1 & & & & \\ \text { LFBT } & 2 & & & & \\ \text { FPOS } & 2.00 & 2.00 & 0.00 & & \\ \text { FTIME } & 400 . & & & & \\ \text { FMASS } & 0.0014 & 0.0014 \\ \text { FHIGH } & 0.00 & 0.01 & & & \\ \text { FAREA } & 0.00 & 0.00 & & \\ \text { FQDOT } & 2.53 E+04 & 2.53 E+04 \\ \text { CJET } & \text { OFF } & & \\ \text { HCR } & 0.333 & 0.333 \\ \text { CO } & 0.010 & 0.010\end{array}$

\section{Key word: CHEMI \\ Inputs: $\quad$ Molar Weight, Relative Humidity, Lower Oxygen Limit, Heat of Combustion, Initial Fuel Temperature (see Section 6.3.1), Gaseous Ignition Temperature (see Section 6.3.1), Radiative Fraction (see Section 6.3.1)}

\begin{tabular}{|c|l|}
\hline Molar Weight & $\begin{array}{l}\text { Molecular weight of the fuel vapor. This is the conversion factor } \\
\text { from mass density to molecular density for "tuhc." Default is } 16 . \\
\text { It is used only for conversion to ppm, and has no effect on the } \\
\text { model itself. }\end{array}$ \\
\hline $\begin{array}{c}\text { Relative Humidity } \\
(\%)\end{array}$ & $\begin{array}{l}\text { The initial relative humidity in the system. This is converted to } \\
\text { kilograms of water per cubic meter [13]. }\end{array}$ \\
\hline $\begin{array}{c}\text { Lower Oxygen } \\
\text { Limit } \\
(\%)\end{array}$ & $\begin{array}{l}\text { The limit on the ratio of oxygen to other gases in the system below } \\
\text { which a flame will not burn. This is applicable only to type } \\
\text { (LFBT) } 2 \text { or later fires. The default is 10. }\end{array}$ \\
\hline $\begin{array}{c}\text { Heat of } \\
\text { Combustion } \\
(\mathrm{J} / \mathrm{kg})\end{array}$ & $\begin{array}{l}\text { Heat of combustion of the fuel. Default is } \\
50000000 .\end{array}$ \\
\hline
\end{tabular}




\begin{tabular}{|l|l|}
\hline $\begin{array}{l}\text { Key word: } \\
\text { Input: }\end{array}$ & $\begin{array}{l}\text { CJET } \\
\text { OFF, CEILING, WALL, or ALL }\end{array}$ \\
\hline & $\begin{array}{l}\text { To include the calculation for the ceiling, wall, or both surfaces, } \\
\text { the CJET key word is used together with one of the identifiers } \\
\text { CEILING, WALL, or ALL. For example, to turn the ceiling on, } \\
\text { use "CJET CEILING". At present, this key word effects only the } \\
\text { calculation of the convective heating boundary condition for the } \\
\text { conduction routines. If a particular surface is ON, the ceiling jet } \\
\text { algorithm is used to determine the convective heating of the } \\
\text { surface. If OFF, the bulk temperature of the upper layer } \\
\text { determines the convective heating. }\end{array}$ \\
\hline
\end{tabular}

\begin{tabular}{|c|l|}
\hline $\begin{array}{l}\text { Key word: } \\
\text { Inputs: }\end{array} \quad$ FAREA \\
\hline $\begin{array}{c}\text { Fuel Area } \\
(\mathrm{m})\end{array}$ & The area of the fire at the base of the flames. \\
\hline
\end{tabular}

\begin{tabular}{|c|c|c|}
\hline $\begin{array}{l}\text { Key word: } \\
\text { Inputs: }\end{array}$ & $\begin{array}{l}\text { FHIGH } \\
\text { Fuel Height }\end{array}$ & \\
\hline & & $\begin{array}{l}\text { The height of the base of the flames above the floor of the } \\
\text { compartment of fire origin for each point of the specified fire. }\end{array}$ \\
\hline
\end{tabular}

\section{Key word: FMASS \\ Inputs: Mass Loss Rate}

Mass Loss Rate $(\mathrm{kg} / \mathrm{s})$

The rate at which fuel is pyrolyzed at times corresponding to each point of the specified fire. 


\begin{tabular}{|c|l|}
\begin{tabular}{l} 
Key word: $\begin{array}{l}\text { Inputs: } \\
\text { Depth, Breadth, Height (relative to the left rear corner of the compartment }- \text { see } \\
\text { figure above) }\end{array}$ \\
\hline Depth
\end{tabular} & $\begin{array}{l}\text { Position of the fire as a distance from the rear wall of the } \\
\text { compartment (X direction). }\end{array}$ \\
\hline Breadth & $\begin{array}{l}\text { Position of the fire as a distance from the left wall of the } \\
\text { compartment (Y direction). }\end{array}$ \\
\hline Height & $\begin{array}{l}\text { Height of the fire above the floor (Z direction). This value is } \\
\text { simply added to the fire height at each time specified by the } \\
\text { FHIGH key word. }\end{array}$ \\
\hline
\end{tabular}

\section{Key word: FQDOT \\ Inputs: Heat Release Rate}

Heat Release

Rate

(W)

\begin{tabular}{ll} 
Key word: & FTIME \\
Inputs: & Time Points \\
\hline
\end{tabular}

Time Points

(s)

The heat release rate of the specified fire.

An entry indicates a point on the timeline where mass loss rate, fuel height and species are specified for the fire. This time is independent of the simulation time which is specified for the TIMES label. If the simulation time is longer than the total duration of the fire, the final values specified for the fire (mass loss rate, fuel height, fuel area, and species) are continued until the end of the simulation.

\begin{tabular}{|l|l|}
\hline $\begin{array}{l}\text { Key word: } \\
\text { Input: }\end{array}$ & LFBO \\
\hline & Compartment of Fire Origin \\
\hline $\begin{array}{c}\text { Compartment of Fire } \\
\text { Origin }\end{array}$ & $\begin{array}{l}\text { Compartment of fire origin is the compartment number in which } \\
\text { the fire originates. Default is 0. The outside can not be specified } \\
\text { as a compartment. An entry of 0 turns off the main fire leaving } \\
\text { only object fires specified by the OBJECT key word. }\end{array}$ \\
\hline
\end{tabular}




\section{Key word: LFBT \\ Input: Fire Type}

This is a number indicating the type of fire.

1 Unconstrained fire

Fire Type

The default is 1 . See section 3.10 for a discussion of the implications of this choice.

Key words: HCN, HCL, CT, HCR, or O2

Inputs:

Composition of the Pyrolyzed Fuel

Units are kilogram of species produced per kilogram of fuel

Production Rate

$(\mathrm{kg} / \mathrm{kg})$ pyrolyzed for $\mathrm{HCN}$ and HCL. The input for CT is the kilograms of "toxic" combustion products produced per kilogram of fuel pyrolyzed. Input for HCR is the mass ratio of hydrogen to carbon and oxygen to carbon as it becomes available from the fuel for $\mathrm{O} 2$.

Key words: $\quad O D$ and $C O$

Inputs: Yield

Yield

$(\mathrm{kg} / \mathrm{kg})$

Input the ratio of the mass of carbon to carbon dioxide produced by the oxidation of the fuel for OD. The input for $\mathrm{CO}$ is the ratio of the mass of carbon monoxide to carbon dioxide produced by the oxidation of the fuel. 


\subsubsection{Objects}

The OBJECT key word allows the specification of additional objects to be burned in the fire scenario. The object name and object compartment are required if the OBJECT key word is used. All other input items have default values if they are not specified. These defaults are: start time 0.0 , first element 1 , depth (x position) one half the depth of the compartment, breadth (y position) one half the width of the compartment, and height (z position) 0.0 . To specify any input item, all preceding items on the OBJECT line must also be specified. For example, the first element can not be set if start time is not set. Positioning of the object within a compartment is specified in the same manner as for the main fire. See figure below.

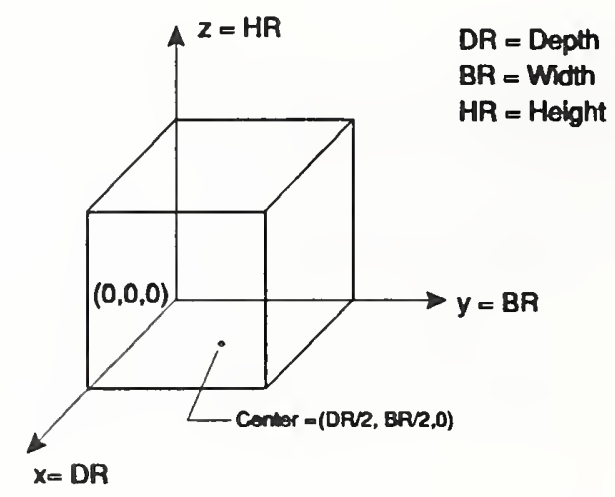

EXAMPLE:

$\begin{array}{lllllll}\text { OBJECT SOFA } & 1 & 10 & 1 & 4.00 & 2.00 & 0.00 \\ \text { OBJECT WARDROBE } & 1 & 30 & 3 & 0.00 & 2.00 & 0.00\end{array}$

Key word: OBJFL

Input: Objects Database

Objects Database

The name specifies a file (up to 17 characters) from which the program obtains object data. If this parameter is not specified, then either the default (OBJECTS.DAT) is used, or the name is read from the configuration file. 


\begin{tabular}{|c|l|}
\hline \begin{tabular}{c} 
Key word: $\begin{array}{l}\text { Inputs: } \\
\text { OBJECT } \\
\text { Object Name, Object Compartment, Start Time, First Element, Depth, Breadth, } \\
\text { Height }\end{array}$ \\
\hline Object Name
\end{tabular} $\begin{array}{l}\text { The name from the objects database for the desired object. } \\
\text { Specifying a name not found in the database causes CFAST to stop } \\
\text { with an appropriate error message. CEdit considers such an object } \\
\text { undefined and does not display the entry. }\end{array}$ \\
\hline Object Compartment & $\begin{array}{l}\text { The compartment that the object is in during the simulation. If a } \\
\text { compartment number outside the range of specified compartments } \\
\text { is used, CFAST provides an error message and stops. CEdit } \\
\text { considers such an object undefined and does not display the entry. }\end{array}$ \\
\hline Start Time & $\begin{array}{l}\text { The earliest time during the simulation when the CFAST model } \\
\text { should check the fire scenario to determine if conditions have been } \\
\text { met for the object to begin burning. If the flux to the object and } \\
\text { the surface temperature are high enough, the object starts to burn. }\end{array}$ \\
\hline First Element & $\begin{array}{l}\text { Indicates the position on the object's surface where burning starts. } \\
\text { This value is not currently used but needs to be set for future } \\
\text { compatibility with the CFAST model. If a value is not known, } \\
\text { enter a value of 1. }\end{array}$ \\
\hline Depth & $\begin{array}{l}\text { Position of the object as a distance from the rear wall of the object } \\
\text { compartment (X direction). }\end{array}$ \\
\hline Breadth & $\begin{array}{l}\text { Position of the object as a distance from the left wall of the object } \\
\text { compartment (Y direction) }\end{array}$ \\
\hline Height & \begin{tabular}{l} 
Height of the object above the floor (Z direction). \\
\hline
\end{tabular} \\
\hline
\end{tabular}




\subsubsection{Files}

There are several files which CFAST uses to communicate with its environment. They include 1) a configuration file, 2) the thermal database, 3) the objects database, 4) a history file, and 5) a restart file. The format of the thermal database and objects database are detailed in Appendices $C$ and $D$. To access an alternate database see the appropriate input file section above.

The output of the simulation may be written to a disk file for further processing by programs such as CPlot or to restart CFAST. At each interval of time as specified by the history interval in the TIMES label, the output is written to the file specified. For efficient disk storage and optimum speed, the data is stored in an internal format and cannot be read directly with a text editor.

Example:

DUMPR PRM.HI

\section{Key word: DUMPR}

Input: History File

\section{Key word: RESTR \\ Input: $\quad$ Restart File, Restart Time (see Section 6.2.1)}

The name specifies a file (up to 17 characters) from which the

Restart File

The name specifies a file (up to 17 characters) to which the program outputs for plotting are written. History file is an History File $\quad$ optional input. If omitted, the file will not be generated. Note that in order to obtain a history of the variables, this parameter must be specified, and the history interval (see Section 6.2.1) must be set to a non-zero value.

\begin{tabular}{|l|l|}
\hline Restart File & $\begin{array}{l}\text { The name specifies a file (up to } 17 \text { characters) from which the } \\
\text { program reads data to restart the model. This data must have been } \\
\text { generated (written) previously with the history parameter discussed } \\
\text { earlier. }\end{array}$ \\
\hline
\end{tabular}




\subsection{Additional Key Words Unavailable in CEdit}

\subsubsection{Fire Specification}

The LFPOS key word is provided to maintain backward compatibility with previous versions of FAST and CFAST. For exact positioning of the main fire, use the FPOS key word in section 6.2.8. The CHEMI line discussed in section 6.2 .8 corresponds to chemical kinetics entry available in CEdit. At this time, CEdit does not support entry of the initial fuel temperature, gaseous ignition temperature, or the radiative fraction. These parameters must be entered on the CHEMI line using an ASCII text editor.

Example:

CHEMI 16. 0. 10.0 18100000. 300. 400. 0. LFPOS 1

\begin{tabular}{|c|c|}
$\begin{array}{l}\text { Key word: } \\
\text { Inputs: }\end{array}$ & $\begin{array}{l}\text { CHEMI } \\
\text { Molar Weight(see Section 6.2.8), Relative Humidity(see Section 6.2.8), Lower } \\
\text { Oxygen Limit(see Section 6.2.8), Heat of Combustion(See section 6.2.8), Initial } \\
\text { Fuel Temperature, Gaseous Ignition Temperature, Radiative Fraction }\end{array}$ \\
\hline $\begin{array}{c}\text { Initial Fuel } \\
\text { Temperature } \\
(\mathrm{K})\end{array}$ & $\begin{array}{l}\text { Typically, the initial fuel temperature is the same as the ambient } \\
\text { temperature as specified in the ambient conditions section. }\end{array}$ \\
\hline $\begin{array}{c}\text { Gaseous Ignition } \\
\text { Temperature } \\
(\mathrm{K})\end{array}$ & $\begin{array}{l}\text { Minimum temperature for ignition of the fuel as it flows from a } \\
\text { compartment through a vent into another compartment. If omitted, } \\
\text { the default is arbitrarily set to the initial fuel temperature plus } \\
\text { 100K. }\end{array}$ \\
\hline Radiative Fraction & $\begin{array}{l}\text { The fraction of heat released by the fire that goes into radiation. } \\
\text { Default is 0.15. }\end{array}$ \\
\hline
\end{tabular}




\begin{tabular}{|c|c|c|c|}
\hline $\begin{array}{l}\text { Key word: } \\
\text { Input: }\end{array}$ & $\begin{array}{l}\text { LFPOS } \\
\text { Fire Position }\end{array}$ & & \\
\hline \multirow{3}{*}{\multicolumn{2}{|c|}{ Fire Position }} & \multicolumn{2}{|c|}{$\begin{array}{l}\text { The fire position indicates where in the compartment of fire origin } \\
\text { the fire originates and is one of the following values: }\end{array}$} \\
\hline & & $\begin{array}{l}1 \\
2 \\
3\end{array}$ & $\begin{array}{l}\text { Center of the compartment, } \\
\text { Corner of the compartment, or } \\
\text { Along a wall of the compartment, but not near a corner of } \\
\text { the compartment. }\end{array}$ \\
\hline & & \multicolumn{2}{|c|}{$\begin{array}{l}\text { The fire position is used to account for the entrainment rate of the } \\
\text { plume, which depends on the location of the fire plume within the } \\
\text { compartment. Fire positions } 2 \text { and } 3 \text { should only be used when the } \\
\text { fire is very close to the corner or wall respectively. The default is } \\
1 \text {. }\end{array}$} \\
\hline
\end{tabular}

\subsubsection{Graphics Specification}

A graphics specification can be added to the data file. Details of the meaning of some of the parameters is best left to the discussion of the device independent graphics software used by CFAST[14]. However, the information necessary to use it is straightforward. The general structure is similar to that used for the compartment and fire specification. One must tell the program "what to plot," "how it should appear," and "where to put it."

The key words for "where to put it" are:

$\begin{array}{ll}\text { DEVICE } & \text { where to plot it } \\ \text { BAR } & \text { bar charts } \\ \text { GRAPH } & \text { specify an x-y plot } \\ \text { TABLE } & \text { put the data into a table } \\ \text { PALETTE } & \text { specify the legend for CAD views } \\ \text { VIEW } & \text { show a perspective picture of the structure } \\ \text { WINDOW } & \text { the size of the window in "user" space. }\end{array}$

The complete key word is required. That is, for the "where to put it" terms, no abbreviations are allowed. Then one must specify the variables to be plotted. They are:

VENT, HEAT, PRESSUR, WALL, TEMPERA, INTERFA, $\mathrm{H}_{2} \mathrm{O}, \mathrm{CO}_{2}, \mathrm{CO}, \mathrm{OD}, \mathrm{O}_{2}$, TUHC, HCN, HCL, CT 
As might be expected, these are similar key words to those used in the plotting program, CPlot. In this case, it is a reduced set. The application and use of CFAST and CPlot are different.

For each key word there are parameters to specify the location of the graph, the colors and finally, titles as appropriate. For the variables, there is a corresponding pointer to the graph of interest.

The WINDOW label specifies the user space for placement of graphs, views, etc. The most common values (which are also the default) are:

$$
\begin{aligned}
& \mathrm{Xl}=0 ., \mathrm{Yb}=0 ., \mathrm{Zf}=0 . \\
& \mathrm{Xr}=1279 ., \mathrm{Yt}=1023 ., \mathrm{Zb}=10 .
\end{aligned}
$$

This is not a required parameter; however, it is often convenient to define graphs in terms of the units that are used. For example, if one wished to display a house in terms of a blueprint, the more natural units might be feet. In that case, the parameters might have the values:

$$
\begin{aligned}
& X I=0 ., Y b=0 ., Z f=0 \\
& X r=50 ., Y t=25 ., Z b=30
\end{aligned}
$$

Up to five graphs, tables, bar charts, and views may be displayed at one time on the graphics display. Up to five labels may be displayed at one time on the graphics display. Each type of output and each label is identified by a unique number (1-5) and placed in the window at a specified location. $\mathrm{Xl}, \mathrm{Yb}, \mathrm{Zf}, \mathrm{Xr}, \mathrm{Yt}$ and $\mathrm{Zb}$ have a meaning similar to WINDOW. However, here they specify where in the window to put the output.

The PALETTE label performs a specialized function for showing colors on the views. A four entry table is created and used for each type of filling polygon used in a view. Up to five palettes may be defined. Each palette is identified by a unique number and placed in the window at a specified location. $\mathrm{Xl}, \mathrm{Yb}, \mathrm{Zf}, \mathrm{Xr}, \mathrm{Yt}$ and $\mathrm{Zb}$ have a meaning similar to WINDOW. However, here they specify where in the window to put the palette.

In order to see the variables, they must be assigned to one of the above displays. This is accomplished with the variable pointers as:

(Variable) (nmopq) (Compartment) (Layer). 
Variable is one of the available variables VENT, HEAT, PRESSUR, WALL, TEMPERA, INTERFA, $\mathrm{N}_{2}, \mathrm{O}_{2}, \mathrm{CO}_{2}, \mathrm{CO}, \mathrm{HCN}, \mathrm{HCL}, \mathrm{TUHC}, \mathrm{H}_{2} \mathrm{O}, \mathrm{OD}, \mathrm{CT}$ used as a label for the line. The species listed correspond to the variable "SPECIES" in CPlot. (nmopqr) is a vector which points to:

\begin{tabular}{|l|}
\hline index display in \\
\hline (1) $\mathrm{n} \rightarrow$ bar chart \\
(2) $\mathrm{m} \rightarrow$ table \\
(3) $0 \rightarrow$ view \\
(4) $\mathrm{p} \rightarrow$ label \\
(5) $\mathrm{q} \rightarrow$ graph \\
\hline
\end{tabular}

respectively. These numbers vary from 1 to 5 and correspond to the value of " $n$ " in the "where to put it" specification. Compartment is the compartment number of the variable and Layer is "U" or "L" for upper and lower layer, respectively.

\section{Example:}

\begin{tabular}{|c|c|c|c|c|c|c|c|c|c|c|c|}
\hline WINDOW & & & 0 & c & & -100 & & & 110 & & \\
\hline GRAPH 1 & & 100. & & 050 . & 0. & 600 & 475 . & 10. & 3 & TIME & HEIGHT \\
\hline GRAPH 2 & & 100. & & 550 . & 0. & 600 & 940. & 10. & 3 & TIME & CELSIUS \\
\hline GRAPH 3 & & 720 . & & 050. & 0. & 1250. & 475 . & 10. & 3 & TIME & FIRE_SIZE ( $\mathrm{kW})$ \\
\hline GRAPH 4 & & 720 . & & 550 . & 0. & 1250. & 940. & 10. & 3 & TIME & $0 \mid D 2\lceil O(8)$ \\
\hline INTERFA & 0 & 0 & 0 & 1 & 1 & U & & & & & \\
\hline TEMPERA & 0 & 0 & 0 & 2 & 1 & U & & & & & \\
\hline HEAT & 0 & 0 & 0 & 3 & 1 & U & & & & & \\
\hline 02 & 0 & 0 & 0 & 4 & 1 & U & & & & & \\
\hline INTERFA & 0 & 0 & 0 & 1 & 2 & U & & & & & \\
\hline TEMPERA & 0 & 0 & 0 & 2 & 2 & U & & & & & \\
\hline HEAT & 0 & 0 & 0 & 3 & 2 & U & & & & & \\
\hline 02 & 0 & 0 & 0 & 4 & 2 & $U$ & & & & & \\
\hline
\end{tabular}

$\begin{array}{ll}\text { Key word: } & \text { DEVICE } \\ \text { Input: } & \text { Plotting Device }\end{array}$

Plotting Device

The Plotting Device specifies the hardware device where the graphics is to be displayed. It is installation dependent. In general it specifies which device will receive the output. For most systems, 1 is for the screen from which keyboard input comes, and 6 is for the hpgl files. 


\begin{tabular}{|l|l|}
\hline $\begin{array}{l}\text { Key word: } \\
\text { Inputs: }\end{array}$ & $\begin{array}{l}\text { WINDOW } \\
\mathrm{Xl}, \mathrm{Yb}, \mathrm{Zf}, \mathrm{Xr}, \mathrm{Yt}, \mathrm{Zb}\end{array}$ \\
\hline $\mathrm{Xl}$ & Left hand side of the window in any user desired units. \\
\hline $\mathrm{Yb}$ & Bottom of the window in any user desired units. \\
\hline $\mathrm{Zf}$ & Forward edge of the 3D block in any user desired units. \\
\hline $\mathrm{Xr}$ & Right hand side of the window in any user desired units. \\
\hline $\mathrm{Yt}$ & Top of the window in any user desired units. \\
\hline $\mathrm{Zb}$ & $\begin{array}{l}\text { Rear edge of the 3D block in any user desired units. These } \\
\text { definitions refer to the 3D plotting block that can be seen. }\end{array}$ \\
\hline
\end{tabular}

\begin{tabular}{|c|c|}
\hline $\begin{array}{l}\text { Key word: } \\
\text { Inputs: }\end{array}$ & $\begin{array}{l}\text { BAR } \\
\text { Bar Chart Number, Xl, Yb, Zf, Xr, Yt, Zb, Abscissa Title, Ordinate Title }\end{array}$ \\
\hline $\begin{array}{l}\text { Bar Chart } \\
\text { Number }\end{array}$ & $\begin{array}{l}\text { The number to identify the bar chart. Allowable values are from } 1 \\
\text { to } 5 \text {. }\end{array}$ \\
\hline $\mathrm{Xl}$ & $\begin{array}{l}\text { Left hand side of the bar chart within the window in the same units } \\
\text { as that of the window. }\end{array}$ \\
\hline $\mathrm{Yb}$ & $\begin{array}{l}\text { Bottom of the bar chart within the window in the same units as that } \\
\text { of the window. }\end{array}$ \\
\hline $\mathrm{Zf}$ & $\begin{array}{l}\text { Forward edge of the 3D block within the window in the same units } \\
\text { as that of the window. }\end{array}$ \\
\hline $\mathrm{Xr}$ & $\begin{array}{l}\text { Right hand side of the bar chart within the window in the same } \\
\text { units as that of the window. }\end{array}$ \\
\hline Yt & $\begin{array}{l}\text { Top of the bar chart within the window in the same units as that of } \\
\text { the window. }\end{array}$ \\
\hline $\mathrm{Zb}$ & $\begin{array}{l}\text { Back edge of the 3D block within the window in the same units as } \\
\text { that of the window. }\end{array}$ \\
\hline Abscissa Title & $\begin{array}{l}\text { Title for the abscissa (horizontal axis). To have blanks in the title, } \\
\text { use the underscore character "_.". }\end{array}$ \\
\hline Ordinate Title & $\begin{array}{l}\text { Title for the ordinate (vertical axis). To have blanks in the title, } \\
\text { use the underscore character "_". }\end{array}$ \\
\hline
\end{tabular}




\begin{tabular}{|c|l|}
\hline $\begin{array}{c}\text { Key word: } \\
\text { Inputs: }\end{array}$ Graph Number, $\mathrm{Xl}, \mathrm{Yb}, \mathrm{Zf}, \mathrm{Xr}, \mathrm{Yt}, \mathrm{Zb}$, Color, Abscissa Title, Ordinate Title \\
\hline Graph Number & $\begin{array}{l}\text { The number to identify the graph. Allowable values are from 1 to } \\
\text { 5. The graphs must be numbered consecutively, although they do } \\
\text { not have to be given in order. It is acceptable to define graph 4 } \\
\text { before graph 2, but if graph 4 is to be used, then graphs 1 through } \\
\text { 3 must also be defined. }\end{array}$ \\
\hline $\mathrm{Xl}$ & $\begin{array}{l}\text { Left hand side of the graph within the window in the same units as } \\
\text { that of the window. }\end{array}$ \\
\hline $\mathrm{Yb}$ & $\begin{array}{l}\text { Bottom of the graph within the window in the same units as that of } \\
\text { the window. }\end{array}$ \\
\hline $\mathrm{Zf}$ & $\begin{array}{l}\text { Forward edge of the 3D (three dimensional) block within the } \\
\text { window in the same units as that of the window. }\end{array}$ \\
\hline $\mathrm{Xr}$ & $\begin{array}{l}\text { Right hand side of the graph within the window in the same units } \\
\text { as that of the window. }\end{array}$ \\
\hline $\mathrm{Yt}$ & $\begin{array}{l}\text { Top of the graph within the window in the same units as that of the } \\
\text { window. }\end{array}$ \\
\hline $\mathrm{Zf}$ & $\begin{array}{l}\text { Back edge of the 3D block within the window in the same units as } \\
\text { that of the window. }\end{array}$ \\
\hline Color & $\begin{array}{l}\text { The color of the graph and labels which is specified as an integer } \\
\text { from 1 to 15. Refer to DEVICE (NBSIR 85-3235) for the colors } \\
\text { corresponding to the color values. }\end{array}$ \\
\hline Ordinate Title & $\begin{array}{l}\text { Title for the abscissa (horizontal axis). To have blanks in the title, } \\
\text { use the underscore character "_.". }\end{array}$ \\
\hline $\begin{array}{l}\text { Title for the ordinate (vertical axis). To have blanks in the title, } \\
\text { use the underscore character "_.". }\end{array}$ \\
\hline
\end{tabular}




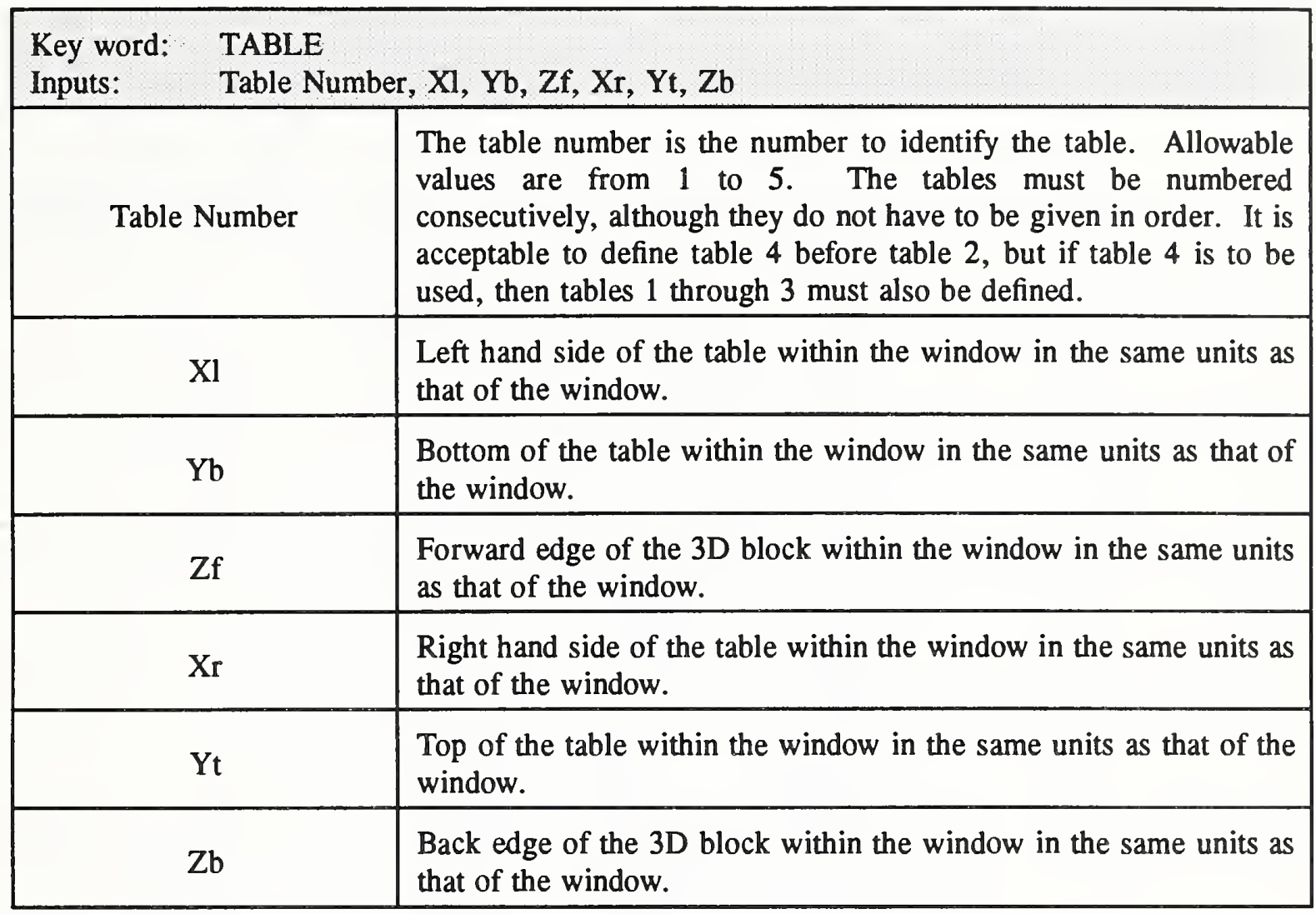




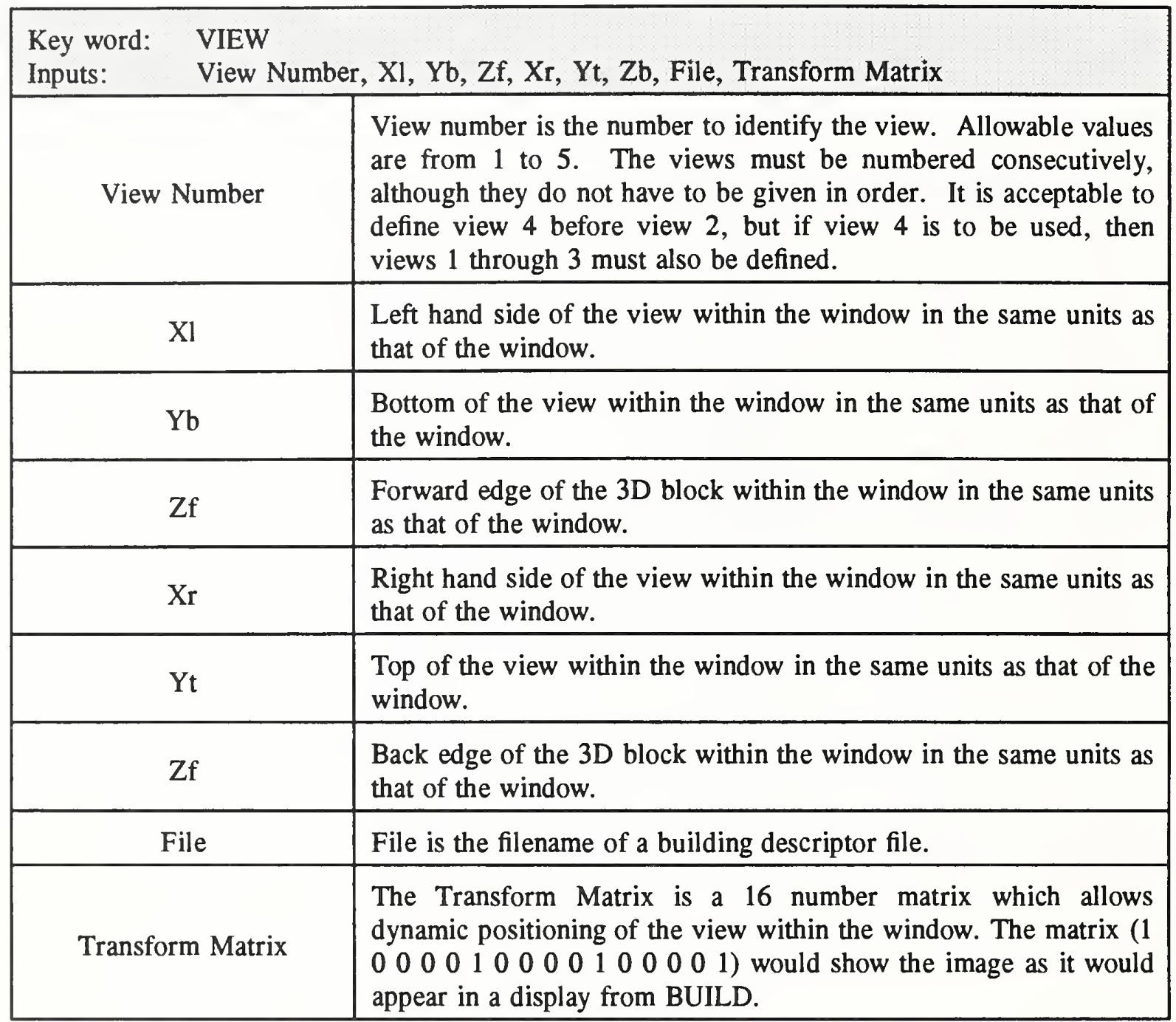




\begin{tabular}{|c|c|}
\hline $\begin{array}{l}\text { Key word: } \\
\text { Inputs: }\end{array}$ & $\begin{array}{l}\text { LABEL } \\
\text { Label Number, Xl, Yb, Zf, Xr, Yt, Zb, Text, Angle1, Angle2 }\end{array}$ \\
\hline Label Number & $\begin{array}{l}\text { Label number is the number to identify the label. Allowable } \\
\text { values are from } 1 \text { to } 5 \text {. }\end{array}$ \\
\hline $\mathrm{Xl}$ & $\begin{array}{l}\text { Left hand side of the label within the window in the same units as } \\
\text { that of the window. }\end{array}$ \\
\hline $\mathrm{Yb}$ & $\begin{array}{l}\text { Bottom of the label within the window in the same units as that of } \\
\text { the window. }\end{array}$ \\
\hline $\mathrm{Zf}$ & $\begin{array}{l}\text { Forward edge of the 3D block within the window in the same units } \\
\text { as that of the window. }\end{array}$ \\
\hline $\mathrm{Xr}$ & $\begin{array}{l}\text { Right hand side of the label within the window in the same units as } \\
\text { that of the window. }\end{array}$ \\
\hline Yt & $\begin{array}{l}\text { Top of the label within the window in the same units as that of the } \\
\text { window. }\end{array}$ \\
\hline $\mathrm{Zb}$ & $\begin{array}{l}\text { Back edge of the 3D block within the window in the same units as } \\
\text { that of the window. }\end{array}$ \\
\hline Text & $\begin{array}{l}\text { The text to be displayed within the label. To have blanks in the } \\
\text { title, use the underscore character "_". }\end{array}$ \\
\hline Color & Color of the text to be displayed (a number from 0 to 15 ). \\
\hline $\begin{array}{l}\text { Angle1 and } \\
\text { Angle2 }\end{array}$ & $\begin{array}{l}\text { Angles for display of the label in a right cylindrical coordinate } \\
\text { space. At present, only the first angle is used and represents a } \\
\text { positive counterclockwise rotation; set the second angle to zero. } \\
\text { Both angles are in radians. }\end{array}$ \\
\hline
\end{tabular}




\begin{tabular}{|c|l|}
\begin{tabular}{|c|} 
Key word: \\
Inputs: \\
\hline Palette Number, $\mathrm{Xl}, \mathrm{Yb}, \mathrm{Zf}, \mathrm{Xr}, \mathrm{Yt}, \mathrm{Zb}$, Color and Label
\end{tabular} \\
\hline $\mathrm{Xl}$ & $\begin{array}{l}\text { Palette number is the number to identify the palette. Allowable } \\
\text { values are from } 1 \text { to 5. }\end{array}$ \\
\hline $\mathrm{Yb}$ & $\begin{array}{l}\text { Left hand side of the palette within the window in the same units as } \\
\text { that of the window. }\end{array}$ \\
\hline $\mathrm{Zf}$ & $\begin{array}{l}\text { Bottom of the palette within the window in the same units as that } \\
\text { of the window. }\end{array}$ \\
\hline $\mathrm{Xr}$ & $\begin{array}{l}\text { Forward edge of the 3D block within the window in the same units } \\
\text { as that of the window. }\end{array}$ \\
\hline $\mathrm{Yt}$ & $\begin{array}{l}\text { Right hand side of the palette within the window in the same units } \\
\text { as that of the window. }\end{array}$ \\
\hline $\mathrm{Zb}$ & $\begin{array}{l}\text { Top of the palette within the window in the same units as that of } \\
\text { the window. }\end{array}$ \\
\hline & $\begin{array}{l}\text { Back edge of the 3D block within the window in the same units as } \\
\text { that of the window. }\end{array}$ \\
\hline Color and Label & $\begin{array}{l}\text { There are four pairs of color/text combinations, each corresponding } \\
\text { to an entry in the palette. The color number is an integer from 1 } \\
\text { to 15 and the text can be up to 50 characters (total line length of } \\
128 \text { characters maximum). As before, spaces are indicated with an } \\
\text { underscore character "_.". }\end{array}$ \\
\hline
\end{tabular}




\section{UTILITY PROGRAMS}

There are several programs which are not really part of the simulation model but are aids in using the software. These utility programs are provided to ease the implementation and use of the model. These include:
List_obj List the OBJECTS database
List_tpp List the thermophysical properties database
List_clr Test the graphics compatibility of the graphics drivers and the video display

Obj2df Convert the prototype objects database to the direct access version used by the model (see Appendix D)

CF_set Set the search paths, colors and other miscellaneous information for the various programs. This is the only safe way to modify HV1.CF.

Report Provide an ASCII output of the run, based on the history file generated by the original CFAST run

ReportG Animate the graphics display - this routine will reproduce the run time graphics as was shown by CFAST in the original. This is especially useful for those who use the version of the model which does not generate run time graphics, and those who wish to do a side by side comparison of various runs of the model.

The first five routines, List_obj, List_tpp, List_clr, Ojb2df and CF_set, are simply entered as commands. The latter two use a file and the option "/rnn." For Report, the meaning of " $\mathrm{nn}$ " is

$$
\begin{aligned}
1 & =>\text { building configuration } \\
2 & =>\text { normal temperature/interface history } \\
4 & =>\text { flow field } \\
8 & =>\text { species } \\
16 & =>\text { type } 1 \text { FED results (fixed nose per compartment) } \\
32 & =>\text { type } 2 \text { and } 3 \text { FED results } \\
64 & =>\text { temperature profiles in the walls }
\end{aligned}
$$

or combinations, such as $/ \mathrm{r} 3$ for a normal output sequence. For ReportG, the value of " $\mathrm{nn}$ " is a wait time between frames. With no time specified, the screen is updated as rapidly as ReportG can access the data file. With an option $/ \mathrm{r} 10$, there is a ten second pause between each frame, and so on. 


\section{REFERENCES}

[1] Jones, W. W., A Multicompartment Model for the Spread of Fire, Smoke and Toxic Gases. Fire Safety Journal, 9 , 55 (1985).

[2] Jones, W. W. and Peacock, R. D., Refinement and Experimental Verification of a Model for Fire Growth and Smoke Transport, Proceedings of the 2nd International Symposium on Fire Safety Science, Tokyo (1989); Jones, W. W. and Peacock, R. D., Technical Reference Guide for FAST Version 18, National Institute Standards and Technology Technical Note 1262 (1989).

[3] Forney, G. P. and Cooper, L. Y., The Consolidated Compartment Fire Model (CCFM) Computer Application CCFM.VENTS - Part II: Software Reference Guide, National Institute Standards and Technology Internal Report 90-4343 (1990).

[4] Peacock, R.D., Jones, W.W., Forney, G.P., Reneke, P., Portier, R., CFAST, the Consolidated Model of Fire and Smoke Transport, National Institute of Standards and Technology, Technical Note 1299 (1992)

[5] Jones, W. W., A Multicompartment Model for the Spread of Fire, Smoke and Toxic Gases, Fire Safety Journal 9, 55 (1985).

[6] Jones, W. W. and Peacock, R. D., Refinement and Experimental Verification of a Model for Fire Growth and Smoke Transport, Proceedings of the 2nd International Symposium on Fire Safety Science, Tokyo (1989)

[7] Jones, W. W. and Forney, G. P., Modeling Smoke Movement through Compartmented Structures, Natl. Inst. Stand. Technol., NISTIR 4872 (1992).

[8] Peacock, R. D., Jones, W. W., and Bukowski, R. W., "Verification of a Model for Fire and Smoke Transport," to be published in Fire Safety J.

[9] Bukowski, R.W., Peacock, R.D., Jones, W.W., and Forney, C.L., Software User's Guide for the HAZARD I Fire Hazard Assessment Method, Handbook 146, Volume I, National Institute of Standards and Technology, June 1991.

[10] Bukowski, R.W., Peacock, R.D., Jones, W.W., and Forney, C.L., Technical Reference Guide for the HAZARD I Fire Hazard Assessment Method, Handbook 146, Volume II, National Institute of Standards and Technology, June 1991

[11] Peacock, R.D., Breese, J.N., Forney, C.L., A Users Guide for RAPID, Version 2.3, National Institute of Standards and Technology Special Publication 798 (1991) 
[12] U.S. Standard Atmosphere (1976), a joint publication of the National Oceanographic and Atmospheric Administration and the National Aeronautics and Space Administration.

[13] Haltiner, G. J. and Martin, F. L., Dynamical and Physical Meteorology, York (1957).

[14] Jones, W.W. and Fadell, A.B., A Device Independent Graphics Kernel, NBSIR 85-3235 National Bureau of Standards (USA) (1988) 


\section{Appendix A: EXAMPLE INPUT FILES}

\section{A.1 PRM.DAT}

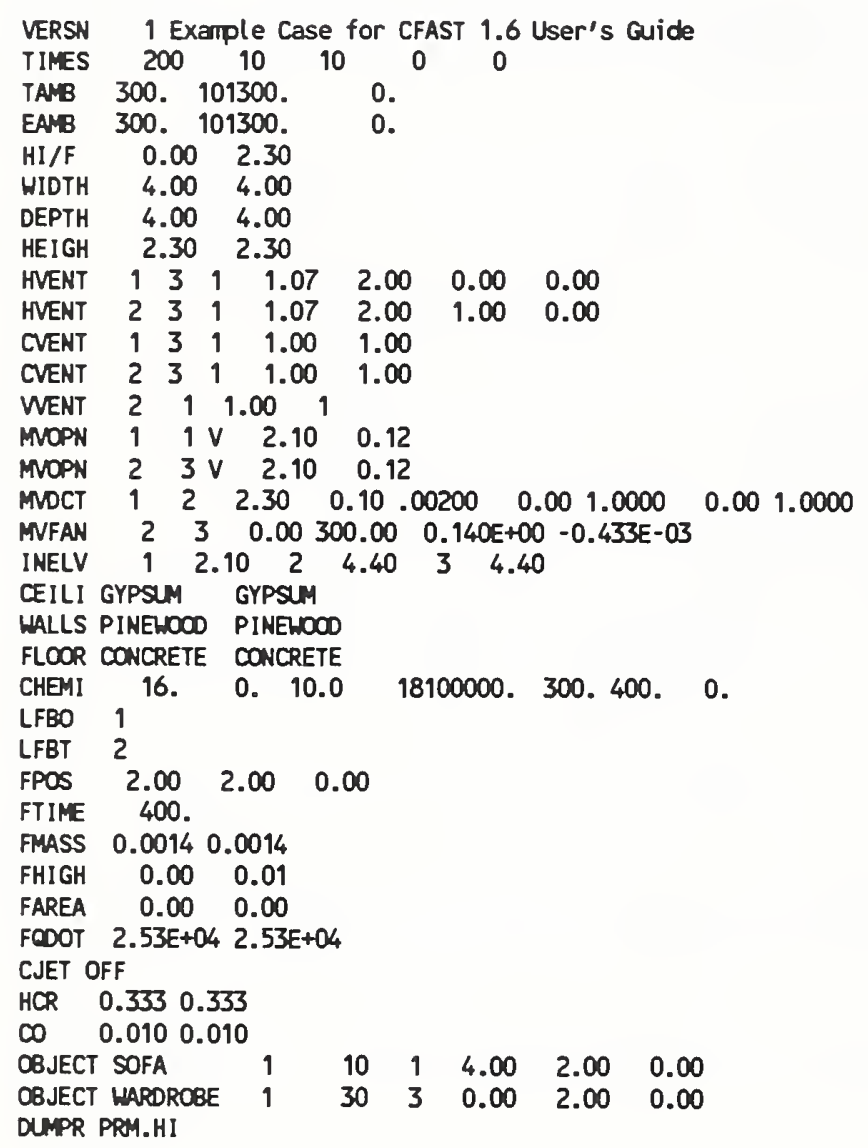

Use Function key f6 on the CEdit Files Screen to append:

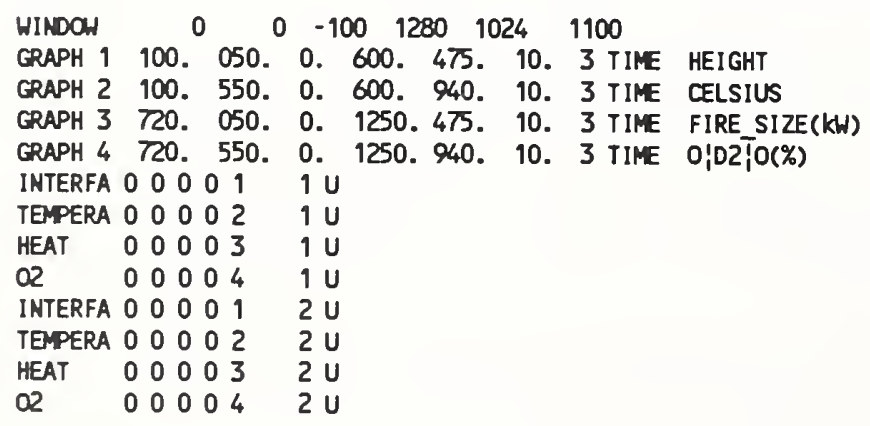




\section{A.2 School Building Fire}

Aus[10] used HAZARD I to provide an alternative for a code equivalency determination. As a test, an actual case from California was examined using this process. The question involved a small school building which was found in violation of the Uniform Building Code (UBC) with respect to the required separation of alternate exits. The analysis performed examined several alternative approaches to compliance with the intent of the code, with a significant variation in cost. The two story structure is bordered by a balcony on one side limiting exit travel. The scenario included here is one of several examined by Aus. It is presented to show the application of the model to an existing structure. This example illustrates the use of CFAST for applications other than residences. Although obviously not a residential structure, the scale of the building and the fire are similar to those in residences.

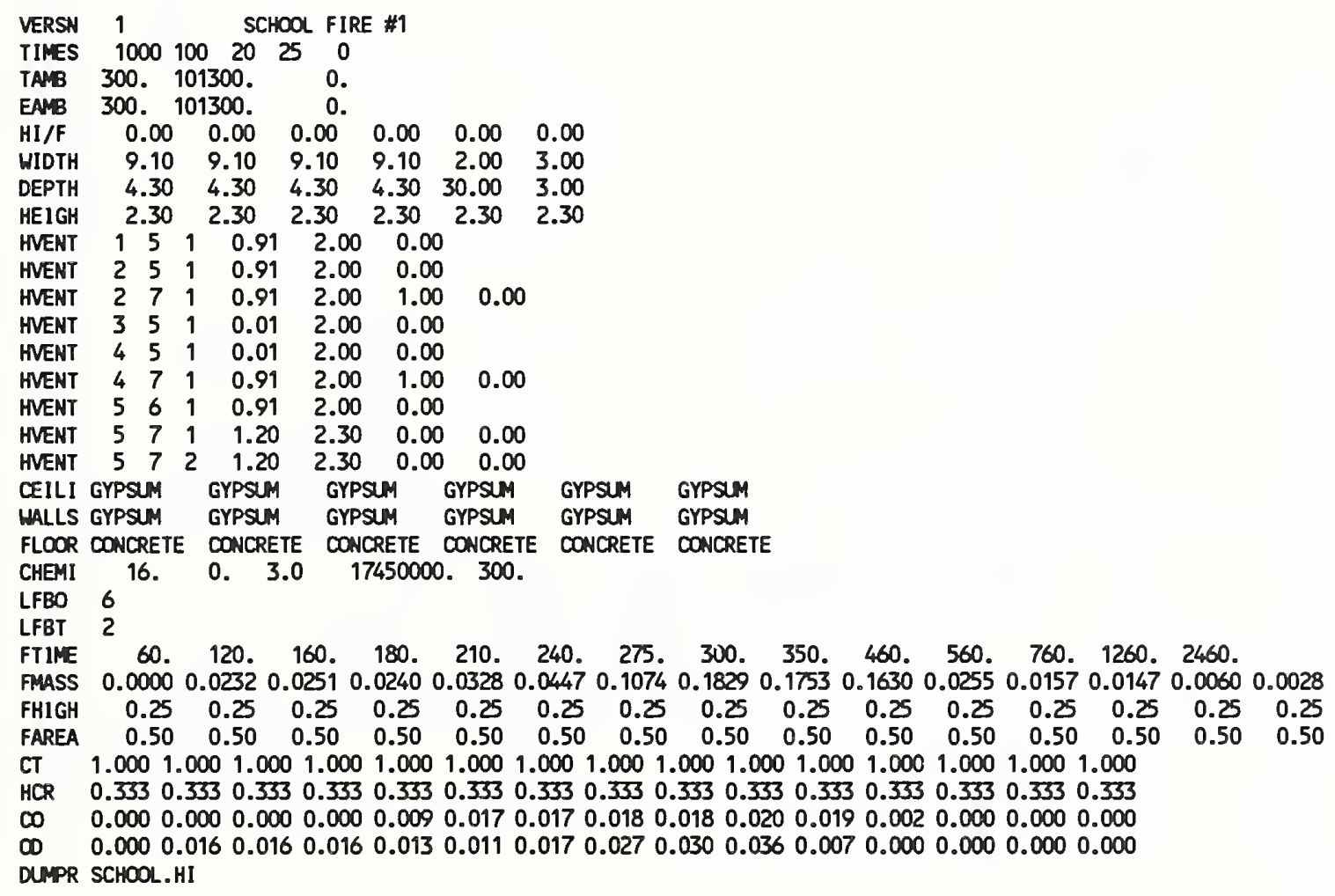




\section{A.3 Mechanical Ventilation}

In this example, the mechanical ventilation capabilities of CFAST are demonstrated. Four key words in the CFAST input file implement this capability for a simple fan-forced ventilation system:

- MVOPN - describe an opening between a compartment and the ventilation system,

- $\quad$ MVDCT - describe a piece of (circular) duct work,

- $\quad$ MVFAN - give the pressure - flow relationship for a fan, and

- INELV - specify interior node elevations.

For this example, a simple three compartment test case is used. As before, only the CFAST input data file and a sample of the output is presented.

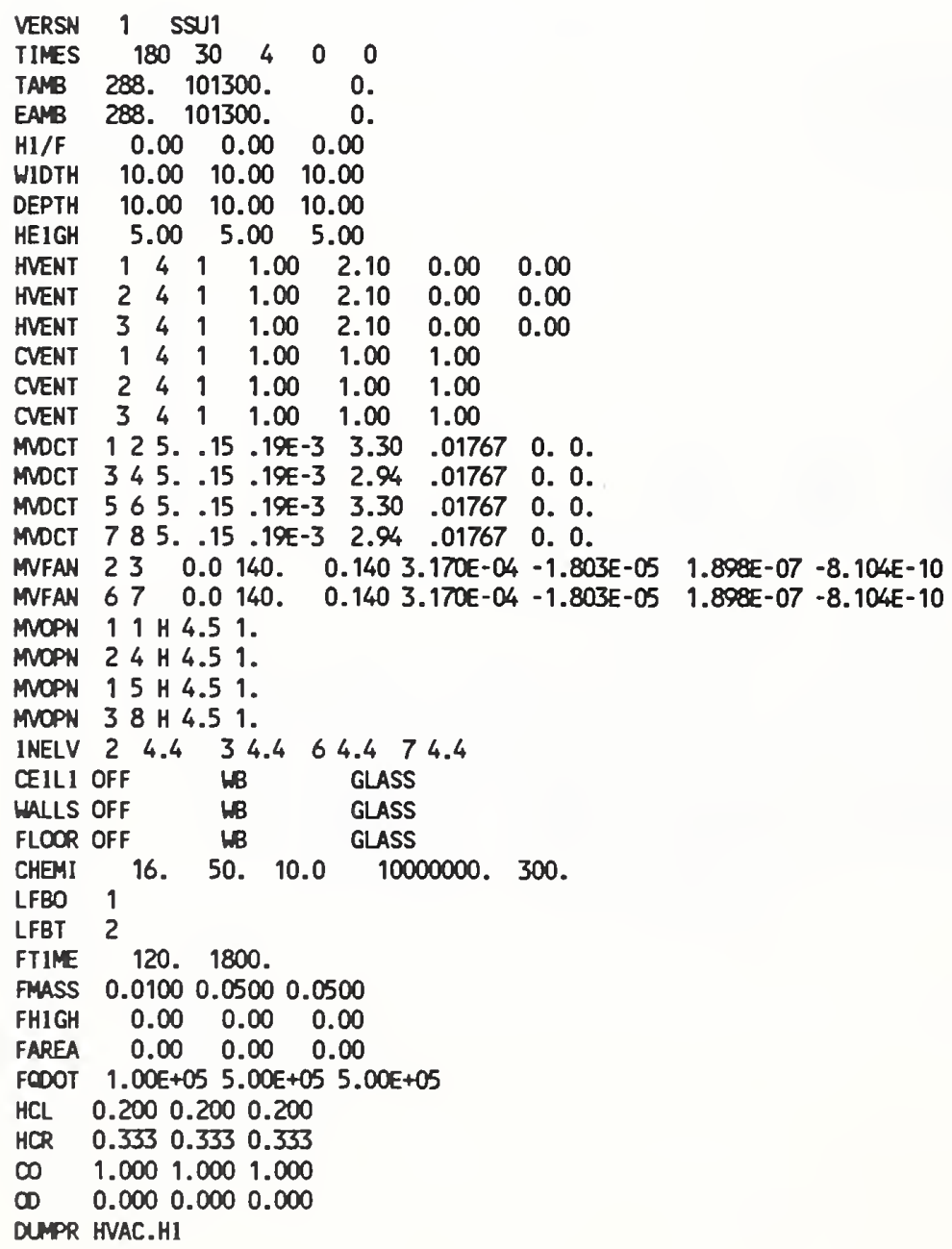




\section{A.4 Hotel Lobby Fire}

In this deceptively simple example, an extremely large fire (peak heat release rate $30 \mathrm{MW}$ ) is simulated in a large hotel lobby $(32.3 \times 9.4 \times 4.2 \mathrm{~m})$. Although clearly not residential in scale, the relative scale of the fire and the openings when compared to the room size is similar to those in residences. This would lend some confidence to the results of the predictions. As with any simulation, the user's expertise should serve as a reality check on the predicted results.

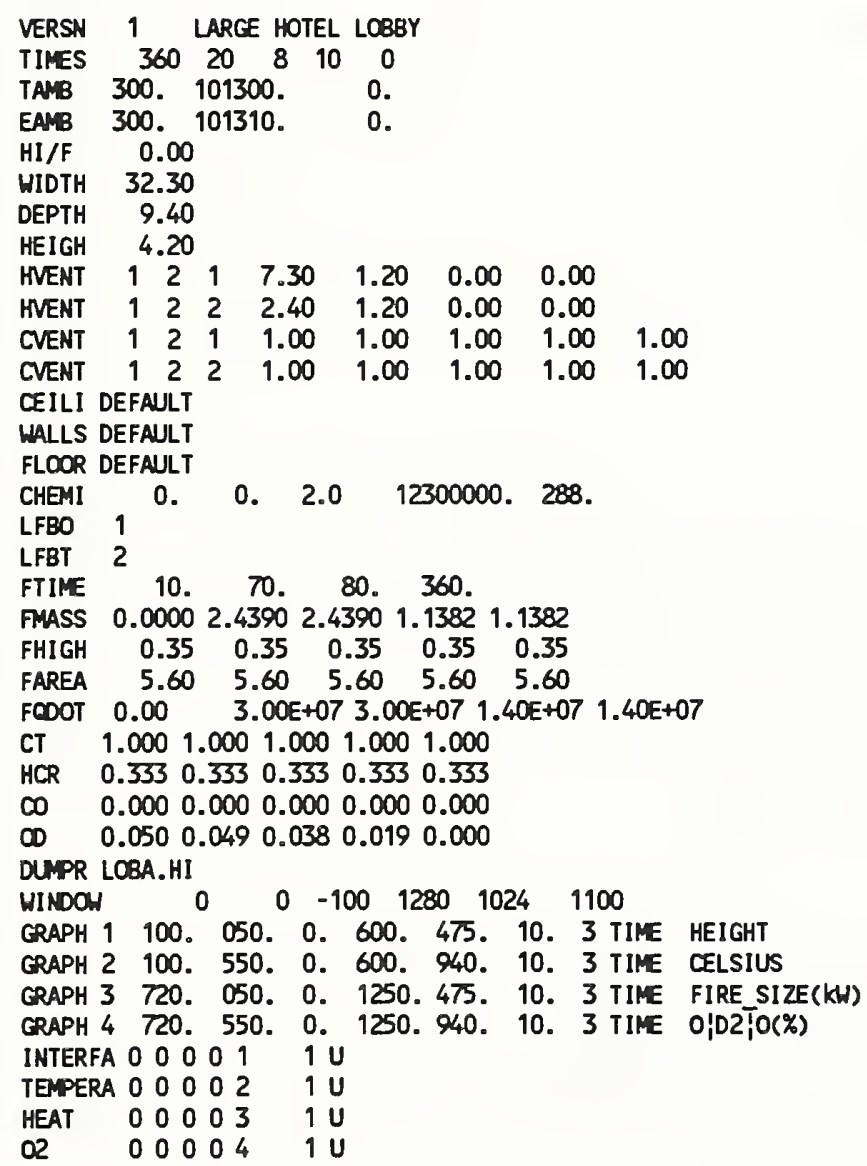




\section{A.5 Opening and Closing Doors and Windows}

In this example, the CVENT key word in the CFAST input file is used to simulate the opening and closing of doors and windows during the course of a fire in a two-story house. Although the opening and closing times in this example are arbitrary; they could also be based upon occupant actions predicted by evacuation models or breakage of windows caused by elevated temperature or other criteria in the rooms (through multiple runs of the model).

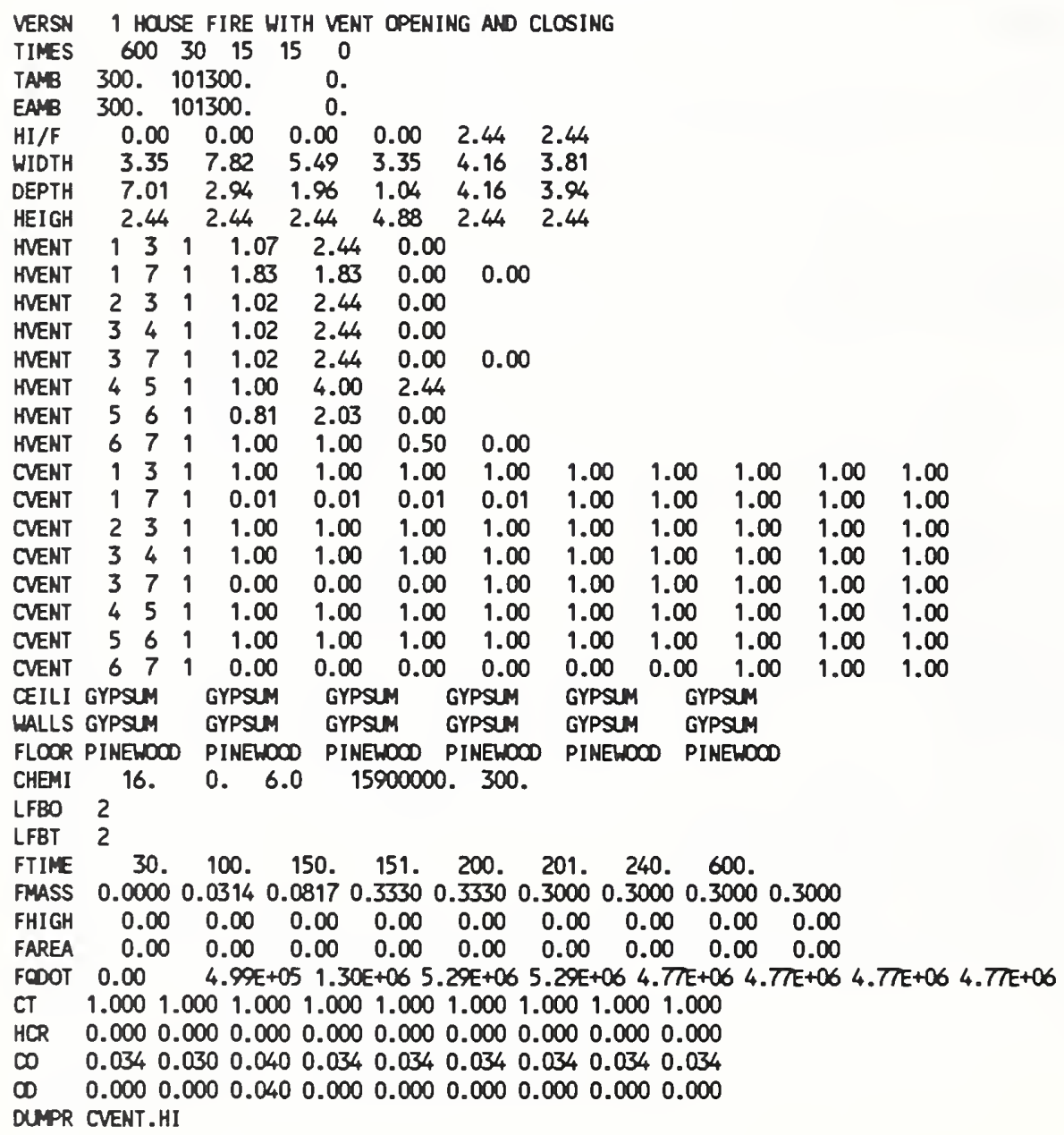




\section{A.6 Interaction of Mechanical Ventilation and $\mathrm{HCl}$ Deposition}

An example of the interaction of mechanical ventilation with hydrogen chloride deposition $(\mathrm{HCl})$ can be shown using the following data file:

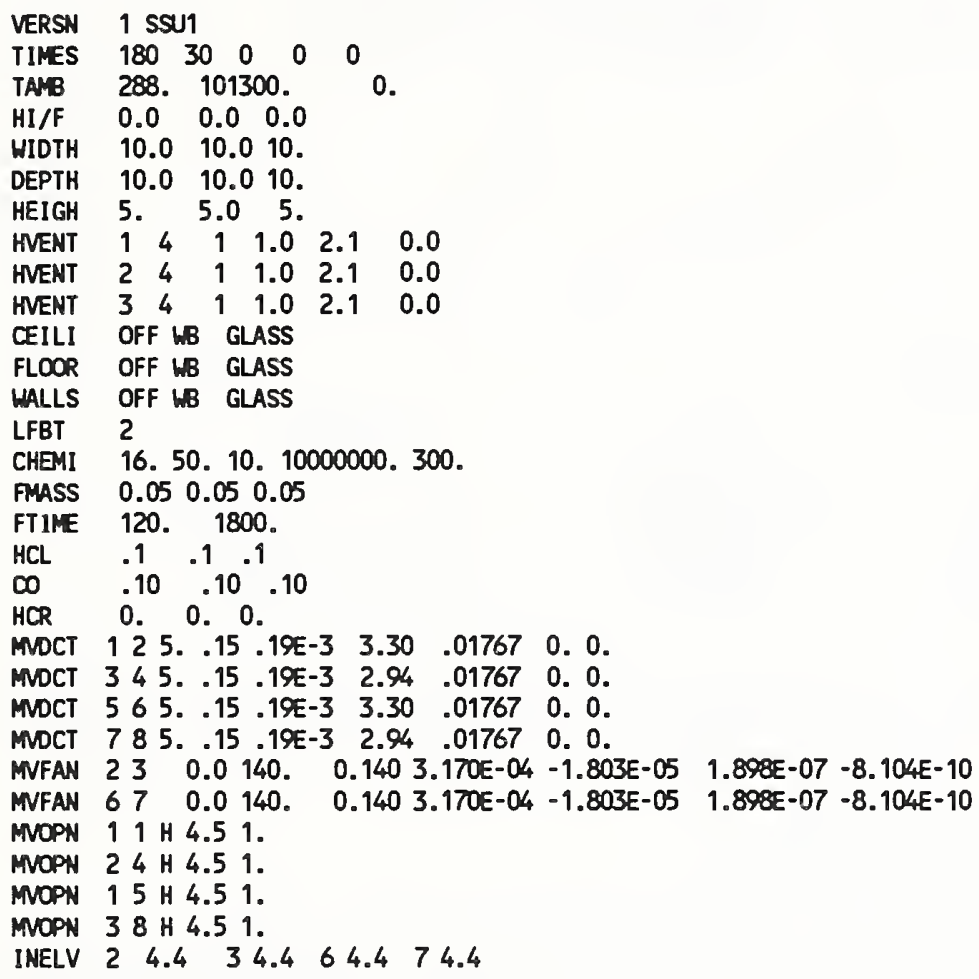

In this case, there are three compartments, each with a normal vent only to the outside. The three compartments are connected to each other by mechanical ventilation ducts. The compartment layout is shown in Figure 6, with compartment \#2 on the left, compartment \#1 in the center and compartment $\# 3$ on the right hand side of the figure. The fire is in the center compartment (\#1) and a pair of fans blows the fire gases into the other two compartments (\#2 and \#3). The wall lining for the second compartment is wall board, and for the third compartment glass. The two compartments are symmetric in that all openings to the outside are the same size and the fans have the same pressure curves, so flow will be the same to both sides. The fire is small, and the pyrolyzate contains $10 \%$ hydrogen chloride, to emphasize the effect of mechanical ventilation and deposition.

Figure 7 shows the difference in the $\mathrm{HCl}$ concentration in the lower layer of the two compartments not containing the fire. With no wall adsorption, the concentrations of $\mathrm{HCl}$ in the two gas layers would be the same. As can be seen, the deposition onto the wall is influenced by the concentration in the environment, with the $\mathrm{HCl}$ concentration lower in the compartment which is lined with gypsum. 


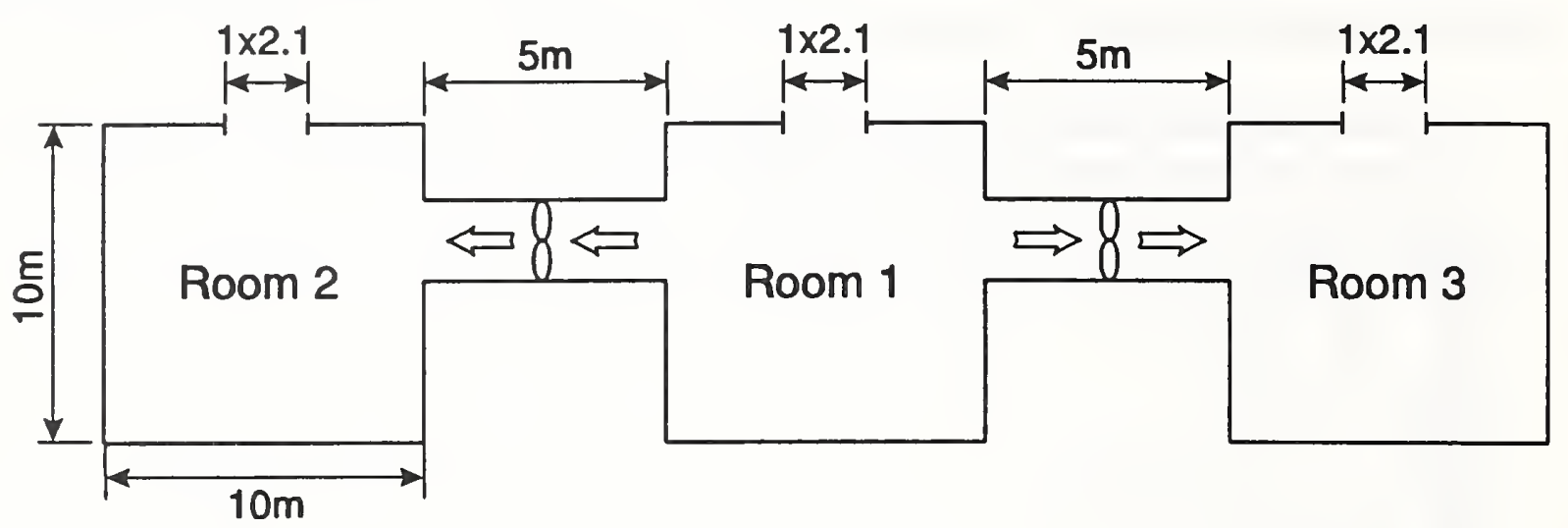

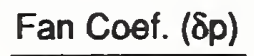
1. 0.14
$\hookleftarrow 8 \hookleftarrow$
2. $3 \times 10^{-4}$
3. $-1.8 \times 10^{-5}$
Mechanical
4. $1.8 \times 10^{-6}$
5. $-8.1 \times 10^{-10}$
Ventilation
Fan

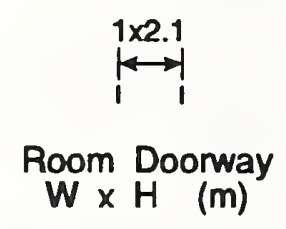

Figure 6. Plan diagram of the geometry used in the mechanical ventilation and $\mathrm{HCl}$ deposition calculation.

\section{A.7 Specification of Graphical Output from CFAST}

Several examples are included which illustrate the specification of graphical output for the CFAST model.

The first example is for a single compartment. This is also the $1 \mathrm{R}$ data file referred to in CEdit. In the latter case, the graphics descriptors are not included.

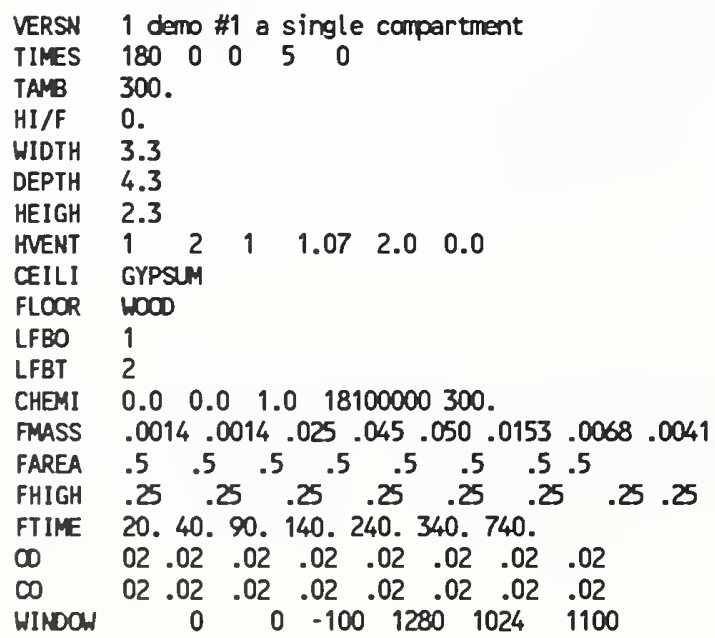




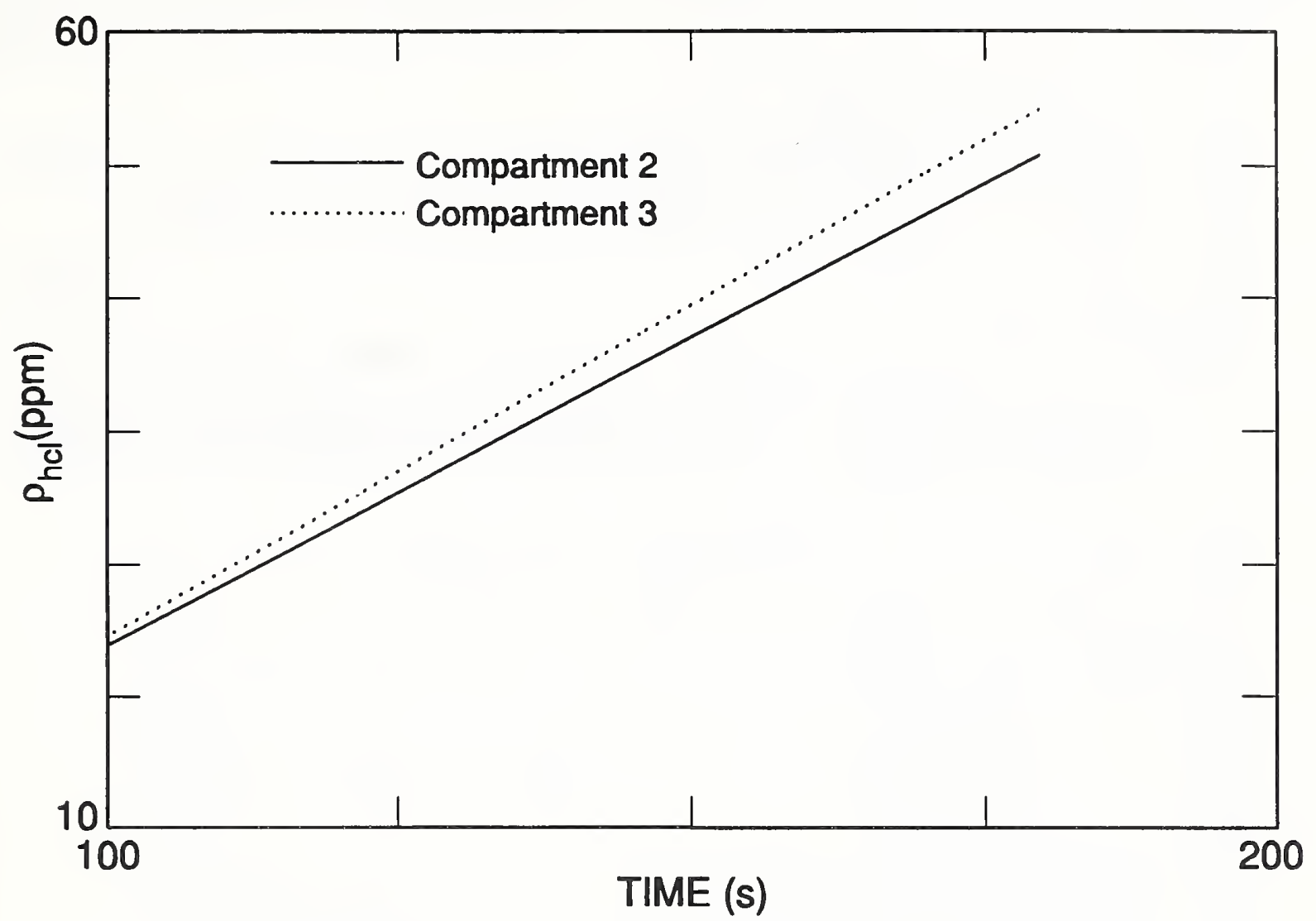

Figure 7. $\mathrm{HCl}$ concentration in the lower layer of compartments 2 and 3.
GRAPH 1120.300.
GRAPH 2740.300.
LABEL 1970.960.
LABEL 2 690. 960.
LABEL 3200.050.
CO $000011 \mathrm{U}$
0. 600. 920.10 .5 TIME PPM
0. 1220.920 .
0.1231 .1005 .
0.987 .1005 .
10. 5 TIME CELSIUS
10. 15 00:00:00
10. 13 TIME [S]
0.0 . 0.
0. 520.125 .
10. 2 CO'D 2 jo_CONCENTRATION 0.0 .

TEMPERA 0000002014

TEMPERA $00000021 \mathrm{~L}$

Demonstration $\# 2$ is a similar run, but showing other types of displays which are available.

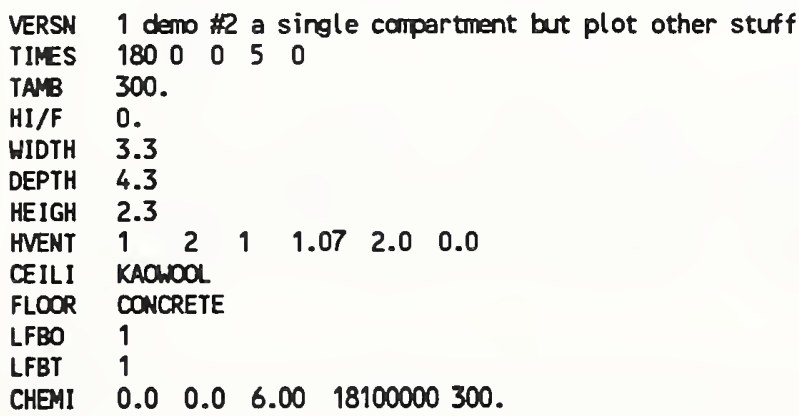




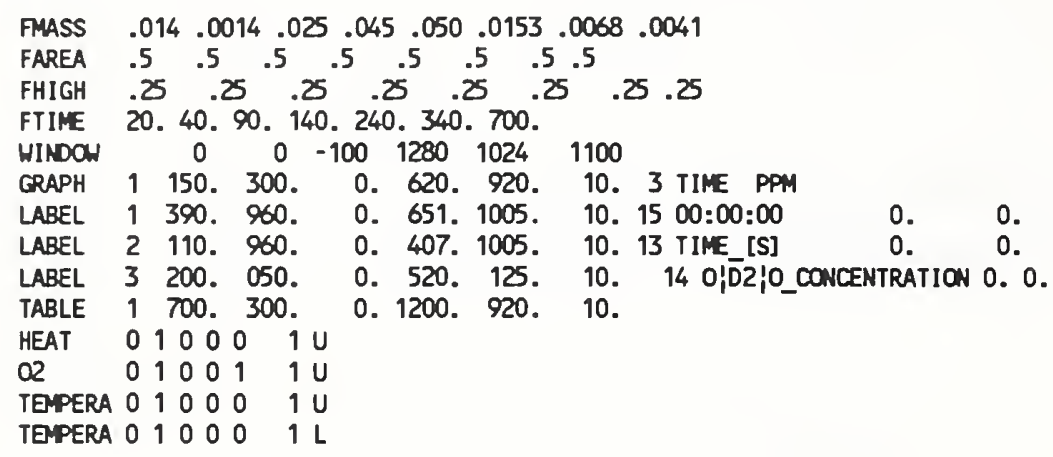

This data set produces two views of a building along with a table of selected quantities calculated during the simulation.

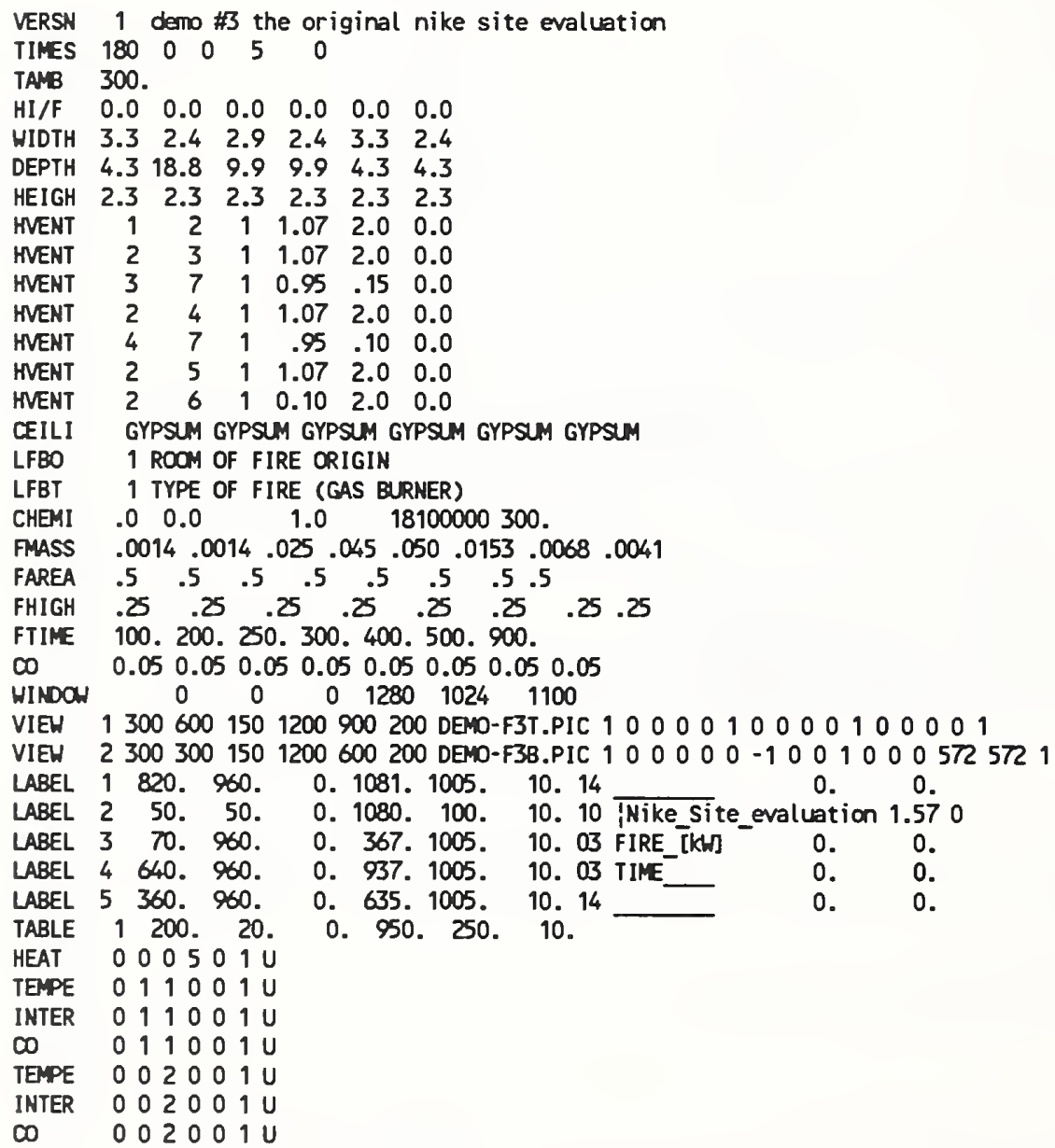




\section{Appendix B: COMMAND LINE OPTIONS}

In general, the command line for starting each of the CFAST routines is:

\section{name [option(s)] file1 file2}

Options:

For the PC, an option is preceded by a "/" while on a Unix platform it is "-". There are several possible options which are used to control the CFAST programs: $n, f, l$ and $r$. The interaction between these options and the various modules is:

\begin{tabular}{|l|c|c|c|c|}
\hline & $-\mathrm{n}(/ \mathrm{n})^{3}$ & $-\mathrm{f}(/ \mathrm{f})$ & $-\mathrm{l}(/ \mathrm{l})$ & $-\mathrm{r}(/ \mathrm{r})$ \\
\hline CEdit & no header & $\begin{array}{c}\text { context } \\
\text { vector }\end{array}$ & $\begin{array}{c}\text { error } \\
\text { logging }\end{array}$ & na \\
\hline CFAST & $" "$ & $"$ & $"$ & na \\
\hline CPlot & $" "$ & $"$ & $"$ & na \\
\hline Report & $" "$ & na & $"$ & $\begin{array}{c}\text { what to } \\
\text { report }\end{array}$ \\
\hline ReportG & $" "$ & na & $"$ & time delay \\
\hline
\end{tabular}

n prevents display of the disclaimer notice,

$f$ passes a configuration file - used by the shell to pass the current configuration,

1 turns on error logging,

$\mathrm{r}$ specification for the report generators, Report and ReportG. Refer to Section 7.

The possible file specifications on the command line for each program are:

CEdit - If a file1 is specified, CEdit reads it as a configuration file first. If the file is not a configuration file, then CEdit will access it as a data file. If file1 is omitted, CEdit uses the HV1.CF configuration file and the last data file by default. file2 is not supported by CEdit.

CFAST - If filel is specified, CFAST reads it as a configuration file first. If the file is not a configuration file, then CFAST will access it as a data file. If file1 is omitted, CFAST uses the HV1.CF configuration file and the last data file by default. If file2 is specified, it is used as an output file. Otherwise, CFAST displays to the screen. If file2

${ }^{3}$ The first form is for Unix, and the second is for the PC 
is to be specified and file1 is not, a "," must separate file 2 from the CFAST program name.

CPlot - file1 is an ASCII file containing the CPlot commands as they would have been entered interactively. If file1 is omitted, CPlot uses an interactive text interface.

Report - file1 is a history file created by CFAST when using the DUMPR key word in the CFAST data input file. Report requires entry of file1. On a Unix system only, the file name is case-sensitive.

ReportG - file1 is a data file which was used to run CFAST originally. At present, file1 is required. 


\section{Appendix C: THERMAL DATABASE}

Thermal data is read from a file which is in an ASCII format. The default name is THERMAL. DAT. The distributed configuration file (HV1.CF) renames this to THERMAL.DF. An alternative can be used by changing the default with the routine CF_Set, or by using the key word THRMF in the data file that is passed to CFAST.

The relationship is by the name used in specifying the boundary. The example data file shown in Appendix A uses concrete, gypsum and pinewood. Any name can be used so long as it is in the thermal database. If a name is used which is not in the database, then CEdit will turn off the conduction calculation, and CFAST will stop with an appropriate error message. The form of an entry in the database is:

name conductivity specific heat density thickness emissivity

and the units are:

$\begin{array}{ll}\text { name } & 1 \text { to } 8 \text { alphanumeric characters } \\ \text { conductivity } & \text { Watts/meter/Kelvin } \\ \text { specific heat } & \text { Joules/kilogram/Kelvin } \\ \text { density } & \text { kilograms/cubic meter } \\ \text { thickness } & \text { meters } \\ \text { emissivity } & \text { dimensionless. }\end{array}$

The default database that comes with CFAST (THERMAL.DF) includes:

$\begin{array}{lcrrrr}\text { Name } & \text { Conductivity } & \begin{array}{c}\text { Specific } \\ \text { heat }\end{array} & \text { Density } & \text { Thickness } & \text { Emissivity } \\ \text { DFIR30 } & 0.1800 & 900.0 & 790.0 & 0.0160 & 0.9000 \\ \text { PINEWOOD } & 0.1200 & 2500.0 & 540.0 & 0.0160 & 0.8000 \\ \text { CONCRETE } & 1.7500 & 1000.0 & 2200.0 & 0.1500 & 0.9400 \\ \text { REDOAK } & 0.1500 & 1300.0 & 640.0 & 0.0160 & 0.9000 \\ \text { FIBER } & 0.0500 & 1250.0 & 240.0 & 0.0160 & 0.9000 \\ \text { GYPSUM } & 0.1600 & 900.0 & 800.0 & 0.0160 & 0.9000 \\ \text { WOOD } & 0.0700 & 1000.0 & 250.0 & 0.0160 & 0.9800 \\ \text { DFIR0 } & 0.1300 & 1400.0 & 510.0 & 0.0127 & 1.0000 \\ \text { DFIR10 } & 0.1500 & 1500.0 & 560.0 & 0.0160 & 0.9000 \\ \text { GLASS } & 1.4000 & 760.0 & 2500.0 & 0.0160 & 0.9500 \\ \text { GLASFIBR } & 0.0360 & 720.0 & 32.0 & 0.0160 & 0.9000 \\ \text { KAOWOOL } & 0.2200 & 1047.0 & 128.0 & 0.1160 & 0.9700 \\ \text { GYP1 } & 0.1200 & 900.0 & 800.0 & 0.0250 & 0.9000 \\ \text { GYP2 } & 0.1200 & 900.0 & 800.0 & 0.0500 & 0.9000 \\ \text { BRICK } & 0.1800 & 900.0 & 790.0 & 0.0160 & 0.9000\end{array}$


The output listing of CFAST, and the thermal database screen for CEdit show a table of "codes." The code is an eight character string whose fields are:

1-3 number of nodes if it exceeds 'NN' which is currently 48 (36 for the PC version)

4 always blank

5 too many slabs - greater than mxslb (S)

6 inconsistent number of slabs - all properties must have the same number of slabs (I)

7 duplicate names - the first in the list is used (D)

8 used in the present calculation (U)

All of the examples shown above represent single layer partitions. The model, however, will handle up to three layers, or slabs, per partition. To specify multiple layers, each property is given one, two or three values separated by slashes. It is important that this be consistent across the whole entry, otherwise CFAST will have an ambiguous situation. The ambiguity is resolved by using the lowest number of layers.

The layers are numbered from the inside to outside. That is, the first material property represents the material on the compartment interior, and the last property is on the outside. There are several examples of this format in the THERMAL.DF file included in this distribution. One example is:

FC1_L003 .15/.03/.22 1500./1042./1047. 790./1.2/128. .016/.24/.019 .9

Since the emissivity applies only to the interior surface, it will always have only a single entry. Other values are ignored. This example represents a three layer assembly taken from Underwriters Laboratory(UL) "Fire Resistance Directory." The code stands for Floor Combustible 1 Hour, and L003 is assigned by UL.

Finally, the $\mathrm{HCl}$ coefficients are included for each entry in THERMAL.DF since they pertain to surface effects, and the current algorithm uses a similarity solution for the heat and mass transfer. There are seven coefficients for the $\mathrm{HCl}$ absorption. If the first two are zero, the others are not used even though they must be present. These coefficients have only been measured for a few materials. The most commonly used material is:

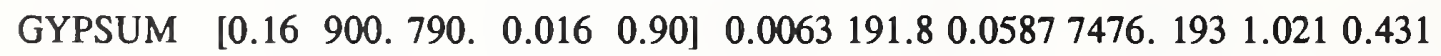

The numbers in brackets are shown above as the normal properties. The final seven coefficients and their units are discussed in reference [4]. 


\section{Appendix D: OBJECTS DATABASE}

OBJECTS.DF is the database of objects used by CFAST and CEdit. The distributed configuration file (HV1.CF) provides the default name. An alternative is available by changing the default with the routine CF_Set, or for individual data files by using the key word OBJFL.

OBJECTS.DF has a special format to allow both CFAST and CEdit to access the information as quickly as possible. For that reason, a second file, OBJECTS.ORG, has been created. OBJECTS.ORG is designed so that it can be edited with any ASCII text editor. When an entry in OBJECTS. ORG is added or changed, the routine OBJ2DF should be used to convert OBJECTS.ORG to OBJECTS.DF. Failure to do this will prevent CFAST and CEdit from recognizing the changes.

The format of an object entry in OBJECTS. ORG is listed below along with the CFAST variables to which the data is assigned. Each section will first specify the format of that line for the Ith object in the data file using the CFAST variable names. The variables are then listed individually with the appropriate dimensions and units as well as a brief description. The OBJECT key word on line 1 is required in the OBJECTS. ORG file in order to generate an accurate OBJECTS.DF. Note that the default values for flux for ignition and surface temperature for ignition are infinity and the ambient respectively.

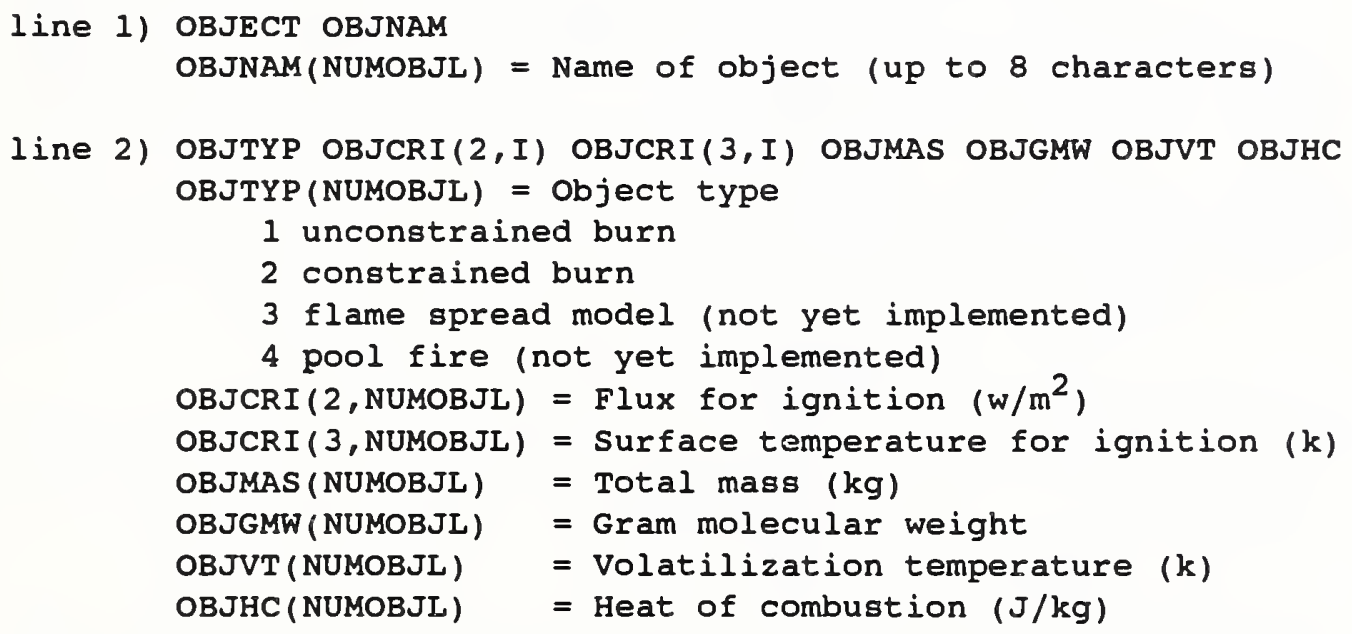


line 4) Second panel (ignored for now)

line 5) Third panel (ignored for now)

line 6) Fourth panel (ignored for now)

line 7) OTIME (1,I) to OTIME (TOTJ, I)

$\operatorname{OTIME}(\mathrm{NV}, \mathrm{NUMOBJL})$ = Time history (sec)

Each OTIME ( $J, I)$ represents a point on the objects burn timeline where the variables below are defined exactly. CFAST will interpolate values between any two points. TOTJ is the total number of points on the specified timeline. CFAST automatically assigns an initial time zero for the objects timeline so that there will always be one fewer specified value for the timeline than for the history variables below.

The following lines are the histories for the individual parameters at each of the OTIME points.

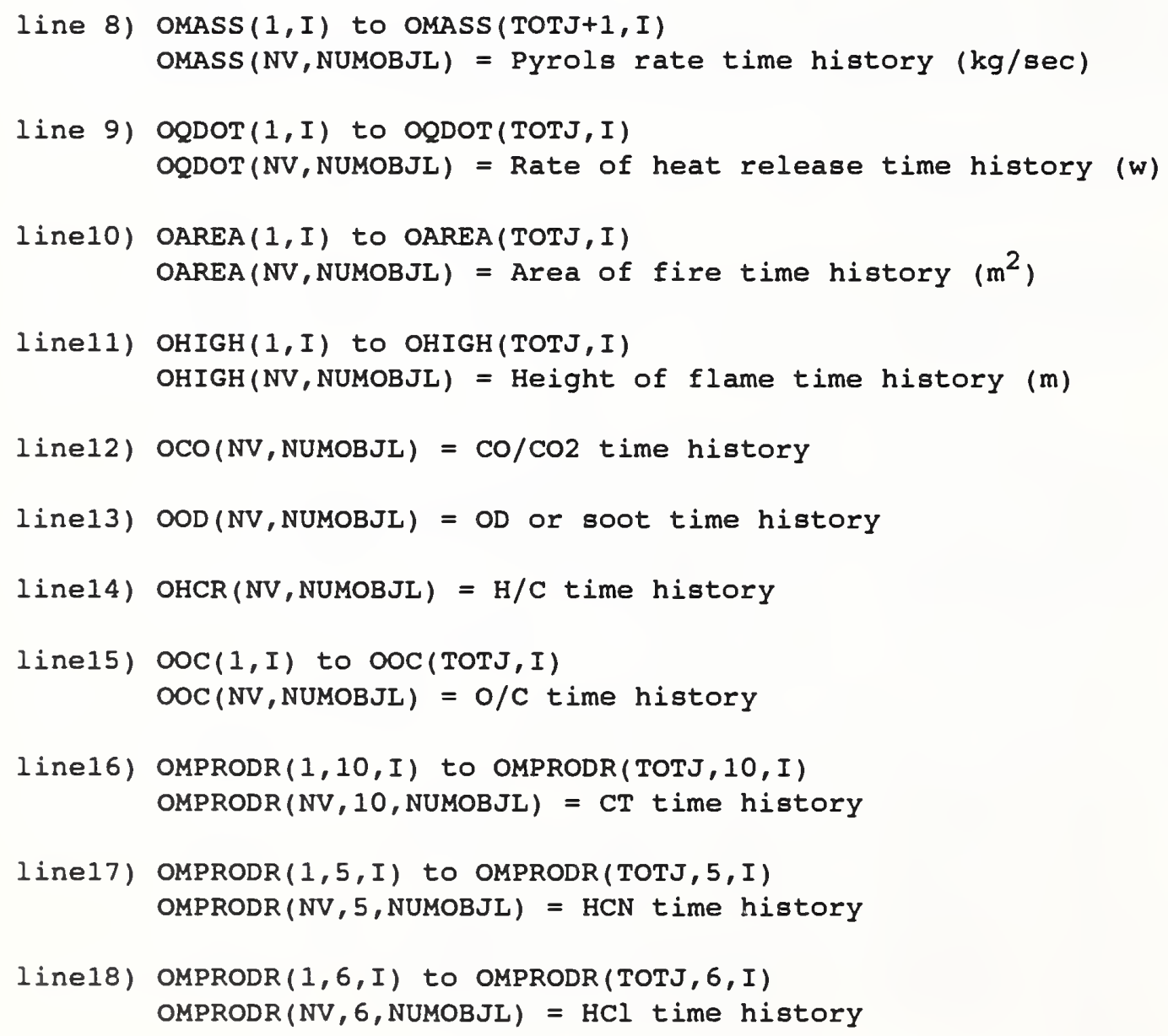




\section{Appendix E: GRAPHICS DISPLAYS}

\begin{tabular}{|c|c|c|c|c|}
\hline Card Type & Resolution & Driver & Mode & ID \\
\hline AST VGA Plus & $800 \times 600$ & AHDPARP & 0 & PPO \\
\hline ATI VGA Wonder & $800 \times 600$ & AHDATIP & 0 & APO \\
\hline Everex Viewpoint VGA & $800 \times 6001024 \times 768$ & AHDEVGP & $\begin{array}{l}3 \\
4\end{array}$ & $\begin{array}{l}\text { EP3 } \\
\text { EP4 }\end{array}$ \\
\hline Genoa 6000 Series VGA & $\begin{array}{l}800 \times 600 \\
1024 \times 768\end{array}$ & AHDGVGP & $\begin{array}{l}1 \\
2\end{array}$ & $\begin{array}{l}\text { VP1 } \\
\text { VP2 }\end{array}$ \\
\hline Headland/Video-7 VRAM VGA & $\begin{array}{l}752 \times 410 \\
720 \times 540 \\
800 \times 600 \\
1024 \times 768\end{array}$ & AHDV7VP & $\begin{array}{l}0 \\
1 \\
2 \\
3\end{array}$ & $\begin{array}{l}\text { 7P0 } \\
\text { 7P1 } \\
\text { 7P2 } \\
\text { 7P3 }\end{array}$ \\
\hline Headland/Video-7 VGA $1024 \mathrm{i}$ & $\begin{array}{l}752 \times 410 \\
720 \times 540 \\
800 \times 600 \\
1024 \times 768\end{array}$ & AHDV7VP & $\begin{array}{l}0 \\
1 \\
2 \\
3\end{array}$ & $\begin{array}{l}\text { 7P0 } \\
\text { 7P1 } \\
\text { 7P2 } \\
\text { 7P3 }\end{array}$ \\
\hline IBM EGA & $640 \times 350$ & AHDIBME & 2 & IE2 \\
\hline IBM Personal System/2 VGA & $640 \times 480$ & AHDIBMV & 3 & IV3 \\
\hline Orchid Technology Designer VGA or Designer 800 & $\begin{array}{l}800 \times 600 \\
1024 \times 768\end{array}$ & AHDVLIN & $\begin{array}{l}2 \\
3\end{array}$ & $\begin{array}{l}\text { LN2 } \\
\text { LN3 }\end{array}$ \\
\hline Paradise VGA Professional & $800 \times 600$ & AHDPARP & 0 & PPO \\
\hline Prism Elan, Elite, or Eclipse VGA & $\begin{array}{l}720 \times 540 \\
800 \times 600 \\
1024 \times 768\end{array}$ & AHDPSMP & $\begin{array}{l}2 \\
3 \\
4\end{array}$ & $\begin{array}{l}\text { SP2 } \\
\text { SP3 } \\
\text { SP4 }\end{array}$ \\
\hline STB VGA Extra/EM & $\begin{array}{l}800 \times 600 \\
1024 \times 768\end{array}$ & AHDVPLN & $\begin{array}{l}2 \\
3\end{array}$ & $\begin{array}{l}\text { PN2 } \\
\text { PN3 }\end{array}$ \\
\hline Tecmar VGA A/D & $\begin{array}{l}800 \times 440 \\
800 \times 600 \\
1024 \times 768\end{array}$ & AHDTRIP & $\begin{array}{l}1 \\
2 \\
3\end{array}$ & $\begin{array}{l}\text { TP1 } \\
\text { TP2 } \\
\text { TP3 }\end{array}$ \\
\hline Trident TVGA 8900 & $\begin{array}{l}800 \times 600 \\
1024 \times 768\end{array}$ & AHDTRIP & $\begin{array}{l}0 \\
1\end{array}$ & $\begin{array}{l}\text { TP0 } \\
\text { TP1 }\end{array}$ \\
\hline $\begin{array}{l}\text { Tseng Labs } \\
\text { ET-3000 Extended VGA }\end{array}$ & $\begin{array}{l}800 \times 600 \\
1024 \times 768\end{array}$ & AHDVPLN & $\begin{array}{l}2 \\
3\end{array}$ & $\begin{array}{l}\text { PN2 } \\
\text { PN3 }\end{array}$ \\
\hline $\begin{array}{l}\text { Tseng Labs } \\
\text { ET-4000 Extended VGA }\end{array}$ & $\begin{array}{l}800 \times 600 \\
1024 \times 768\end{array}$ & AHDTLAL & $\begin{array}{l}2 \\
3\end{array}$ & $\begin{array}{l}4 \mathrm{~L} 2 \\
4 \mathrm{~L} 3\end{array}$ \\
\hline
\end{tabular}





\begin{tabular}{lr}
\hline NIST-114 & U.S. DEPARTMENT OF COMMERCE \\
(REV. 9-92) & NATIONAL INSTITUTE OF STANDARDS AND TECHNOLOGY
\end{tabular}

ADMAN 4.09

\section{MANUSCRIPT REVIEW AND APPROVAL}

INSTRUCTIONS: ATTACH ORIGINAL OF THIS FORM TO ONE (1) COPY OF MANUSCRIPT AND SEND TO: THE SECRETARY, APPROPRIATE EDITORIAL REVIEW BOARD. TITLE AND SUBTITLE (CITE IN FULL)

(ERB USE ONLY

\begin{tabular}{|l|l|}
\hline ERB CONTROL NUMBER & DIVSION \\
\hline $\begin{array}{l}\text { PUBLCATION REPOAT NUMBEA } \\
\text { NISTIR 49 } 495\end{array}$ & CATEOORY CODE \\
\hline $\begin{array}{l}\text { PUBLCATION DATE } \\
\text { DeCEMbET 1992 }\end{array}$ & 106 \\
\hline
\end{tabular}

A User's Guide for CFAST Version 1.6

\begin{tabular}{|c|l}
\hline CONTRACT OR GRANT NUMBER & TYPE OF REPORT AND/OR PERIOD COVERED \\
Internal Report &
\end{tabular}

AUTHOA(S) (LAST MAME, FIRST INITIAL, SECOND INITIAL)

Rebecca W. Portier, Paul A. Reneke, Walter W. Jones,

Richard D. Peacock

PERFORMINQ ORGANIZATION (CHECK $(X)$ ONE BOX)
\begin{tabular}{|l} 
NIST/GATHERSBURG \\
NIST/BOULER \\
JILA/BOULDER
\end{tabular}

LABORATORY AND DIVISION NAMES (FIRST NIST AUTHOR ONLY)

Building and Fire Research Laboratory, Fire Measurement and Research Division SPONSORING ORGANIZATION MAME AND COMPLETE ADDRESS (STREET, CITY, STATE, ZIP)

\section{RECOMMENDED FOA NIST PUBUCATION}

W JOURNAL OF RESEARCH (NIST JAES)

J. PHYS. CHEM. AEF. DATA (JPCAD) HANDBOOK (NIST HB) SPECIAL PUBUCATION (NIST SP) TECHNICAL NOTE (NIST TN)

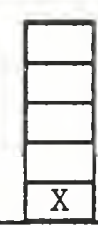

MONOGRAPH (NIST MN) NATL STO. REF. DATA SERIES (NIST NSRDS) FEDERAL INF. PROCESS. STDS. (NIST FIPS) UST OF PUBUCATIONS (MIST LP) MIST INTERAGENCY/INTERNAL REPOAT (NISTIA)

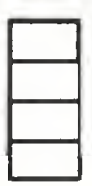

LETTER CIRCULAR BUILDING SCIENCE SERIES PRODUCT STANDARDS OTRER RECOMMENDED FOA NON-NIST PUBLCATION (CITE FULU U.S. FOREION

CFAST is a zone model capable of predicting the environment in a multi-compartment structure subjected to a fire. This guide provides a detailed description of the pre- and post-processing routines used by the model, the data input requirements and the output produced by version 1.6 of the model.

KEY WORDS (MAXIMUM 9 KEY WORDS; 28 CHARACTERS AND SPACES EACH; ALPHABETICAL ORDEA; CAPITALZE ONLY PAOPEA NAMES)

compartment fires; fire growth; mathematical models; numerical models; room fires; smoke; toxicity

\section{AVAILABIUTYY}

UNUMTED

FOR OFFICIAL DISTRIBUTION. DO NOT RELEASE TO NTIS.

ORDER FROM SUPERINTENDENT OF DOCUMENTS, U.S. OPO, WASHINOTON, D.C. 20402

ORDER FROM MTIS, SPRINGFIELL, VA 22161
NOTE TO AUTHOR(S) IF YOU DO NOT WISH THIS MANUSCRIPT ANNOUNCEO BEFORE PUBUCATION, PLEASE CHECK MERE.

\section{ELECTRONIC FORM}




